\title{
Impact of Next Generation AM-PET Helmet and Support Structure on Subjects' Neck
}

\author{
Samantha Melroy
}

Follow this and additional works at: https://researchrepository.wvu.edu/etd

\section{Recommended Citation}

Melroy, Samantha, "Impact of Next Generation AM-PET Helmet and Support Structure on Subjects' Neck" (2018). Graduate Theses, Dissertations, and Problem Reports. 6212.

https://researchrepository.wvu.edu/etd/6212

This Thesis is protected by copyright and/or related rights. It has been brought to you by the The Research Repository @ WVU with permission from the rights-holder(s). You are free to use this Thesis in any way that is permitted by the copyright and related rights legislation that applies to your use. For other uses you must obtain permission from the rights-holder(s) directly, unless additional rights are indicated by a Creative Commons license in the record and/ or on the work itself. This Thesis has been accepted for inclusion in WVU Graduate Theses, Dissertations, and Problem Reports collection by an authorized administrator of The Research Repository @ WVU. For more information, please contact researchrepository@mail.wvu.edu. 


\title{
Impact of Next Generation AM-PET Helmet and Support Structure on Subjects' Neck
}

\author{
Samantha Melroy
}

Thesis submitted

to the Benjamin M. Statler College of Engineering and Mineral Resources at West Virginia University

in partial fulfillment of the requirement for the degree of

Masters of Science in

Industrial Engineering

Thorsten Wuest, Ph.D., Co-Chair

Xiaopeng Ning, Ph.D., Co-Chair

Julie Brefczynski-Lewis, Ph.D.

Department of Industrial and Management Systems Engineering

\author{
Morgantown, West Virginia \\ 2018
}

Keywords: Neck Fatigue, PET scanners, Whiplash, Vicon, Design, EMG

Copyright 2018 Samantha Melroy 


\section{ABSTRACT \\ Impact of Next Generation AM-PET Helmet and Support Structure on Subjects' Neck}

\section{Samantha Melroy}

Ambulatory Micro-dose Positron Emission Tomography (AM-PET) is a portable PET brain scanner that does not require patients to remain still but allows them to move as they regularly would over the course of the scan (i.e. clapping hands, walking in place, and other stationary movements). Traditional PET scanners require patients to remain still for an extended duration in a small confined cavity. This is problematic for those who have conditions such as Parkinson's and Autism; in many cases, they must be sedated before the test can be performed. West Virginia University's AM-PET Helmet allows for these regular human movements to be made. It also allows researchers to see parts of the brain where traditional PET scanners cannot due to the limited mobility of the device. A proof-of-concept AM-PET helmet has been developed and tested on patients. This prototype uses 12 photodetector modules placed in a single circular ring around the subject's head, each sensor weighs 200 grams with an overall ring weight of $\sim 3$ kilograms. This prototype system was developed by researchers at West Virginia University's Health Science Center (HSC) and has been tested successfully. The next generation helmet, currently being developed, will allow for improved images with additional sensor rings to increase brain coverage.

The next generation AM-PET helmet is projected to weigh 10 kilograms. This represents a potential challenge for long time usage and various safety concerns for the patient. Currently, a support system with a counterbalancer is used to reduce the weight off the patient. This counterbalancer assists in alleviating vertical weight off the patient. Patient safety is always a primary concern; therefore the helmet must be tested thoroughly to ensure safety of the patient at all times, especially when rotating ones' head; conceivably many potential patients are frail (i.e., from disease or age). This report describes testing of the system on healthy individuals with the use of an electromyography (EMG) and a Vicon system to explore neck muscle activity and head movements and to determine "safe use" parameters, mechanics and impact of head mounted weight on patients and mechanical support structure. 


\section{ACKNOWLEDGMENTS}

I would like to pay special thankfulness, warmth and appreciation to the persons below who made my research successful and assisted me at every point to cherish my goal:

My advisor, and co-chairman, Dr. Thorsten Wuest for his vital support and assistance throughout my thesis and graduate school. His encouragement made it possible to achieve this goal.

My co-chairman, Dr. Xiaopeng Ning, whose knowledge and lab equipment helped create credible research results.

Professor Julie Brefczynski-Lewis, Head of the AM-PET project, whose excitement always kept me encouraged and motivated.

All the faculty and staff in the Industrial Engineering department at West Virginia University and the participants who took time out of their day to help achieve my goal.

And finally the AM-PET NIH grant No. R24 MH106057 for the financial support. 


\section{TABLE OF CONTENTS}

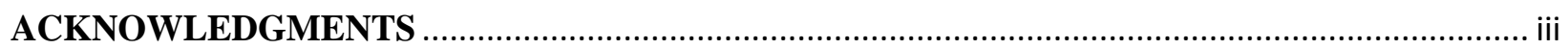

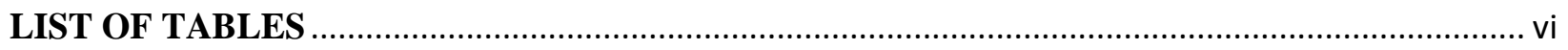

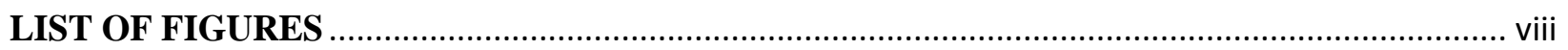

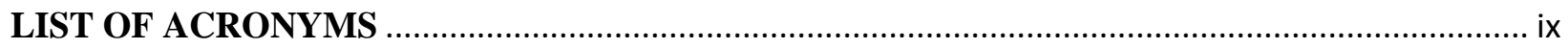

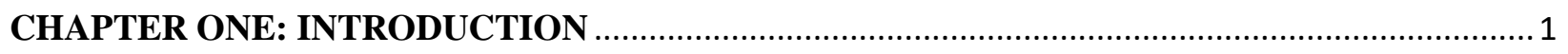

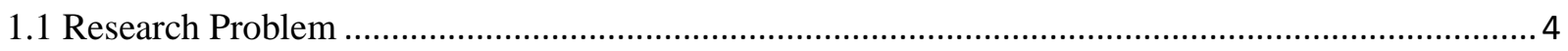

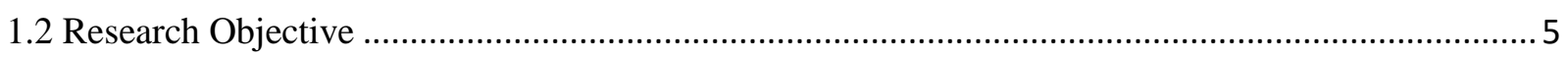

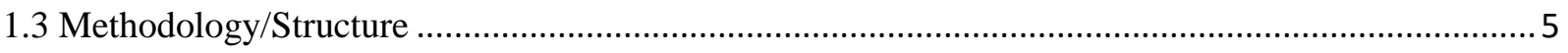

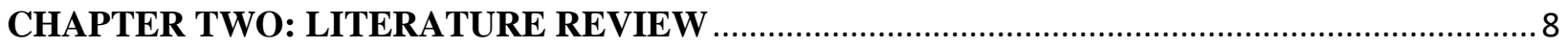

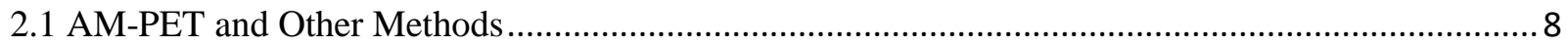

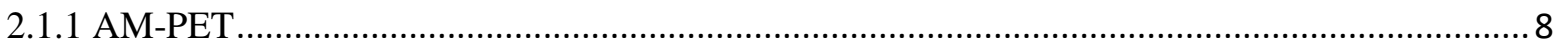

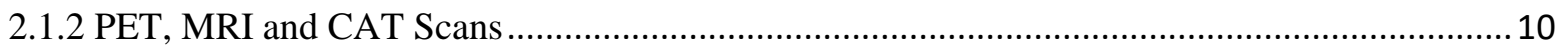

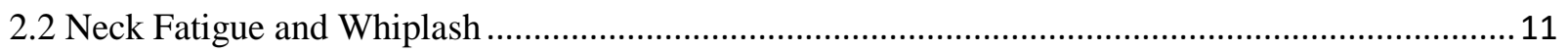

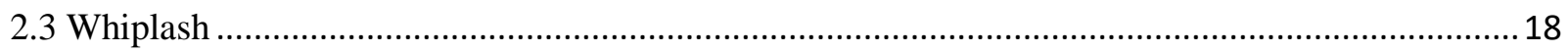

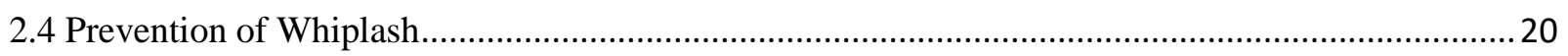

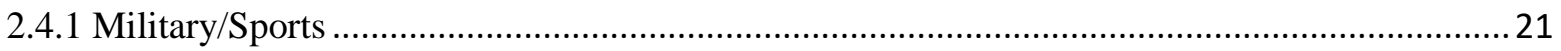

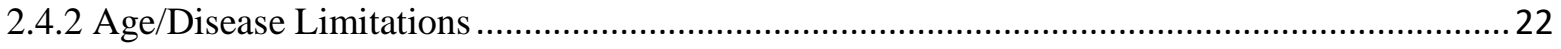

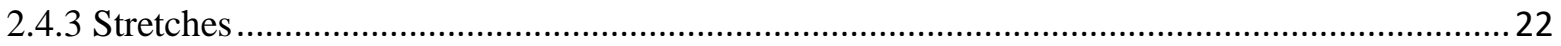

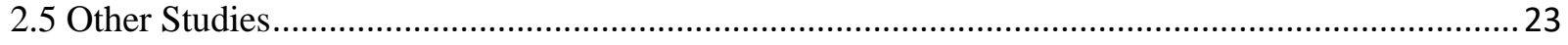

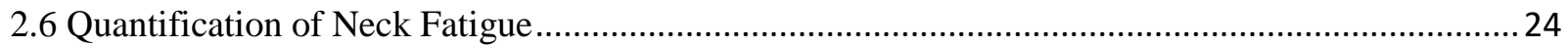

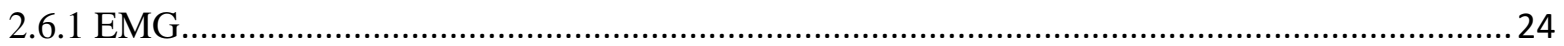

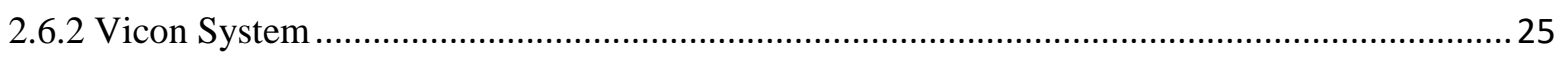

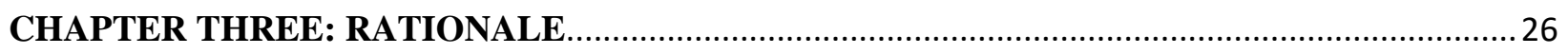

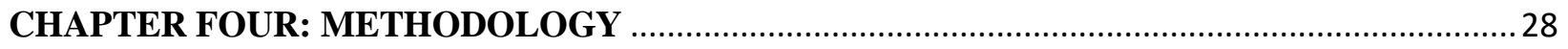

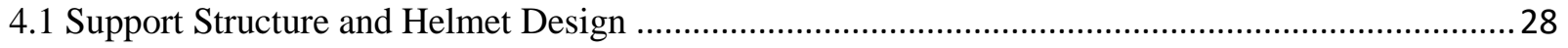

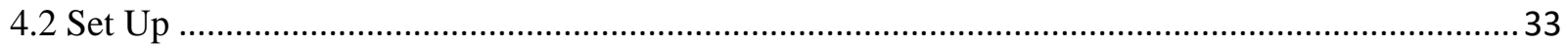

4.2.1 EMG

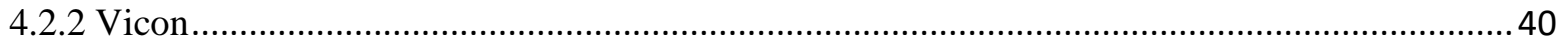

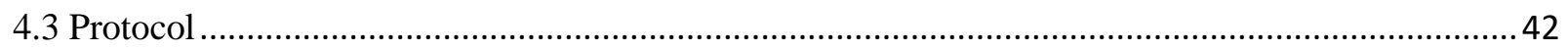

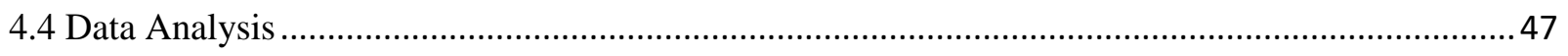




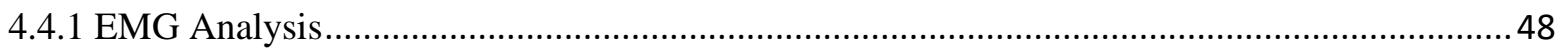

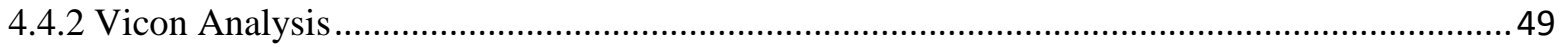

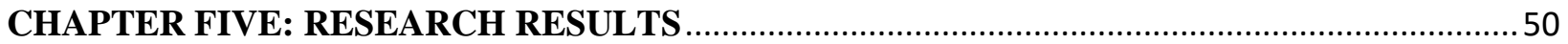

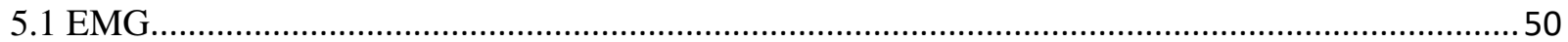

5.1.1 T-test Before and After 30 Minute Helmet Test ...................................................................50

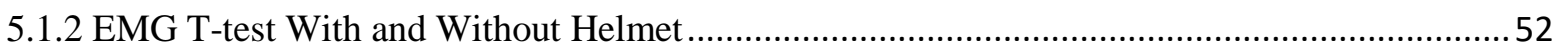

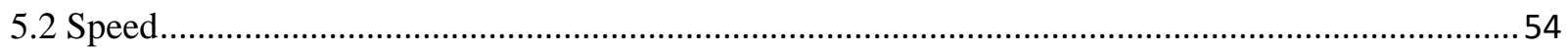

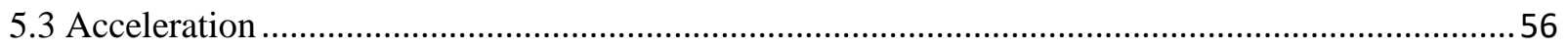

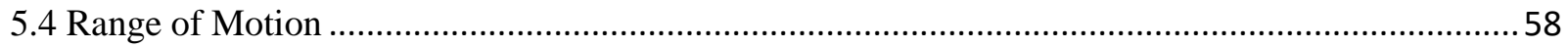

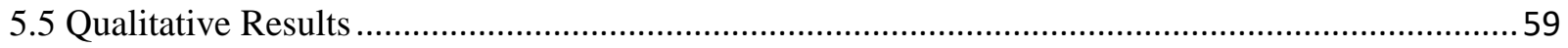

CHAPTER SIX: RESEARCH DISCUSSION AND RECOMMENDATIONS ..............................62

6.1 EMG

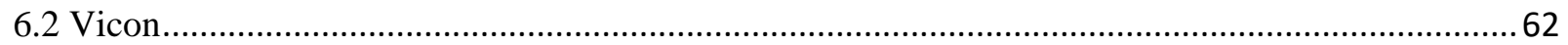

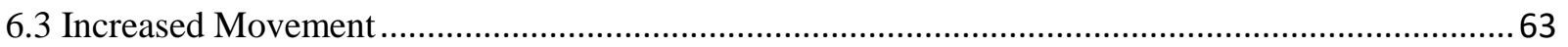

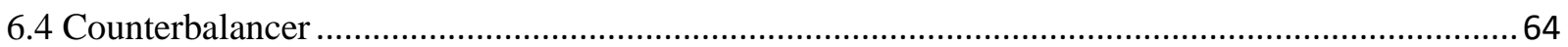

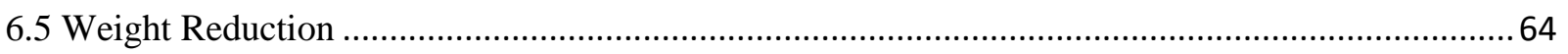

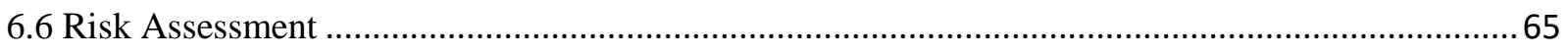

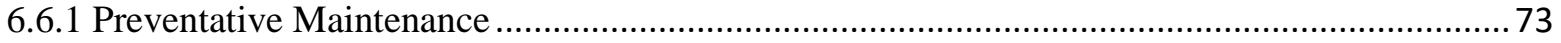

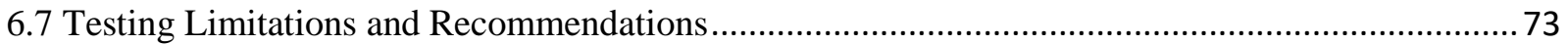

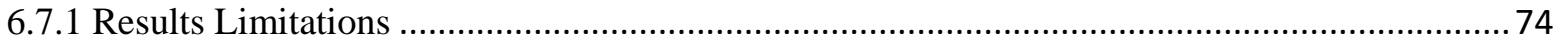

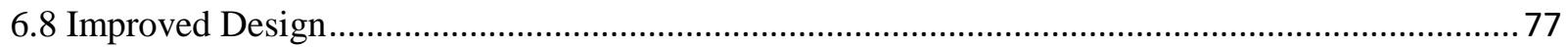

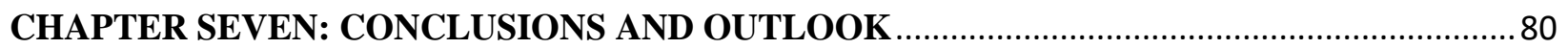

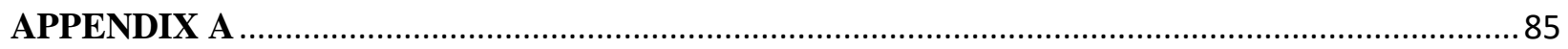

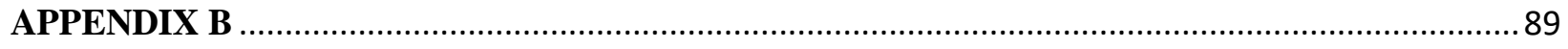

APPENDIX C

APPENDIX D

APPENDIX E 


\section{LIST OF TABLES}

Table 1: Possible neck injuries, common accidents from injury, relevance to AMPET, the rationale behind

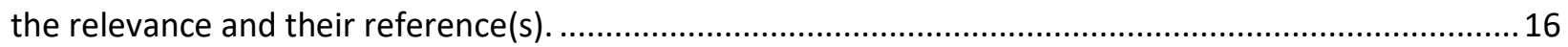

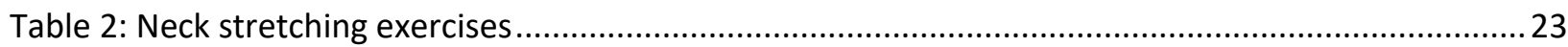

Table 3: Slot number with muscle name used for each participant ..........................................................37

Table 4: The five sets of $t$-tests with populations to be compared ....................................................... 47

Table 5: EMG statistical calculations for nodding head comparing before and after 30 minute helmet session

Table 6: EMG statistical calculations for tapping foot comparing before and after 30 minute helmet session

Table 7: EMG statistical calculations for walking in place comparing before and after 30 minute helmet session

Table 8: EMG statistical calculations for clapping hands comparing before and after 30 minute helmet session

Table 9: EMG statistical calculations for turning head comparing before and after 30 minute helmet session

Table 10: EMG statistical calculations for shaking head comparing before and after 30 minute helmet session.

Table 11: EMG statistical calculations for nodding head comparing with and without helmet ...............52

Table 12: EMG statistical calculations for tapping foot comparing with and without helmet ..................53

Table 13: EMG statistical calculations for walking in place comparing with and without helmet ............53

Table 14: EMG statistical calculations for clapping hands comparing with and without helmet ..............53

Table 15: EMG statistical calculations for turning head comparing with and without helmet..................53

Table 16: EMG statistical calculations for shaking head comparing with and without helmet ................54

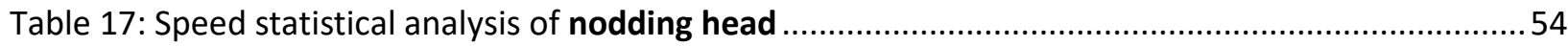

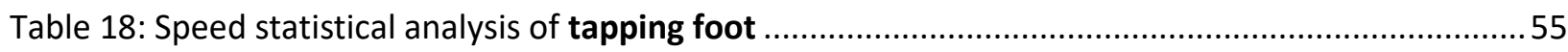

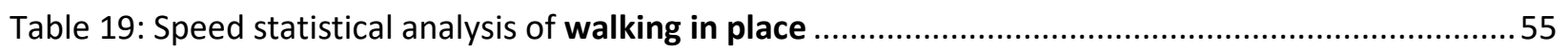

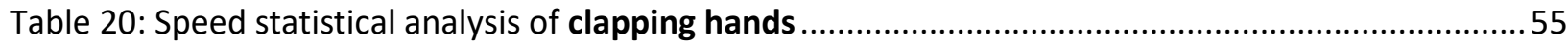

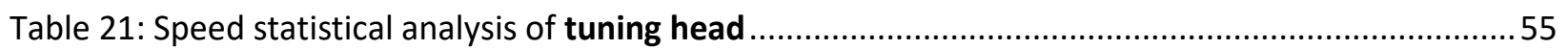

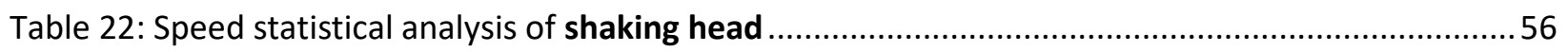

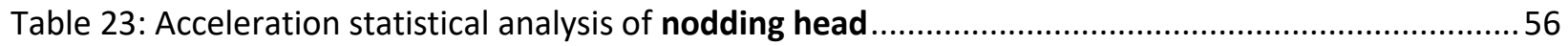

Table 24: Acceleration statistical analysis of tapping foot ...................................................................56

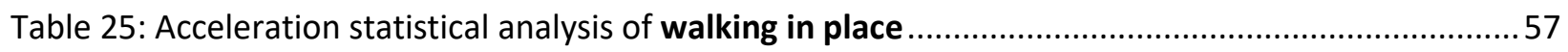

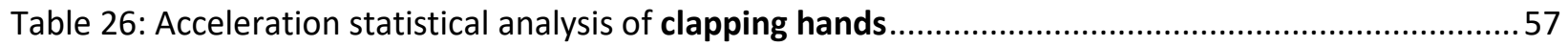

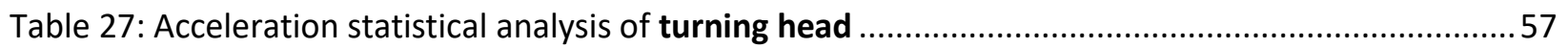

Table 28: Acceleration statistical analysis of shaking head......................................................................58

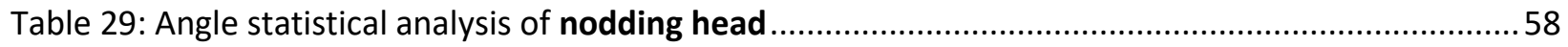

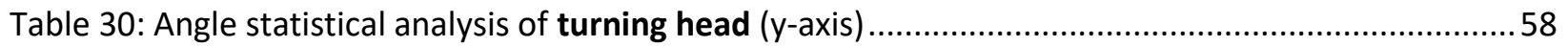

Table 31: Angle statistical analysis of turning head (z-axis) ..............................................................59

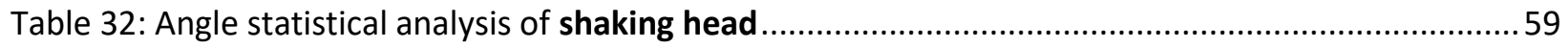

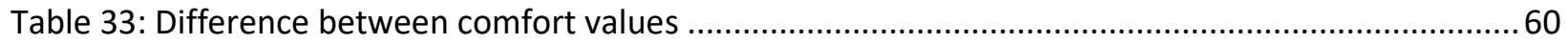

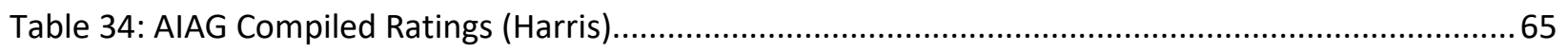


Table 35: FMEA of AM-PET 10kg helmet and support system

Table 36: Normalized EMG data of nodding head (population 1 - gray, population $2-$ white) ..............85

Table 37: Normalized EMG data of tapping foot (population 1 - gray, population $2-$ white) ................ 85

Table 38: Normalized EMG data for walking in place (population 1 gray, population $2-$ white) ............86

Table 39: Normalized EMG data for clapping hands (population 1 gray, population $2-$ white).............86

Table 40: Normalized EMG data for turning head (population 1 gray, population $2-$ white) ................87

Table 41: Normalized EMG data for shaking head (population 1 gray, population $2-$ white) .................88

Table 42: Normalized EMG data for nodding head with and without the helmet (population 1 - gray, population 2 - white) ...................................................................................................90

Table 43: Normalized EMG data for tapping foot with and without the helmet (population 1 - gray,

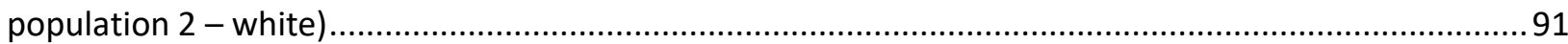

Table 44: Normalized EMG data for walking in place with and without the helmet (population 1 - gray, population 2 - white) .................................................................................................92

Table 45: Normalized EMG data for clapping hands with and without the helmet (population 1 - gray, population 2 - white)

Table 46: Normalized EMG data for turning head with and without the helmet (population 1 - gray, population 2 - white)

Table 47: Normalized EMG data for shaking head with and without the helmet (population 1 - gray, population 2 - white) 95

Table 48: Nodding head data for speed (population 1 - gray, population 2 - white) ...........................96

Table 49: Tapping foot data for speed (population 1 - gray, population 2 - white) .............................96

Table 50: Walking in place data for speed (population $1-$ gray, population $2-$ white) .........................97

Table 51: Clapping hands data for speed (population 1 - gray, population 2 - white) .........................97

Table 52: Turning head data for speed (population 1 - gray, population 2 - white) ............................98

Table 53: Shaking head data for speed (population 1 - gray, population $2-$ white) .............................98

Table 54: Nodding head data for acceleration (population 1 - gray, population 2 - white) ................. 100

Table 55: Tapping foot data for acceleration (population 1 - gray, population $2-$ white) ....................100

Table 56: Walking in place data for acceleration (population 1 - gray, population 2 - white) ............. 101

Table 57: Clapping hands data for acceleration (population 1 - gray, population 2 - white) ............... 101

Table 58: Turning head data for acceleration (population 1 - gray, population $2-$ white) .................. 102

Table 59: Shaking head data for acceleration (population 1 - gray, population 2 - white) .................. 102

Table 60: Normalized range of motion for nodding head (population 1 - gray, population $2-$ white).. 104

Table 61: Range of motion for turning head (y-axis) (population 1 - gray, population 2 - white) .........104

Table 62: Range of motion for turning head (z-axis) (population 1 - gray, population 2 - white) ......... 105

Table 63: Normalized range of motion for shaking head (population 1 - gray, population 2 - white)... 105 


\section{LIST OF FIGURES}

Figure 1: Modified Biodex System displaying the counterbalancer, Biodex system, harness and weighted mock-up helmet 3

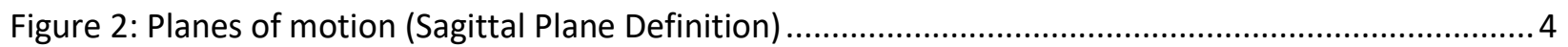

Figure 3: Limitations of using the modified Biodex Unweighing system .................................................... 5

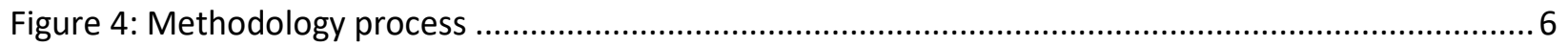

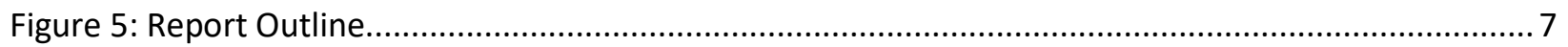

Figure 6: AM-PET next Generation helmet render (Melroy) ............................................................. 10

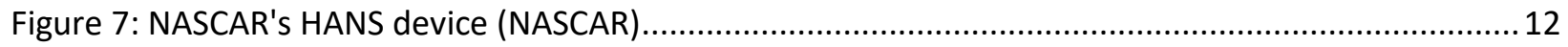

Figure 8: Locations of the sternocleidomastoid, scalene and trapezius muscles (File:Musculi coli

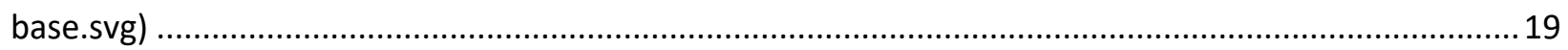

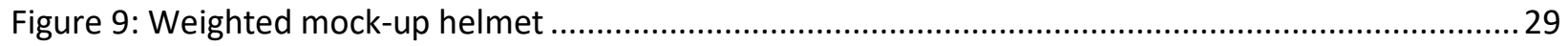

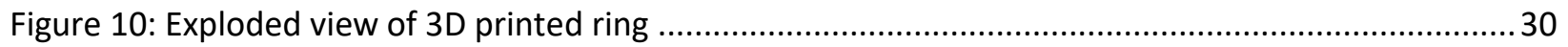

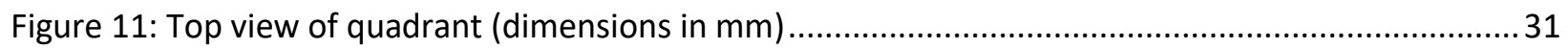

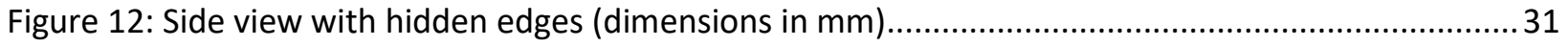

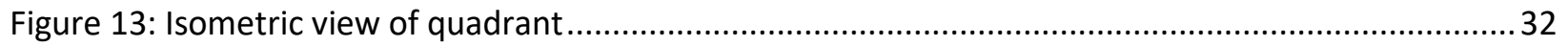

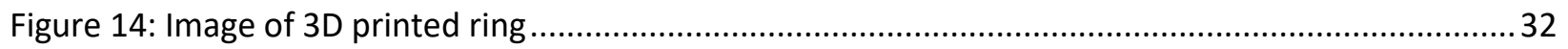

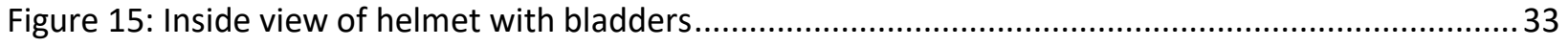

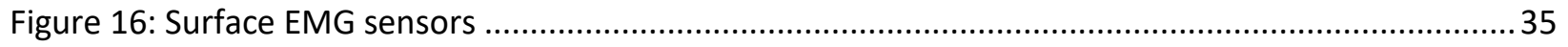

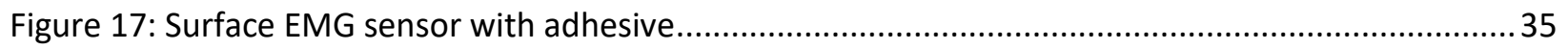

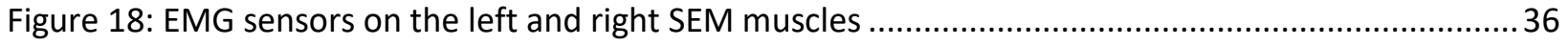

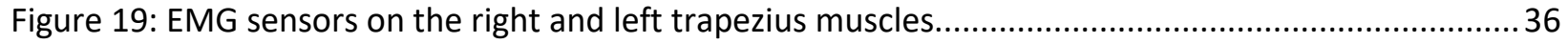

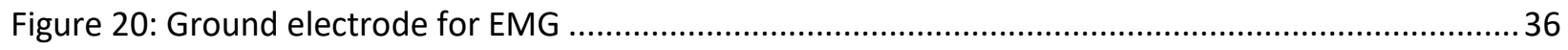

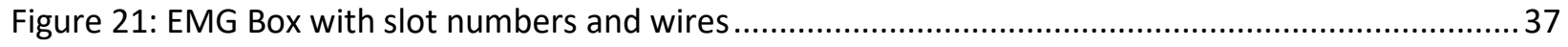

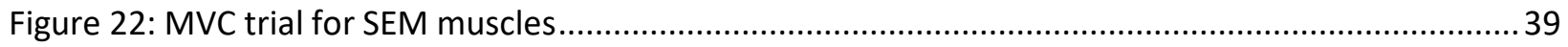

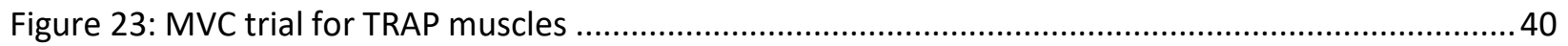

Figure 24: Image of testing room Vicon cameras (circled) .............................................................. 41

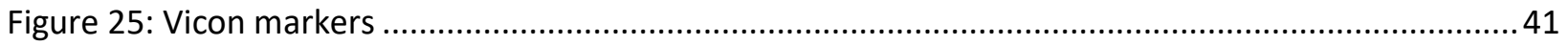

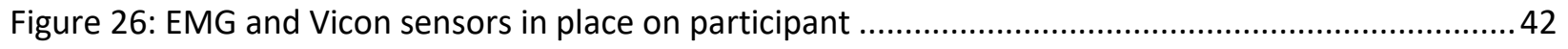

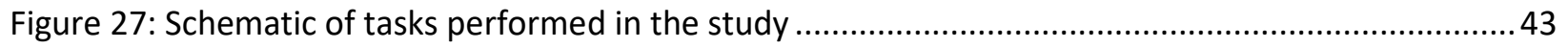

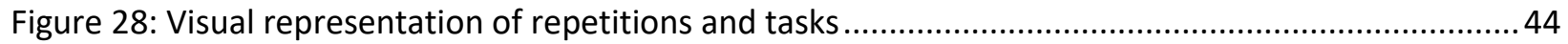

Figure 29: Participant with Biodex support and helmet on in the designated position............................46

Figure 30: Modified Biodex before safety assessment ..................................................................... 71

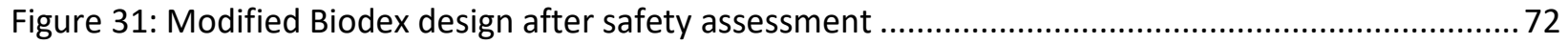

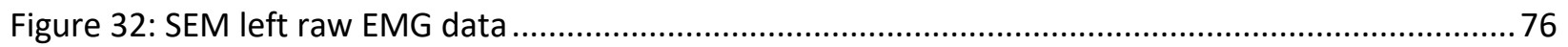

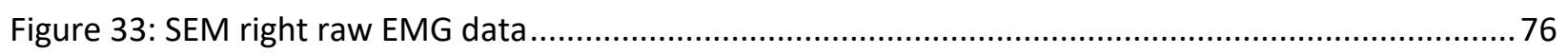

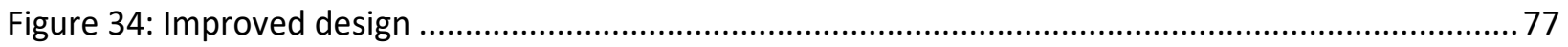

Figure 35: Gyroscope design (File:3D Gyroscope.pn) ...................................................................... 78 


\section{LIST OF ACRONYMS}

AM-PET

CAT

CT

EMG

FMEA

HANS

HSC

MD

MRI

MVC

NASCAR

PET

PPE

RMDs

SCI

SEM

TRAP

VR

WAD

WVU
Ambulatory Micro-dose Positron Emission Tomography

Computer Aided Tomography

Computed Tomography

Electromyography

Failure Modes and Effects Analysis

Head and Neck Support

Health Science Center

Muscular Dystrophic

Magnetic Resonance Imaging

Maximum Voluntary Contraction

National Association for Stock Car Auto Racing

Positron Emission Tomography

Personal Protective Equipment

Repetitive Motion Disorders

Spinal Cord Injuries

Sternocleidomastoid

Trapezius

Virtual Reality

Whiplash Associated Disorders

West Virginia University 


\section{CHAPTER ONE: INTRODUCTION}

A portable positron emission tomography (PET) scanner has been developed to remotely provide PET assessments to patients. This system allows doctors to see the primary concern areas of the brain to help better understand what condition and treatment options are available for individual patients. Modern PET scanners are large, bulky and immobile. This creates a challenge because all tests must be completed in a dedicated room, typically a hospital. Regular PET scanners are restricted to one room where patients remain still for several minutes, even up to an hour. This limitation has caused problems with people who are e.g. claustrophobic and patients who cannot, or will not remain still for long periods of time (i.e. pediatrics and Parkinson's). Current PET uses an injectable radioactive tracer into a vein that allows very few PET scans over the course of a lifetime due to the high amount of radiation in a single scan. This does not allow doctors to properly monitor the progression of a disease to a high degree.

AM-PET (Ambulatory Micro-dose Positron Emission Tomography) proposes a solution to these challenges and will allow researchers to test a broader patient range and gain previously unseen insights. This system allows patients to be tested while in a seated, standing and/or walking position and reduce the injectable radioactive tracer by factor 10 allowing for less radiation (and thus more scans in succession) (Bauer). Not only does this increase the number of patients to be tested but also enables researchers to acquire previously unseen images of a) the brain itself and b) brains/brain activity of patients previously deemed impossible to capture. These previously not available images are captured as a result of a patient moving his/her body to highlight parts of the brain used amongst other regular movements. AM-PET might be outbound to study brains of world class artists and scientists as they do their work (i.e., Yo-Yo 
Ma playing the cello). This will allow researchers to really get inside the heads of some truly gifted individuals and patients to gain a new level of understanding the brain.

A proof of concept design for AM-PET has been confirmed using a 12 photodetectormodule ring that images distinct segments of the brain by an interdisciplinary research team led by West Virginia University (WVU). This has allowed researchers to see, for the first time, brain images of people clapping, tapping their foot, standing and even walking in place. This ring can be manually tilted to image various areas of the brain. The next generation helmet will image the full brain using a multi-ring system. This multi-ring system will weigh upwards of $10 \mathrm{~kg}(\sim 22$ pounds) and tests must be completed to ensure the safety of patients. This significant weight, when placed on the subject's head, requires external support to allow the subjects to perform the required tasks throughout a scan and not be in danger of falling or of injury.

A support structure was designed and built based on a Biodex Unweighing system and a counterbalancer was attached that holds constant tension on the helmet, like that of a counterweight system, see Figure 1. A mock-up helmet was made utilizing an American football helmet as the structure and 3D printed "mock-up" modules that were filled with metal to simulate predicted weight of each sensor module (200g) and placed in respective areas on the helmet. This mock-up helmet consists of two rings that hold 16 simulated modules in each ring (32 total modules). 


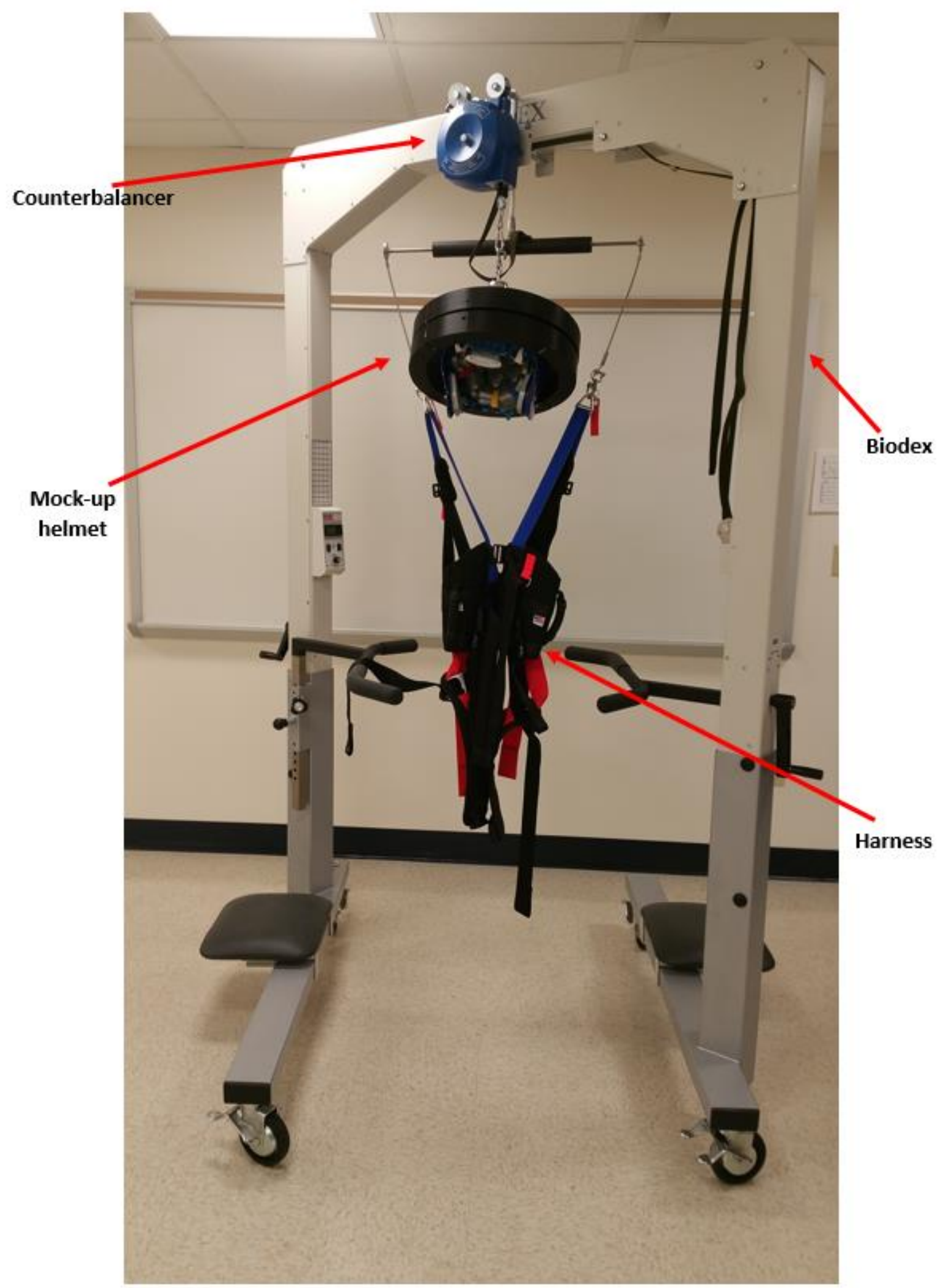

Figure 1: Modified Biodex System displaying the counterbalancer, Biodex system, harness and weighted mock-up helmet 


\subsection{Research Problem}

Although a counterweight system has been developed for this need, the effectiveness of this counterbalancer system has not yet been quantified. Therefore, to ensure the safety of the test subject and increase the efficacy of the procedural results, test protocols and subject ergonomics must be evaluated. This Biodex and counterbalancer solve weight dilemma in the vertical directions and rotations on the transverse plane, however, it does not account for movements around the frontal and sagittal planes (see Figure 2 and Figure 3). Due to the large weight of the helmet, there is significant inertia that will be placed on the neck as someone rotates their head, and the faster they rotate or move their head the larger the moment of inertia becomes. This could cause injury if precautions are not taken and the system is not carefully tested and evaluated before it is used on patients.

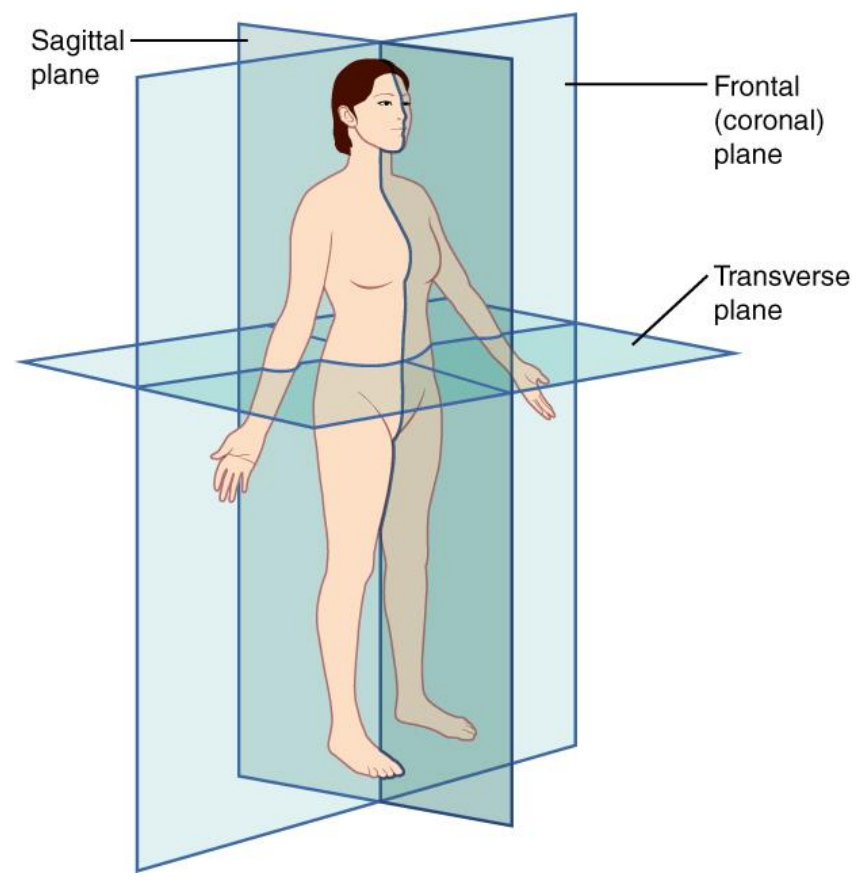

Figure 2: Planes of motion (Sagittal Plane Definition) 


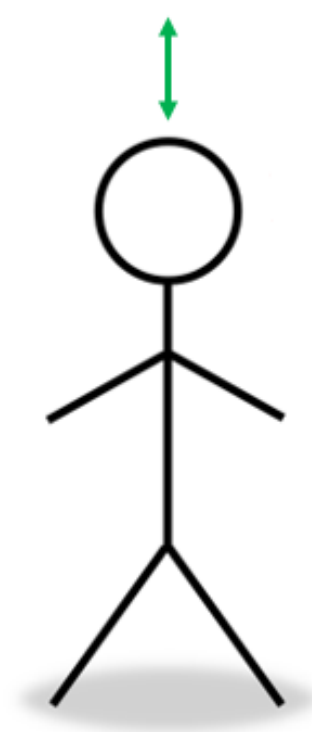

Up and Down Motions

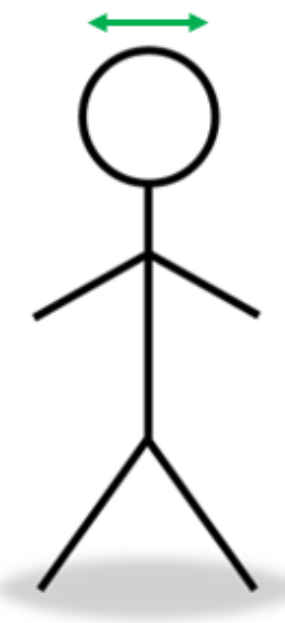

Rotations on the Transverse Plane

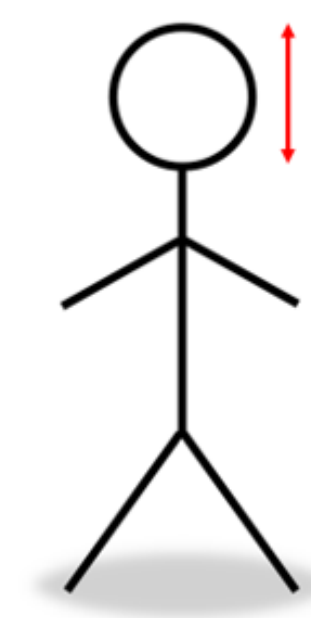

Rotations on the Sagittal Plane

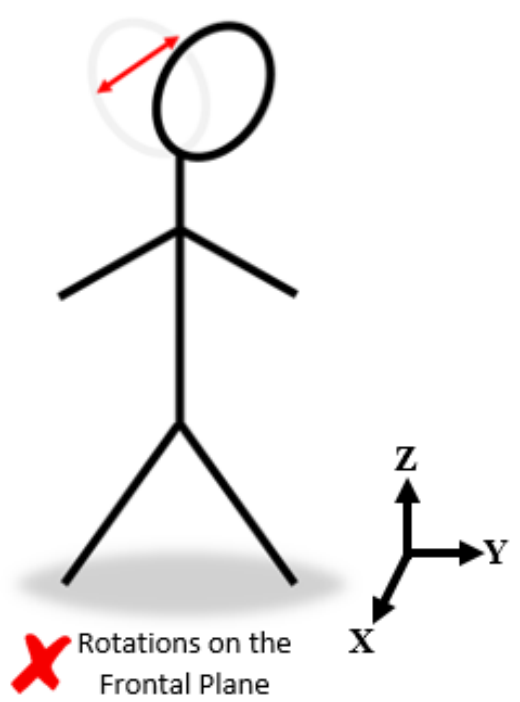

Figure 3: Limitations of using the modified Biodex Unweighing system

\subsection{Research Objective}

In this report, we will assess the $10 \mathrm{~kg}$ AM-PET helmet and if the current support system is physically safe to use and identify limitations of the system to ensure the patient's safety at all times. The following research questions will be answered.

- First, what effect does the AM-PET prototype have on a test subject regarding muscle activity and head movements?

- Second, what measures and protocols must be established to provide a safe testing environment for subjects using the portable PET scanner during the prescribed physical activities?

\subsection{Methodology/Structure}

To achieve the objectives, we need to have a measurement device to numerically quantify muscle usage and regular head movements; in the past, the use of EMG has successfully 
measured muscles in the human body to identify and/or solve a physical problem. This is done by performing tasks to determine differences in muscle activity (i.e., lifting a weight with knees versus lifting a weight with back). To identify the movement of patients, a Vicon system has been used on humans and objects to collect high-resolution/precise movement data in 3D space. Therefore, EMG will be used to quantify prominent muscles that could be injured and a Vicon system will be used to learn about physical movement. EMG has been used to provide quantitative data in movement sciences through the measurement of muscles through surface EMG sensors (Delsys). This allows researchers to understand effects of a movement, weight or outside variable has on a singular muscle. A Vicon system has also been used, occasionally in conjunction with EMG, to show very precise accelerations, velocities and relative movements (Vicon).

The AM-PET $10 \mathrm{~kg}$ prototype, including the support structure, will be tested using EMG and a Vicon system attached to defined points on the head and neck. The EMG system will measure neck muscle activity, while the Vicon system will monitor movements such as speed and acceleration of the head. Questionnaires will be used to determine if there is any noticeable neck strain. See Figure 4 for methodology process. An outline of what is expected in the coming sections is illustrated in Figure 5.

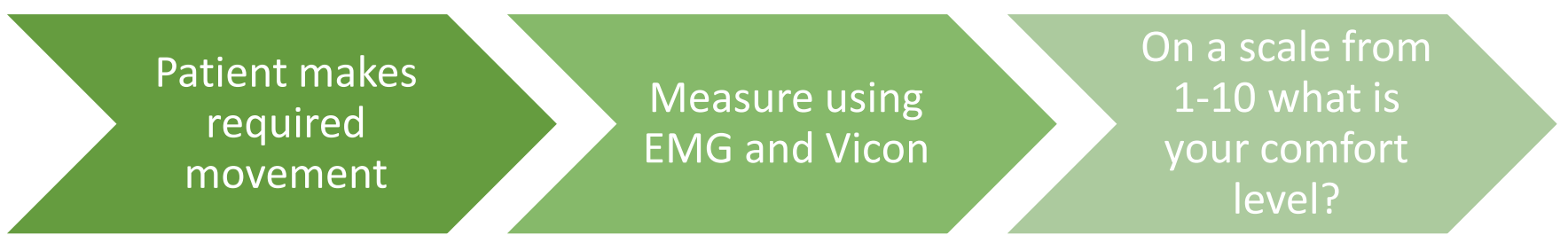




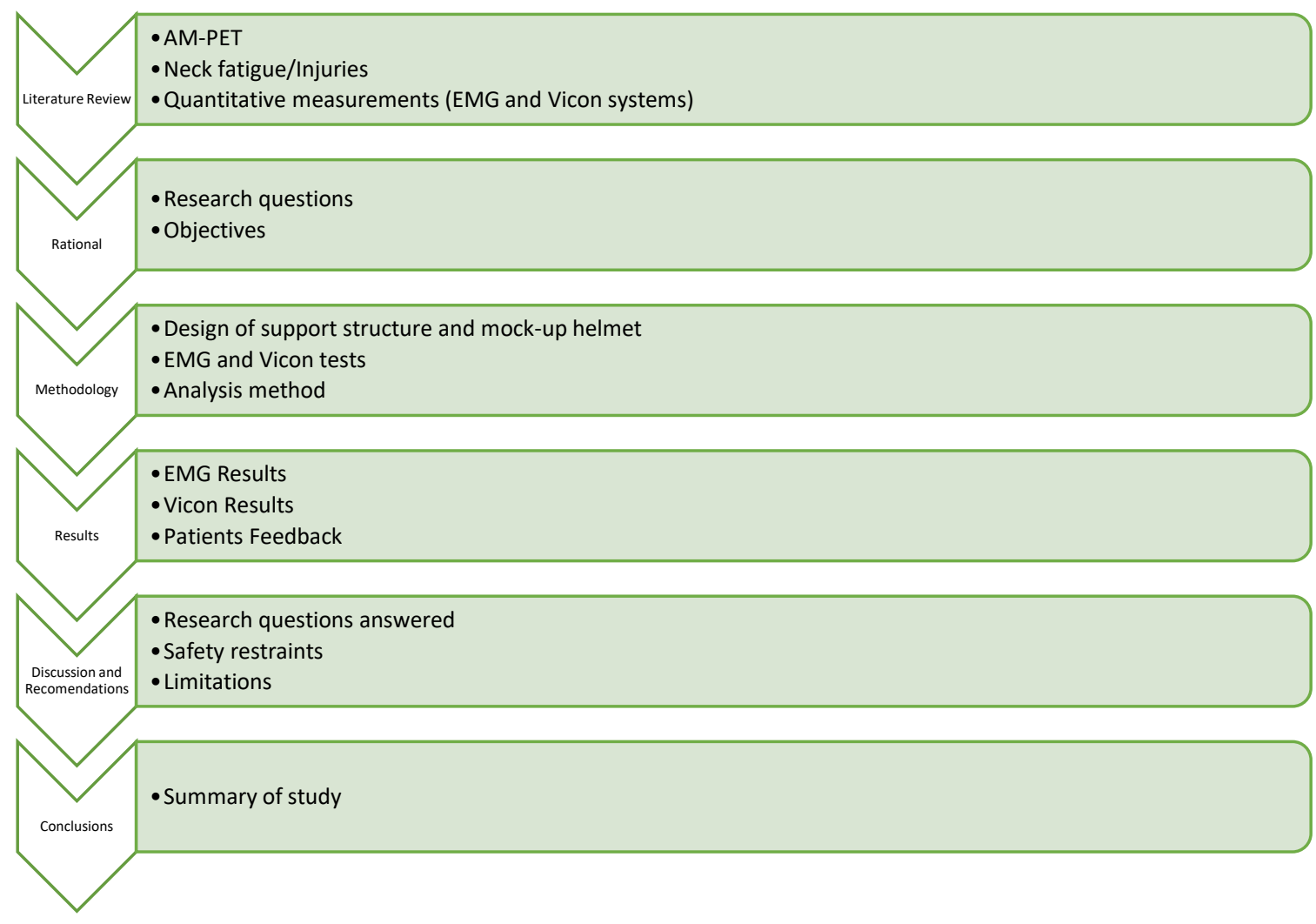

Figure 5: Report Outline 


\section{CHAPTER TWO: LITERATURE REVIEW}

As previously discussed AM-PET is a new innovative neurological system that will help scientists better understand the brain. AM-PET's first prototype was proven successful through testing human patients. Their goal was to provide a portable PET scanner that does not refrain the patient's movement. A PET is different than that of an MRI and a CAT scan. PET is used most to scan a brain and involves radiation; it is different than that of MRI and CAT scans, however, modern PET, MRI and CAT all demand the patient to remain still.

A primary concern and motivation of this study were for patient's safety with the next generation $10 \mathrm{~kg}$ helmet. The neck is most likely to be injured during a scan and discussion about what kind of injury can occur and is relevant to AM-PET in the following sections. Precautions, such as stretches, are applicable and will be taken into consideration to ensure user safety. In the military and other physically demanding professions, individuals build muscles around their neck and body while using protective equipment to prevent injury; however, with age, muscle strength lessens. This leads to limitations due to age and extra precautions are needed for the elderly users.

\subsection{AM-PET and Other Methods}

\subsubsection{AM-PET}

AM-PET is part of the brain initiative and was shown to have verified the new approach to PET scanning. US Patent 7,884,331 (United States of America Patent No. 7,884,331, 2008) describes the portable (AM-PET) brain imager amplifying the helmet design and modules in the ring like structure that can be secured around the head. The helmet-like structure attaches to a patient's head and maintains relative head to imager geometry throughout the entirety of the 
scan. A support system can alleviate the weight of the helmet allowing the patient to move their head normally. This helmet can scan for neurological brain functions, cancer and effects of trauma with limited space needs for use and storage.

The goal of WVU's AM-PET helmet is to create an upright portable PET scanner that will allow exploration and image parts of the brain that have yet to be reached from normal PET scanners. The first conceptual version of the brain imager had two rings. This helmet assembly was fully enclosed with a mechanical support to hold the weight of the helmet. The helmet was composed of 20 silicon photomultiplier (SiPS) detector modules. This AM-PET helmet was designed to image a $5 \mathrm{~cm}$ thick slice of the brain according to (Majewski). The first AM-PET helmet prototype has twelve Photomultiplier detectors assembled in a circular ring that can be secured to the head. This device only has to use $25 \%$ (or even as low as $10 \%$ ) of the injectable solution as compared to a normal PET scanner (Bauer). This proof of concept prototype is the first demonstration of imaging on a human subject that allows for normal human movements. This ring has an inner diameter of $\sim 21 \mathrm{~cm}$ with a thickness of $5 \mathrm{~cm}$ of the detectors where each detector weighing $\sim 200$ grams with an overall weight of the ring being $\sim 3 \mathrm{~kg}$. This helmet was the first portable PET scanner successfully tested on humans. (Bauer)

The next generation helmet is envisioned as a 4-ring system with an open front for vision and a Virtual Reality set, see Figure 6. This helmet will be able to scan the entire brain. However, it comes with many challenges; the primary challenges involve the weight of the helmet $(\sim 10 \mathrm{~kg})$ and the individual modules must be completely shielded from light. A support system has already been made using a Biodex Unweighing System that comes with an attached safety harness. (Melroy) 


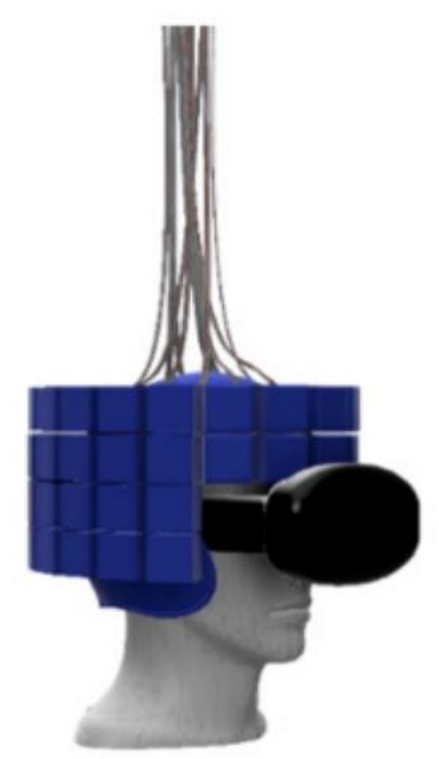

Figure 6: AM-PET next Generation helmet render (Melroy)

Preliminary studies have been conducted on rats called the RatCAP. Animal related PET scanners require anesthesia. Like humans, the anesthesia may significantly confound the interpretation of the animal brain. RatCAP does not require anesthesia and is composed of a miniaturized ring that is attached directly to the rat's head that can image nearly the entire rat's brain. This design used twelve detector blocks. They learned the gaps between each of the detectors was a prevalent challenge that need to be eliminated. (Vaska)

\subsubsection{PET, MRI and CAT Scans}

There are collective differences between MRI, PET and CAT scans and it is important to know the differences to understand why PET is used for AM-PET and why there is a need for an advanced PET system. A PET scan involves injecting a dose of a radioactive tracer into the vein of the patient's arm. The tracer then travels through the body and is absorbed by organs and tissues. The patient must lay down and remain still then is moved slowly into a "doughnut-like" shaped machine. The PET machine detects and records the energy given off by the tracer substance and the energy is converted into a three-dimensional picture. PET scanners are used to 
detect heart problems, brain disorders and most commonly, cancer. A PET scan can see if cancer has spread, has cancer returned, which treatment is likely to be most effective and if the treatment is viable. A typical scan lasts between 30 and 60 minutes. (Guiberteau)

An MRI (Magnetic Resonance Imaging) scan uses radio waves and a powerful magnetic field to image inside the body (Rubin, 2016). An MRI is used when images of the chest, abdomen and/or pelvis are desired; a normal test takes between 30 and 60 minutes to complete. This method is invasive and does not expose the patient to radiation like a PET scan (Rubin). A CT (Computed Tomography), or CAT (Computer Aided Tomography), scan can image any part of the body extremely quickly. This machine combines x-ray equipment with advanced computers to create a quick image of the body. Sometimes a contrast material or "dye" can be given, either injected or drank orally, to highlight blood vessels and diseases. A CT scan can diagnose broken bones, blood clots in the brain and chest, pneumonia and kidney stones to name a few. Like that of a PET scan, radiation is needed to obtain a CT scan (Wald).

\subsection{Neck Fatigue and Whiplash}

In this section, types of neck injury will be examined to determine injuries that regularly occur on human necks and how fatigue can happen to a variety of people. There have been no direct studies performed on the placement of a heavy object on someone's head, knowing that the neck is the most at risk for fatigue, a vigilant look at how this could impact someone's neck to ensure safety of all users.

The neck is the weak point in the body and extra precautions must partake to keep an injury from occurring (Birchard). The cervical spine is very susceptible to injury because it is highly mobile and has relatively small vertebral bodies that support the head (Birchard). Neck injuries occur for many reasons including car crashes, falls, sports, ergonomics and numerous 
others that will be referenced. Much personal protective equipment (PPE) is designed to keep users safe including football helmets and car headrests that, when used correctly, are there for the user's protection (Coakwell).

An example of a PPE in NASCAR (National Association for Stock Car Auto Racing) is the HANS (Head and Neck Support) device; this includes two tethers attached to a shoulder harness to help keep the driver's neck and head stationary. This device is an add on to the driver's helmet. It sits on the shoulders, under the seatbelt and is lightweight and not bulky. Figure 7 shows the HANS device (left), notice in the right picture there are straps that are attached to the HANS device from the sides of the helmet to prevent side to side, up and down and motions between of the driver's head. (NASCAR)
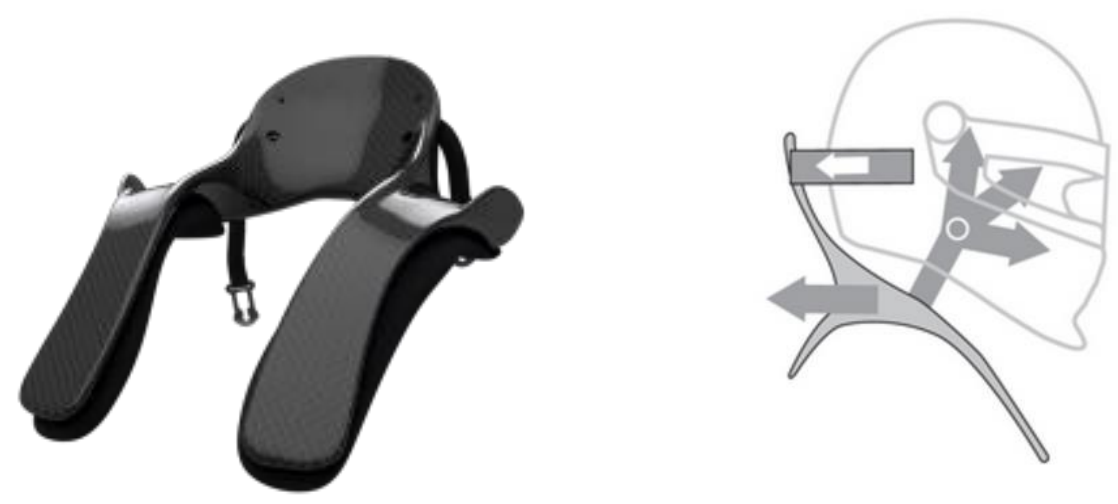

Figure 7: NASCAR's HANS device (NASCAR)

In an office setting, people often suffer from backaches, neck pain, headaches and wrist pain. Ashraf Shikdar conducted a study with 40 randomly selected office employees to improve office ergonomics. Select participants received skills and ergonomically designed accessories to reduce their pain. Before the study began, a questionnaire was completed with $82.5 \%$ of the employees reporting backaches, $58 \%$ headaches, $58 \%$ neck pain and $80 \%$ wrist pain. Six months 
after engaging into the study, health complaints reduced significantly due to the ergonomic training and accessories given to these employees. Shikdar concluded that if employees are given tools and accessories designed to make a more comfortable working environment, which will lead to reduced pain among employees. There was no explanation as to why that office did not already provide ergonomic tools and accessories. One can speculate that cost of ergonomic accessories is high and knowledge on tools were minimal. (Shikdar)

The neck is where the cervical spine is located. Between $26 \%$ and $71 \%$ of the adult population has some type of cervical spine injury (Vetroczky) (Carroll). History of injury in the back, neck and/or shoulder only increases the prevalence of neck fatigue with age and manifestation for those who are overweight (Mäkela). With neck pain and fatigue come reduced neck movements which is shown to have more of an effect on females (Johnston) (Brandt). Those who have a history of neck fatigue have a higher risk of injuring their neck again (Jensen) (Eltayeb). There are many injuries that could occur in the cervical spine and it is important to make these known and eliminate any that are irrelevant for AM-PET's $10 \mathrm{~kg}$ helmet patients (i.e. broken neck and strangulation) (Hu) (Ning).

The injuries to be examined include: 1) cervical fracture, 2) cervical radiculopathy, 3) dislocated neck, 4) hanged, 5) laceration, 6) neck muscle spasm, 7) nerve root or brachial plexus injuries, 8) neck sprain and strain (whiplash), 9) repetitive motion disorders (RMDs), 10) stiff neck and 11) strangulation. Most of these have an extremely low risk of happening using the AM-PET helmet and are considered irrelevant for this study. A table was created to correlate the injury to possible causes in Table 1 alongside its reference and relevance to AM-PET. 
To begin a cervical fracture, or a broken neck is often fatal. Dislocation of the neck is similar to that of a fracture and they both are caused mostly by car accidents and sports. In elderly persons, a broken neck can occur from slips and falls; a fall like this to a young healthy individual is unlikely to break ones' neck but a hard fall from a large distance or diving in shallow water could cause dislocation or a fractured neck (Murray). A cervical fracture and/or dislocation is highly unlikely due to the safety procedures involved including the use of a Biodex Unweighing System that comes equipped with a harness and because the subject will not be traveling at high speeds but remains attached to a support system that will reduce the hazard of falling.

Cervical Radiculopathy, or a pinched nerve, in the neck occurs when one continuously repeats movements; this is often the cause of office ergonomics and in sports (Anandkumar). A pinched nerve is possible using the AM-PET helmet if continuous vigorous movements are conducted; with that said the Biodex Unweighing System will ergonomically discourage subjects from moving far or fast due to the limited to no walking movement which lessens risks from occurring. Subjects will be asked to refrain from making any sudden movements until one is comfortable with the sizable weight of the helmet.

A neck laceration can occur when sharp objects touch the skin or body and cause bleeding. Strangulation happens when something gets wrapped around the neck and cuts off the air and blood flow to the head (Funk). A laceration and strangulation are not relevant for AMPET because subjects will not have anything touching or in proximity to the neck.

The patient will be placed into a $10 \mathrm{~kg}$ helmet so there must be safety factors involved to eliminate the possibility of the patient being accidentally hanged. There is an extremely small chance of this happening to anyone however, safety precautions must partake to not allow this to 
happen even in the most unlikely circumstances. The helmet is attached the Biodex system using 4 nuts and bolts; this allows for a high safety factor and must be examined for fatigue and made sure it is tight before each use. The patient will be attached in a harness and will not be able to fall related to the helmet; in addition, there will always be a supervisor watching over the patient throughout the duration of a scan.

Muscle spasms are common and can occur from an injury over a decade ago (Winslow). A neck spasm can occur from car accidents, falls and sports like diving in shallow waters leaving injury behind (Winslow). The subject will not endure a fall during the duration of the scan that could cause an injury such as a neck spasm. There is a peril of a chance the $10 \mathrm{~kg}$ AM-PET helmet can trigger a neck spasm when the subject turns his/her head. If this occurs the helmet should be taken off immediately.

Brachial plexus injuries occur mostly from motorcycles, but also from excessive stretching and external pressures. The relevance of this occurring from the AM-PET helmet is extremely low because no large outside movement or anything that could cause a blow to the head can occur with the testing setup. To get this kind of injury a large force must be applied to a subject's body or extreme, continuous strain; the subject will have little to no walking area and will not be able to move one's body quickly. (Wen) (Thatte)

Work employees repeat movements which can cause repetitive motion disorders or RMDs; this could be from a sedentary desk job to an active warehouse job. Continuous repetitive movements can cause discomfort in the neck and back if ergonomics and other factors are not considered. This occurs over time and could lessen ones' efficiency at work and/or at home causing distress and more injury if not properly managed. RMDs also occurs in those who have Parkinson's or those who are autistic from their repetitive, typically uncontrollable, movements 
(Kumdee). The 30-minute AM-PET scan duration would not be the cause of an RMDs and is not relevant or considered a repetitive motion disorder because it takes time to develop a repetitive motion disorder.

Relevant injuries for the AM-PET $10 \mathrm{~kg}$ helmet include neck strains and sprains (also known as whiplash) and stiff neck. Neck strain and sprain are common in many normal movements including bending, climbing and reaching. Due to the movements and inertia helical whiplash, strain and sprains are the most common injuries that could occur using the AM-PET $10 \mathrm{~kg}$ helmet. A stiff neck could also occur using AM-PET when someone turns their head sharply; this is a symptom of whiplash and can cause some discomfort. A stiff neck seldom prevents victims from working and usually only persists for a few days to a week (Hult). Formerly hyperextension of the neck was thought to be a cause of injury. However, due to the ergonomics of a car seat in a crash, the assumption has been inadequate (Haibin).

Below is a summary of relevant and some irrelevant neck injuries of the $10 \mathrm{~kg}$ AM-PET helmet, see Table 1. Results from laboratory testing will be used to confirm this table.

Table 1: Possible neck injuries, common accidents from injury, relevance to AMPET, the rationale behind the relevance and their reference(s).

\begin{tabular}{|l|l|c|l|l|}
\hline \multicolumn{1}{|c|}{ Injury } & \multicolumn{1}{|c|}{$\begin{array}{c}\text { Common incident of } \\
\text { injury }\end{array}$} & $\begin{array}{c}\text { Relevant } \\
\text { for } \\
\text { AMPET }\end{array}$ & $\begin{array}{l}\text { Relevance } \\
\text { Rationale }\end{array}$ & \multicolumn{1}{|c|}{ Reference(s) } \\
\hline $\begin{array}{l}\text { 1. Cervical } \\
\text { Fracture (Broken } \\
\text { Neck) }\end{array}$ & $\begin{array}{l}\text { Car accidents, falls, } \\
\text { blow to the head }\end{array}$ & NO & $\begin{array}{l}\text {-No external } \\
\text { forces }\end{array}$ & $\begin{array}{l}\text { (Murray) } \\
\text { (Durbin) }\end{array}$ \\
\hline $\begin{array}{l}\text { 2. Cervical } \\
\text { Radiculopathy } \\
\text { (Pinched nerve) }\end{array}$ & $\begin{array}{l}\text { Repetitive movement, } \\
\text { ergonomics, sports }\end{array}$ & NO & $\begin{array}{l}\text {-No long-term } \\
\text { use } \\
\text {-No external } \\
\text { forces }\end{array}$ & $\begin{array}{l}\text { (Clancy) } \\
\text { (Anandkumar) }\end{array}$ \\
\hline $\begin{array}{l}\text { 3. Dislocated } \\
\text { neck }\end{array}$ & $\begin{array}{l}\text { Car accident, fall, } \\
\text { sports, diving }\end{array}$ & NO & $\begin{array}{l}\text {-No external } \\
\text { forces }\end{array}$ & (Durbin) \\
\hline
\end{tabular}




\begin{tabular}{|c|c|c|c|c|}
\hline & & & $\begin{array}{l}\text {-No falls } \\
\text { possible with } \\
\text { harness }\end{array}$ & \\
\hline 4. Hanged & $\begin{array}{l}\text { Suicide, accidental } \\
\text { head-trapped }\end{array}$ & NO & $\begin{array}{l}\text {-No falls } \\
\text { possible with } \\
\text { harness }\end{array}$ & (Nouma) \\
\hline 5. Laceration & $\begin{array}{l}\text { Sharp objects, extreme } \\
\text { sports }\end{array}$ & NO & $\begin{array}{l}\text {-Nothing } \\
\text { touching the } \\
\text { neck }\end{array}$ & (Sharma) \\
\hline $\begin{array}{l}\text { 6. Neck Muscle } \\
\text { Spasm }\end{array}$ & $\begin{array}{l}\text { Diving, car accident, } \\
\text { sports }\end{array}$ & MAYBE & $\begin{array}{l}\text {-No external } \\
\text { forces }\end{array}$ & (Winslow) \\
\hline $\begin{array}{l}\text { 7. Nerve root or } \\
\text { brachial plexus } \\
\text { injuries }\end{array}$ & $\begin{array}{l}\text { Direct blow, external } \\
\text { pressure, traction or } \\
\text { stretch injury, } \\
\text { motorcycle accidents, } \\
\text { heavy fall }\end{array}$ & NO & $\begin{array}{l}\text {-No external } \\
\text { forces } \\
\text {-No falls } \\
\text { possible with } \\
\text { harness }\end{array}$ & (Wen) (Thatte) \\
\hline $\begin{array}{l}\text { 8. Neck Sprain } \\
\text { and Strain } \\
\text { (Whiplash) }\end{array}$ & $\begin{array}{l}\text { Car accidents, falls, bed } \\
\text { transfers, wheelchairs, } \\
\text { contact sports, bending, } \\
\text { climbing, crawling, } \\
\text { reaching twisting, } \\
\text { overexertion, repeated } \\
\text { overuse, extreme sports }\end{array}$ & YES & $\begin{array}{l}\text {-Possible rapid } \\
\text { twist of the } \\
\text { neck }\end{array}$ & $\begin{array}{l}\text { (Sirikantharajah) } \\
\text { (Kulin) } \\
\text { (Sharma) }\end{array}$ \\
\hline $\begin{array}{l}\text { 9. Repetitive } \\
\text { motion disorders } \\
\text { (RMDs) }\end{array}$ & Repeated motions & NO & $\begin{array}{l}\text {-No long-term } \\
\text { use }\end{array}$ & (Kumdee) \\
\hline 10. Stiff Neck & $\begin{array}{l}\text { Sleeping position, sharp } \\
\text { turn of head, stumbling }\end{array}$ & YES & $\begin{array}{l}\text {-Possible rapid } \\
\text { twist of the } \\
\text { neck }\end{array}$ & (Hult) \\
\hline 11. Strangulation & assault & NO & $\begin{array}{l}\text {-Nothing } \\
\text { touching the } \\
\text { neck }\end{array}$ & (Funk) \\
\hline
\end{tabular}

The most relevant concern for injury with the AMPET $10 \mathrm{~kg}$ helmet was identified as whiplash, stiff neck and muscle spasm. A muscle spasm can occur when a patient has a previous injury and the helmet triggers a muscle spasm (Winslow) and a stiff neck can occur with conjunction with whiplash (Staff). An in-depth study of whiplash follows including ways to prevent whiplash from occurring will conclude the literature review. 


\subsection{Whiplash}

The neck is prone to whiplash injuries during jerk motions. Whiplash mostly occurs in car accidents but also during falls, bed transfers and while traveling by wheelchair. Those who get whiplash often have weaker muscles due to Spinal Cord Injuries (SCI) and Muscular Dystrophic (MD). Whiplash from wheelchair injuries often occurs when a user travels over uneven terrane and sways ones' head back and forth to shift ones' center of mass to avoid tipping over. A study was conducted by Shahini Sirikantharajah testing subjects using EMG electrodes on the left and right Sternocleidomastoid (SCM), Scalene (SCAL) and Trapezius (TRAP) muscles. The subjects sat in a simulator with a belt and shoulder harness. Various rotational movements with and without a Virtual Reality (VR) set were repeated. Head movements were most active with a VR set and neck muscles were used most in the forward rotational movements. During the beginning of the tests head movements were most active then "extensive head domination" occurred as the study transpired. (Sirikantharajah) 


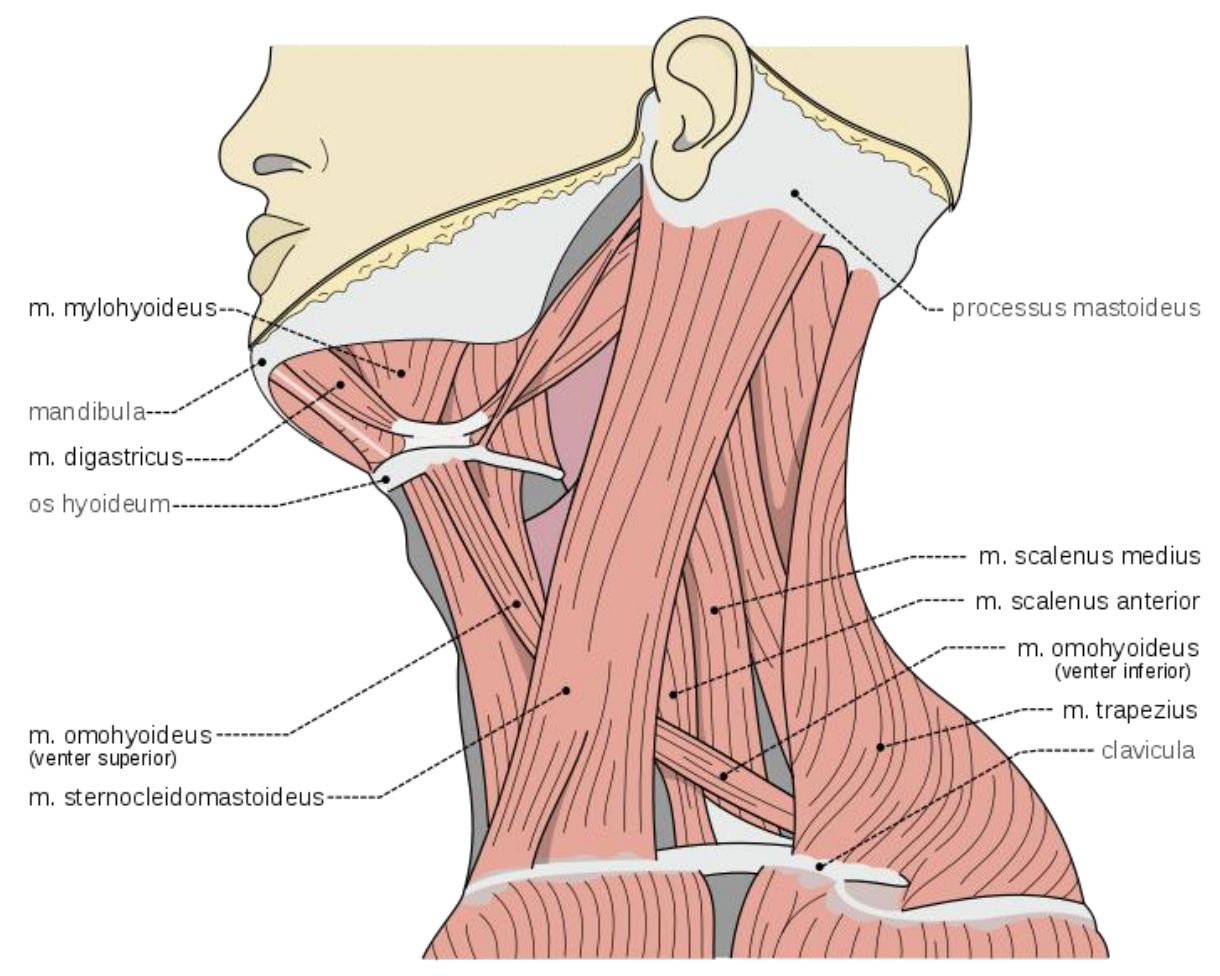

Figure 8: Locations of the sternocleidomastoid, scalene and trapezius muscles (File:Musculi coli base.svg)

Whiplash Associated Disorders, or WAD, will be the primary concern with the users of the $10 \mathrm{~kg}$ AM-PET helmet, as determined from Table 1. The most common form people get whiplash from is rear ending car accidents ( $\sim 51 \%$ of whiplash injuries) but also from contact sports, roller coasters and repetitive neck movements (Spitzer). Whiplash is caused by the “... acceleration-deceleration mechanism of energy transfer to the neck..." as stated by (Spitzer).

Yoganandan and Pintar have researched kinematics of whiplash. They used human cadaver head-necks to mimic a rear-ending impact with most movement in the sagittal plane with the use of a high-resolution digital video to track motions of the individual joints. They concluded that whiplash injury is when the upper cervical spine undergoes flexion while the lower cervical spine is in extension concluding a reverse curvature of the head-neck. The head lags during this stage then catches up, whipping the head. (Stemper) (Cusick). 
Most WAD injuries recover within three months (Suissa). Between 5 and 32 percent suffering is prolonged and leads to chronic WAD (Spitzer). Complains from WAD patients include increased muscle tension and pain during repeated arm and shoulder movements and increased pain and stiffness during repeated neck movements (Öhberg). Below are symptoms of whiplash (Hagström) (Haibin):
a) headache
b) stiffness in the neck
c) pain in the neck
d) paresthesia
e) visual disturbance
f) auditory disturbance
g) shoulder weakness
h) dizziness
i) memory loss

\subsection{Prevention of Whiplash}

The most common way to prevent neck injury with this system would be to use a neck brace on the patient. This, however, would limit the patient with regard to neck movement and downgrade the AM-PET scan and its usefulness, thus this and other similar preventions techniques are not applicable for this case unless found to be necessary during out experiments.

It has been shown that the healthier the individual the less likely neck fatigue will occur. This applies to those who are athletic, have no previous neck injuries and those who are young healthy adults. Exercises and stretches also reduce the risk of an injury as explained in this section. 


\subsubsection{Military/Sports}

Coakwell explains in his review about methods to prevent neck strain including design of aircraft and personal protective equipment (PPE). One option for PPE is to improve the helmet design the pilots use. Preflight warmups (or "G warm-up") have been recommended by many publications including (Burton) and (Vanderbeek) noticing benefit through questionnaires. In addition to stretching, exercise of the neck using resistance training has helped with neck fatigue in the long term.

Astronauts have a high chance of obtaining spinal pain while in space and currently exercise two hours a day to strengthen their muscles and bones while in space. As they are in space the spine straightens out because of the lack of gravity to keep the natural curve of the spine making the surrounding muscles weaken and bone stiffen. According to Alan Hargens there is a need for better exercises for the astronaut's necks. Currently, they do not perform exercises to specifically strengthen their neck which has caused neck pains in some astronauts. (Grush)

In sports, building up neck muscles is important. Rugby does not use any PPE like football and building up neck muscles is extremely important for the safety of the players. Injuries such as hyperextension, forced rotation and compression occur during a game that could cause long term injury. Paul Haylen highlights 5 pillars to reduce neck injuries in rugby: 1) creation of awareness programs and courses, 2) astute player selection, 3) constantly assess and amend rules of the game, 4) impose the rules and 5) emphasize strength and conditioning of players. These five pillars show human and movement limitations, making sure players and coaches know rules, referees must strictly follow rules and muscle building. (Haylen) 


\subsubsection{Age/Disease Limitations}

It is known that age and disease can reduce strength in muscles and density of bones causing people to be more frail, making it easier for an injury to occur. Muscles in young adults generally contribute to $50 \%$ of their body weight, which is $50 \%$ higher than someone in their 70 s or 80 s. After the age of 60 , muscle strength loss accelerates tremendously. As one ages, their dietary and physical lifestyle affects their muscles and bones and people are much healthier if they stay active and have high protein diets. (Kalyani)

Diabetics have an accelerated loss of muscle mass and strength; the longer someone has diabetes the more challenges they will have in their adult life. This is partially due to the overweight nature of some diabetics but is also the cause of the diabetes itself. Obesity occurs when extensive fat accumulation builds up and negatively affects health. Often when someone is obese the individual might have relatively low muscle strength compared to their size. As someone ages loss of muscle mass is offset by gains in fat mass; BMI of middle aged individuals might be suitable however body fat actually increases which could develop into sarcopenic obesity. (Kalyani)

Many diseases such as advanced kidney disease, cancer, rheumatoid arthritis, congestive heart failure, cirrhosis, etc. cause muscle loss either through muscle usage loss, age and/or disease itself. (Kalyani)

\subsubsection{Stretches}

Stretching is scientifically proven to reduce pain when done properly. Stretching the neck is an important part of reducing the possibility of neck pain while using the $10 \mathrm{~kg}$ AM-PET helmet. Some preventative neck stretches to reduce an aching neck include neck rotations, 
shoulder circles, side stretches, resistance exercises and head lifts. Explanations are shown in Table 2 (Ogiela).

Table 2: Neck stretching exercises

\begin{tabular}{l|l} 
Stretch & \multicolumn{1}{|c}{ Explanation } \\
\hline Rotations & $\begin{array}{l}\text { Turning one's head slowly to } \\
\text { the left then the right as far } \\
\text { as one can comfortably, } \\
\text { holding for 10 to 30 seconds } \\
\text { on each side }\end{array}$ \\
$\begin{array}{l}\text { Shoulder } \\
\text { Circles }\end{array}$ & $\begin{array}{l}\text { Standing where one raises } \\
\text { their shoulders up then in a } \\
\text { circle in both directions }\end{array}$ \\
$\begin{array}{l}\text { Side } \\
\text { Stretches }\end{array}$ & $\begin{array}{l}\text { Standing while one ear goes } \\
\text { the direction of the shoulder } \\
\text { without moving shoulders, } \\
\text { repeat on other side }\end{array}$ \\
Resistance \\
Exercises & $\begin{array}{l}\text { Placing one's right hand } \\
\text { against their head above their } \\
\text { ear and gently pressing while } \\
\text { opposing the force with } \\
\text { one's neck }\end{array}$ \\
Head Lifts & $\begin{array}{l}\text { Laying on ones back with } \\
\text { knees bent and feet flat on } \\
\text { the floor. Lifting and } \\
\text { lowering one's head keeping } \\
\text { shoulders flat on the floor. } \\
\text { Repeat on each side and on } \\
\text { stomach }\end{array}$ \\
\end{tabular}

\subsection{Other Studies}

To this day African women carry large amount of weight on their head for transportation needs. They can carry $20 \%$ of their body weight without expending any extra energy and can place as much as $70 \%$ of their overall body weight on their heads with only a strap around their 
forehead for stability. A study was conducted using five African women who walked on a treadmill at five different speeds. In the study they measured the oxygen consumptions of the women to see how much energy is needed to carry large baskets. They also had male subjects who were not conditioned to carry large amounts of weight on their head; they found that increase in load increased oxygen consumption and the males managed to carry $15 \%$ of their body weight on their heads safely. After testing they assumed the African women were able to minimize the movements of the load on their heads and thus were able to carry much more weight and did not use much energy because of how stationary they kept their head. There was no mention of how it was determined that $15 \%$ of the men's body weight was safely carried on their heads. (Maloiy)

\subsection{Quantification of Neck Fatigue}

\subsubsection{EMG}

Electromyography (EMG) is used to quantify muscle movements through recording electrical activity produced by skeletal muscles. EMG sensors are placed directly on a subject's skin through the use of double sided tape. Many studies use EMG for neck studies including a study to learn about neck fatigue while using mobile devices. In this study, an iPhone was used to represent a touch smart phone and an iPad was used to represent a touch screen tablet. In the first condition, the iPhone and iPad were placed on a flat surface adjusted to elbow height; the second condition included them to hold the device using ones left hand during operation. The third condition included the participant performing a task including "reading", "typing" and "gaming". The recorded data was filtered using a $10 \mathrm{~Hz}$ high-pass filter and a low-pass filter of $500 \mathrm{~Hz}$. A notch filter was used to eliminate ambient noise. The EMG data was then fully rectified and smoothers using a 1/8s moving data window. Through the use of Maximum 
Voluntary Contraction (MVC) the data was normalized. A multivariate ANOVA (MANOVA) was performed and the study revealed the location of the device was significant with the tablet on the table placing more strain on the neck than if it were held in the participant's hand. (Ning)

\subsubsection{Vicon System}

Motion capture is the process of recording movement of objects, may it be human, robot or other. A Vicon system has been used to capture movements to a very high accuracy. The Vicon system can be used for many things including biometrics, clinical science, entertainment, tracking, VR, broadcast and many others (Vicon). The use of the Vicon system with the 10kg helmet will determine if there is a difference between having the helmet on versus having the helmet off. 


\section{CHAPTER THREE: RATIONALE}

The operational range of the next generation $(10 \mathrm{~kg})$ helmet is unknown. This includes the bounds in acceleration, normal head movements and range of motion. It is also unknown how fatiguing regular movements will be to the subject's neck. This makes it a challenge to determine how safe the system is for a patient. Possible challenges include whiplash when head movements are too fast or too few and control over range of motion as the patient moves ones' head. This leads to the research questions:

- First, what effect does the AM-PET prototype have on a test subject regarding muscle activity and head movements?

- Second, what measures and protocols must be established to provide a safe testing environment for subjects using the portable PET scanner during the prescribed physical activities?

The scope of this work is to determine if the support structure will be safe for patients using the next-generation 10kg AM-PET helmet through the use of an EMG and Vicon system. The EMG will measure muscle activity while the Vicon system will be used to explore movements with and without the helmet. The work is bound by the following assumptions:

- The support system will exert constant tension at a fixed point on a structural support and will be the only external force acting on the $10 \mathrm{~kg}$ helmet

- An American football helmet with attached "weighted modules" will be used to distribute and simulate the weight of the actual next-generation AM-PET Helmet $(10 \mathrm{~kg})$

- Only healthy individuals will be tested for the safety of the subject in order to determine potential limitations for "non-healthy" subjects 
Objectives include taking current technology (EMG and Vicon) to build a system and a predictive tool to ultimately provide the ability to expand the output to a wider range of individuals, conditions and geographic locations. Four main objectives include 1) design and build the $10 \mathrm{~kg}$ "mock-up" helmet using an American football helmet as a basis, 3D printed parts with added weights to simulate the weight and placement/distribution of the modules, 2) design the experiment to determine if this system is safe through confirmation of EMG and Vicon technology, 3) test to determine if the following hypothesis is correct and this system is safe with minor limitations and 4) develop a "guide" for "safe use" of the $10 \mathrm{~kg}$ system for healthy/unhealthy patients based on the results. The hypothesis states the following:

If the $10 \mathrm{~kg}$ helmet with a single vertical support system is placed on a person's head, then it will not have significant effects on a person's SEM or TRAP muscles. There will be an effect on a person's head movement when the $10 \mathrm{~kg}$ helmet is on versus being off. 


\section{CHAPTER FOUR: METHODOLOGY}

Twenty individuals participated in this IRB approved study (protocol \#1705594393). Upon arrival, the participant was given an explanation of the system, why this study is being conducted and how the data will be analyzed. Nexus data collection software was used to collect both EMG and Vicon data respectively. The design of the system with the 10kg mock-up helmet and modified Biodex system is explained in the following section. To conclude this chapter, the data analysis method will be described.

\subsection{Support Structure and Helmet Design}

As previously shown in Figure 1, the Biodex system is used as the support system for the $10 \mathrm{~kg}$ helmet. The counterbalancer is attached to the top center of the Biodex, directly above where a participant would stand. The counterbalancer holds a constant tension of $10 \mathrm{~kg}$ vertically, alleviating any weight that could otherwise be felt by the participant. A harness is attached to the Biodex system that can be used for patients that are at risk for falling (i.e., narcolepsy).

Two 3D printed circular rings were used to simulate the weight of the 10kg AM-PET helmet. Both rings contain sixteen 30x30x40mm blocks filled with $200 \mathrm{~g}$ of metal weights to simulate a real sensor. The weighted rings were connected to an XL Schutt's American football helmet; this not only provided structural support but included an air bladder to accommodate varying head shapes, see Figure 9. The overall weight of the helmet with metal weights, 3D printed rings, helmet, and hardware gave the desired weight of $\sim 10 \mathrm{~kg}$. 


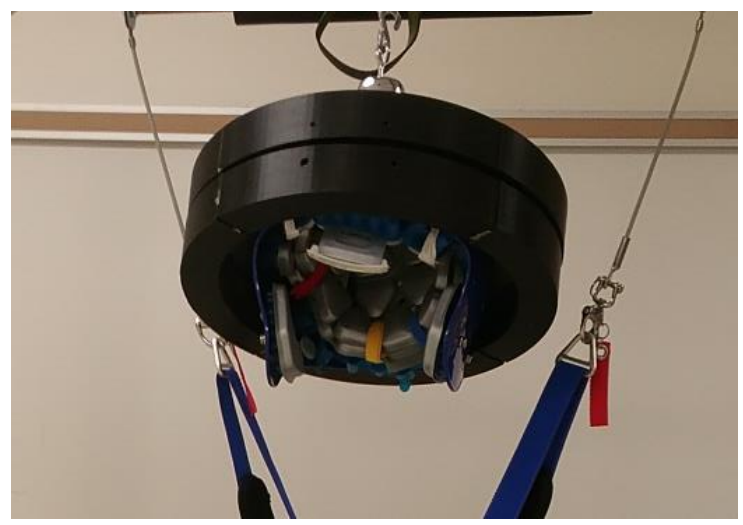

Figure 9: Weighted mock-up helmet

Figure 10 displays the exploded view of the CAD modeled ring. Notice the ring is formed by identical quadrants. The ring was constructed in quadrants to conform to the 3D printer's build plate. Figure 11 displays the top view of the quadrant with dimensions in millimeters. Figure 12 displays the side of the quadrant; the dotted lines show the depth of the space in the ring where the metal weight is placed. Figure 13 displays an isometric view of the quadrant. Notice there is a peg sticking out of one side of the quadrant and a cut out on the other, this links the quadrants together similar to Legos. Glue is added between quadrants for increased durability. Clamps were used to position the quadrants while the glue dried, Figure 14. Both rings were fastened onto the XL football helmet. The lower ring was positioned to align with the bottom of the helmet front, center point and the back center point. The second ring was placed above the first. Each ring was fastened to the helmet using two bolts in the front and one in the back. A ball and socket joint was placed at the mock-up helmet's center of gravity to connect the helmet and counterbalancer. 


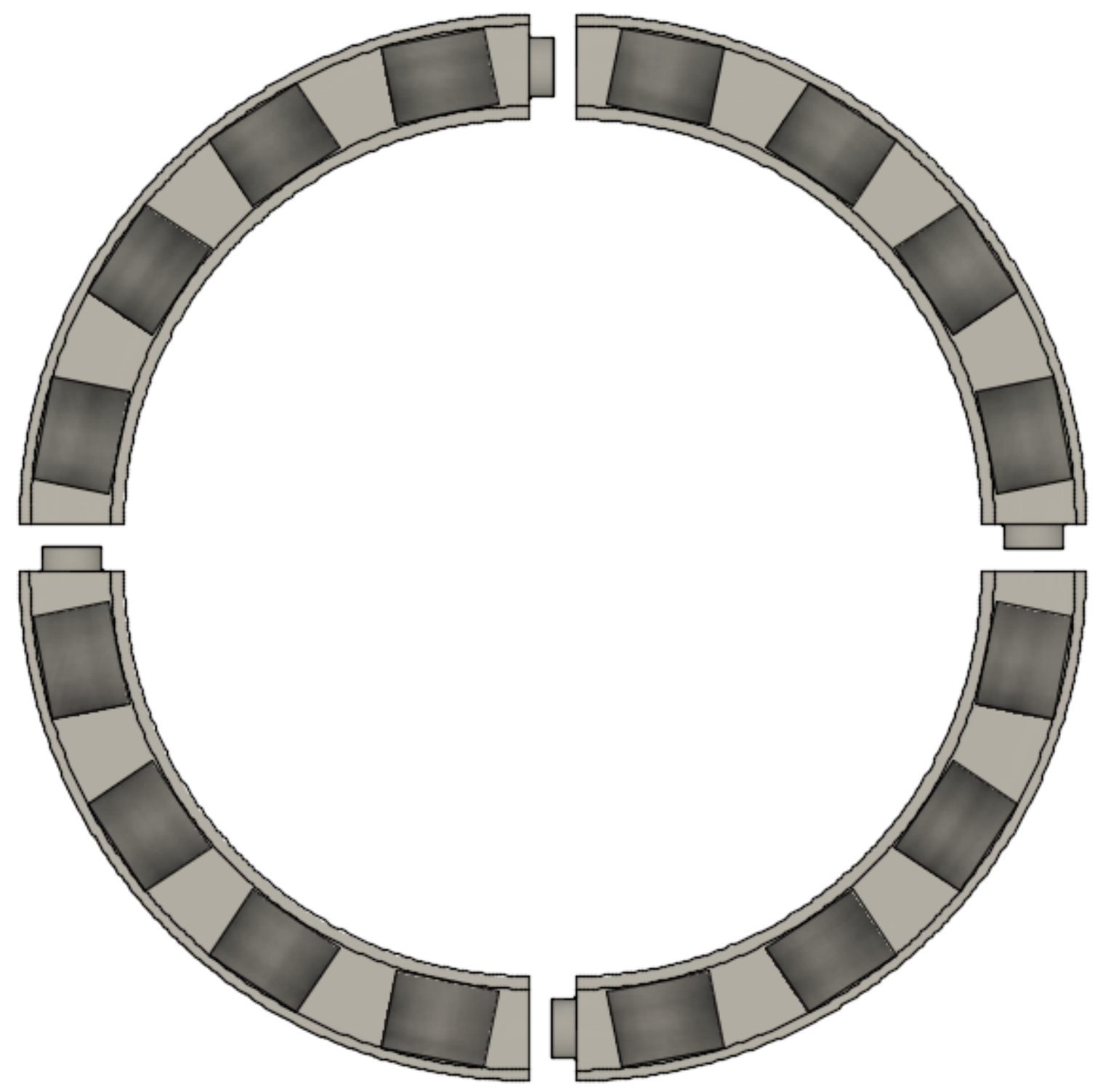

Figure 10: Exploded view of 3D printed ring 


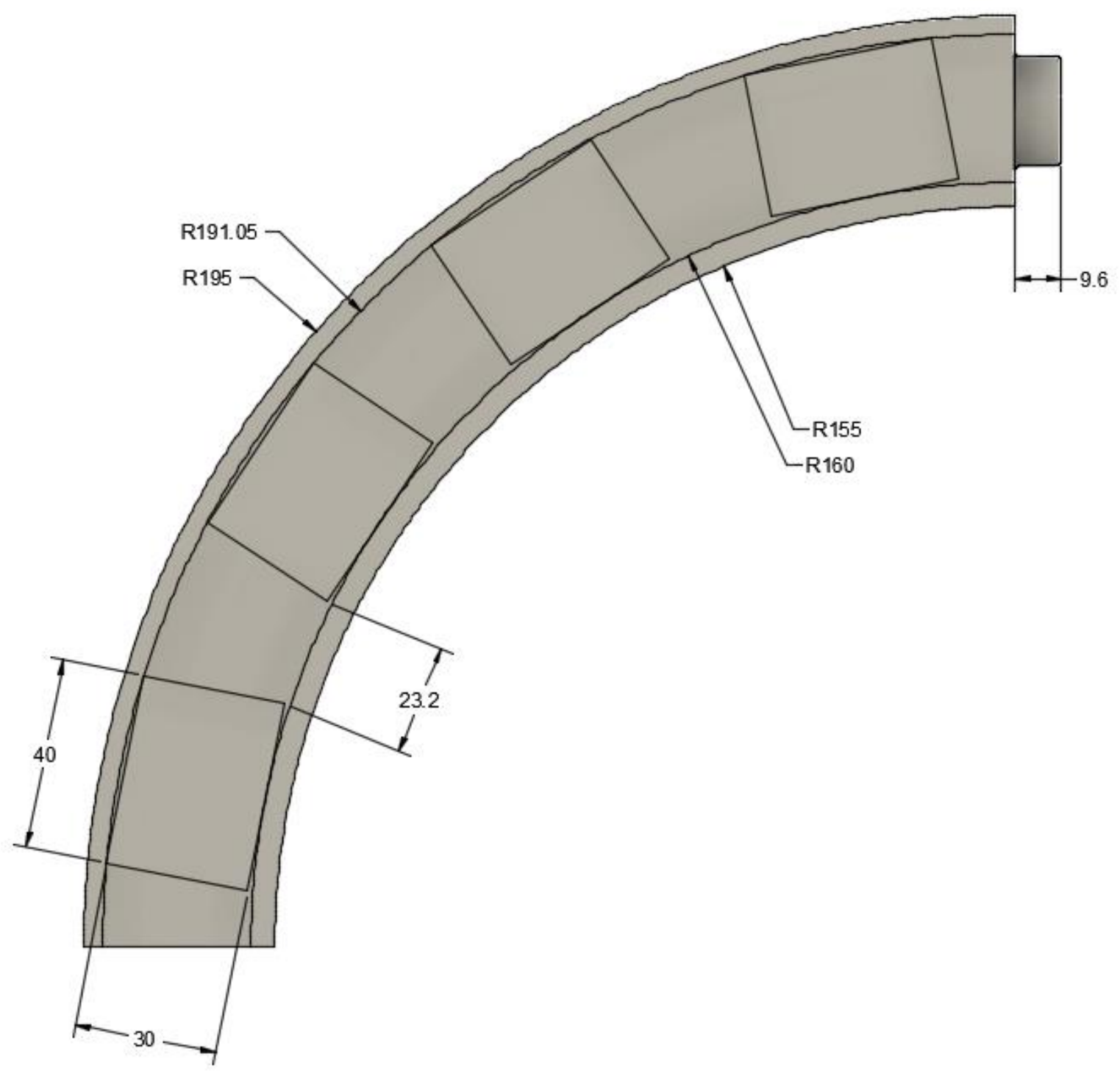

Figure 11: Top view of quadrant (dimensions in $\mathrm{mm}$ )

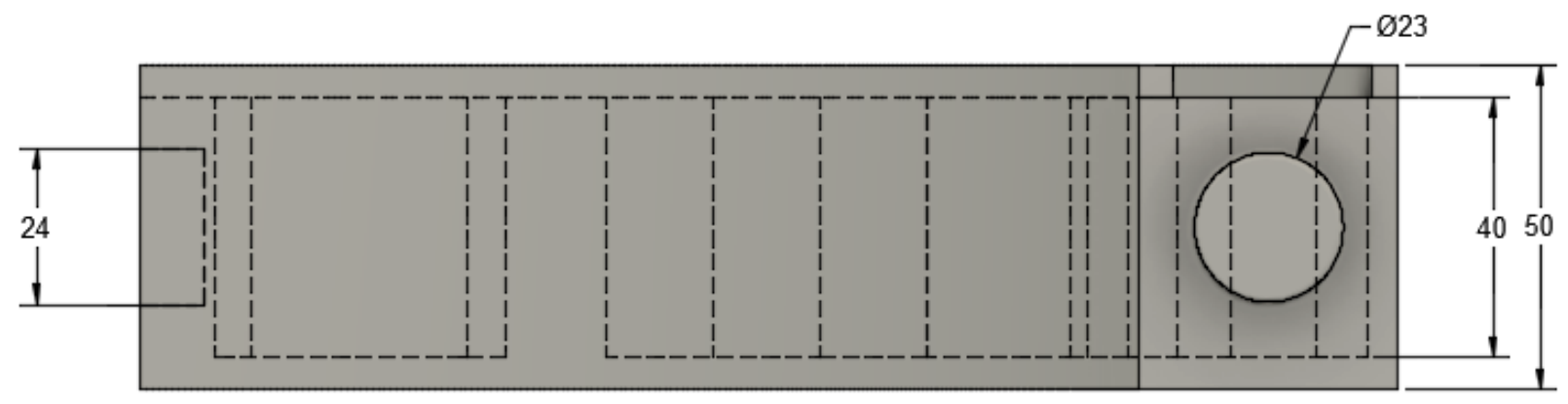

Figure 12: Side view with hidden edges (dimensions in $\mathrm{mm}$ ) 


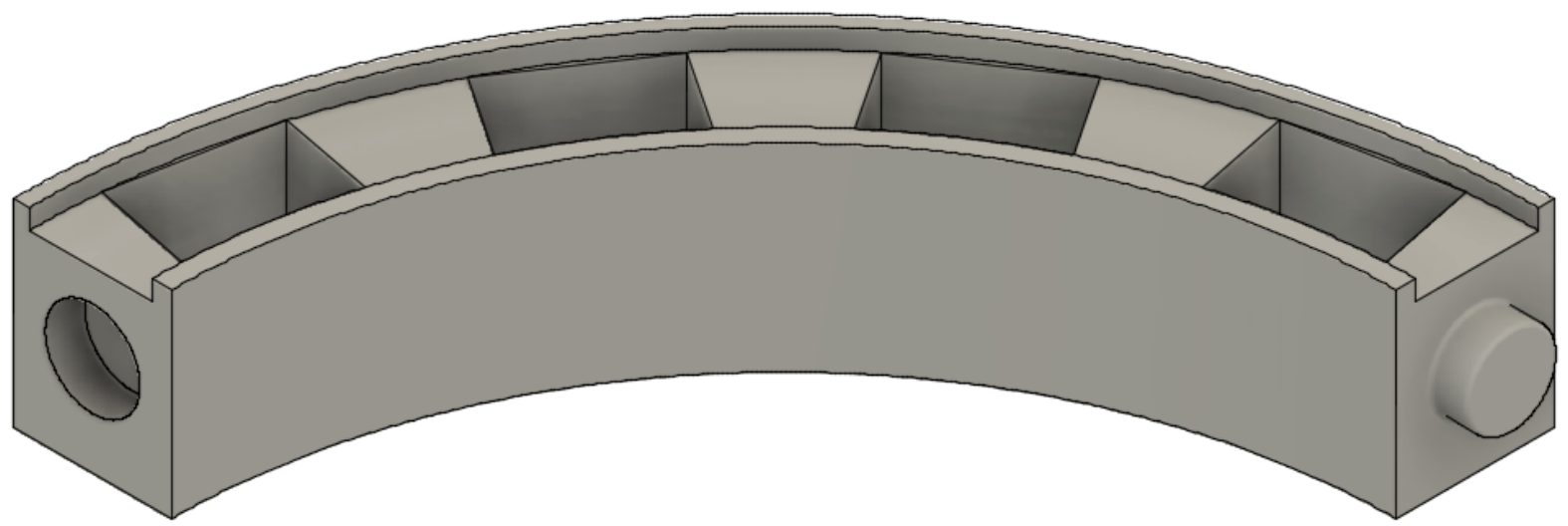

Figure 13: Isometric view of quadrant

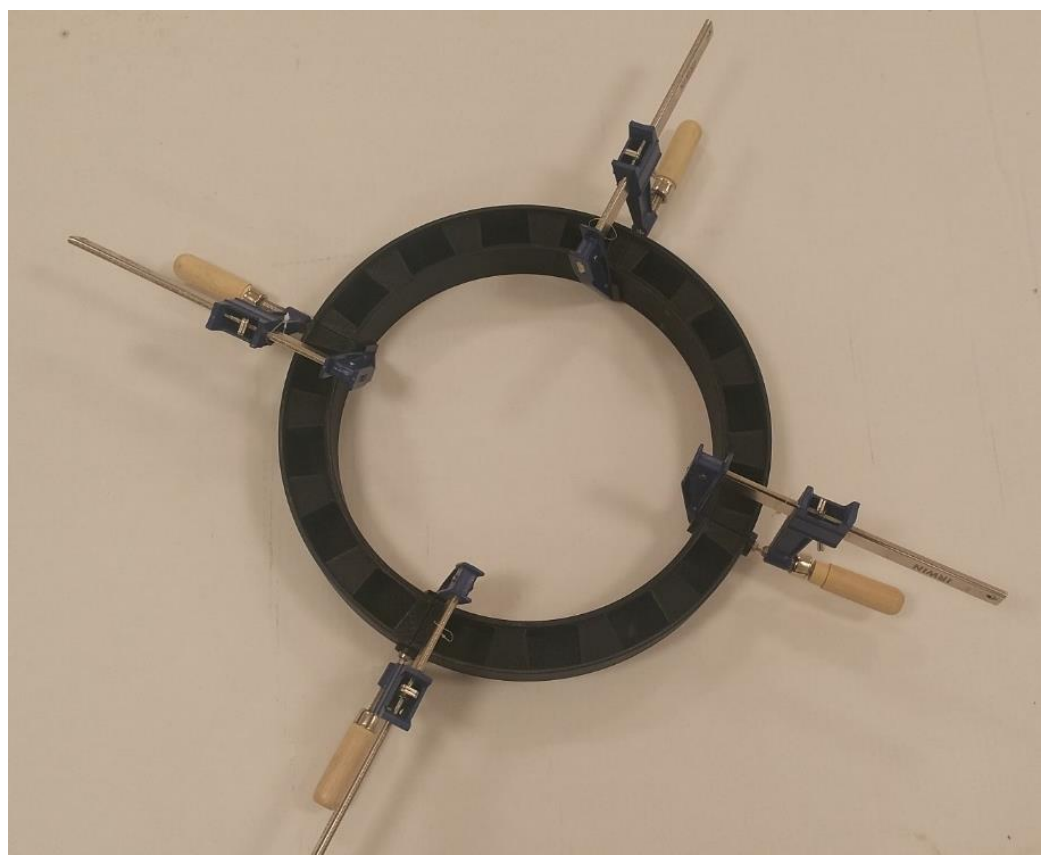

Figure 14: Image of 3D printed ring

The XL football helmet came with an inner liner, used to dampen sports impacts, and an air bladder connected to the helmet. An additional air bladder was inserted around the sides of the helmet to provide a tighter fit that could easily be removed to accommodate various head sizes, see Figure 15. 


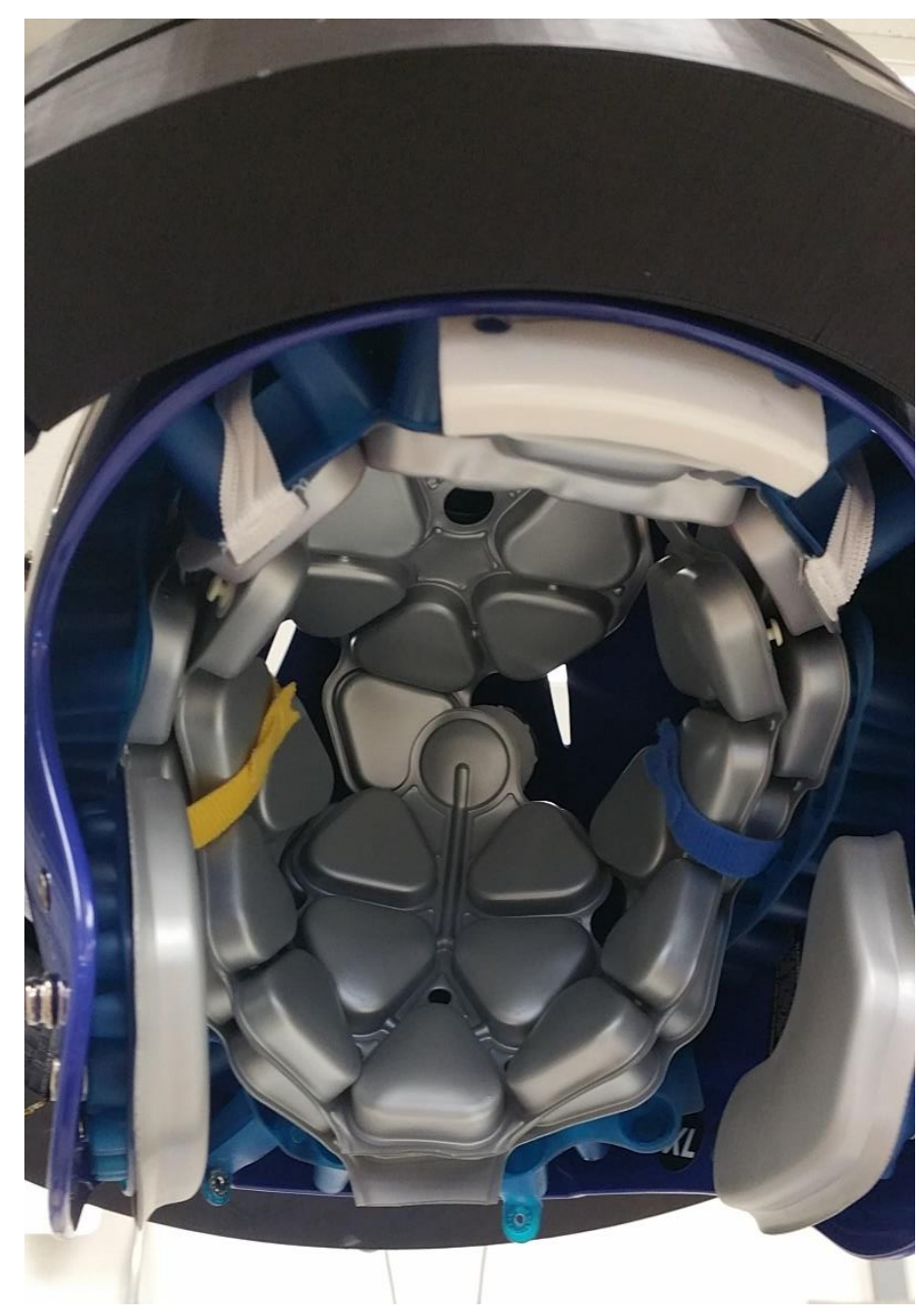

Figure 15: Inside view of helmet with bladders

\subsection{Set Up}

EMG and Vicon sensors were used in data analysis. The following section describes the placement of EMG sensors and Vicon markers as it is related to this study. These areas were cleaned of dirt and oil before being placed on the participant. This allows better adhesion and hence better data collection. Nexus data collection software was used to simultaneously collect EMG and Vicon data. 


\subsubsection{EMG}

EMG sensors are designed to measure muscle activity; in this study, EMG surface sensors were used to measure muscle activity on the left and right sternocleidomastoid (SEM) and trapezius (TRAP) neck muscles.

The SEM muscle sensors were placed on the largest cross sectional area of the muscle. This was found by directing the participant to look over their left shoulder while the tester (or researcher) applied slight pressure over the right SEM muscle to a) find the muscle and 2) locate the largest area; this process was repeated by having the participant look over their right shoulder to locate the left SEM muscle. The sensors should be symmetric to each other. These sensors were secured on either side by setting them on top of the muscle, over the skin using an adhesive designed for 2 slot EMG sensors. Figure 16 displays the rectangular EMG sensors while Figure 17 displays the EMG sensors with the adhesive tape. When placing the sensors on the SEM muscle, the rectangular sensor follows the path of the muscle, see Figure 18. Please note the green flag sticking out behind the sensors, these are part of the EMG adhesive sticker to allow for sensor removal.

The EMG sensors were placed on the TRAP muscles of the left and right side of the neck. These muscles were found by having the participant look down while the researcher applied slight pressure to find the muscle. Again, the sensors should be symmetrical to one another. Figure 19 displays the EMG sensors on a participants TRAP muscles. The rectangular sensor should be perpendicular to the participant's shoulders.

A reference (or ground) electrode is then placed on the participant's connective tissue, in this case, the forehead (Figure 20). The EMG sensors and ground electrode were plugged into the EMG box in their designated places and secured to the participant, see Figure 21. To keep 
each test standard, each EMG muscle sensor was designated a slot on the EMG box as shown in Table 3.

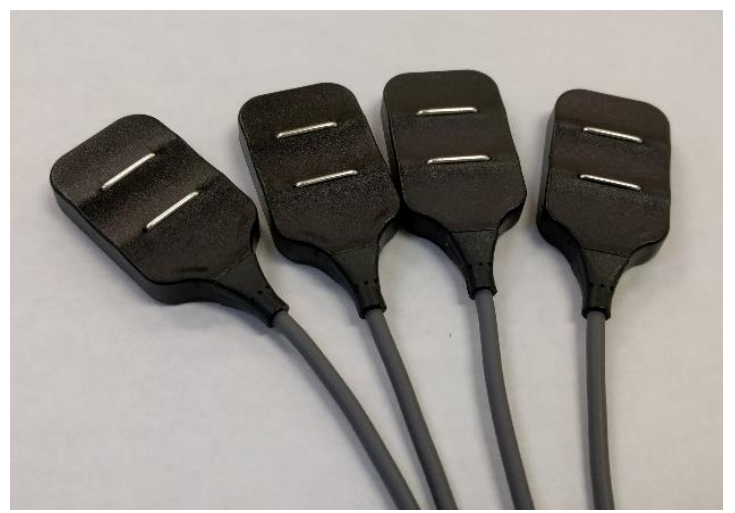

Figure 16: Surface EMG sensors

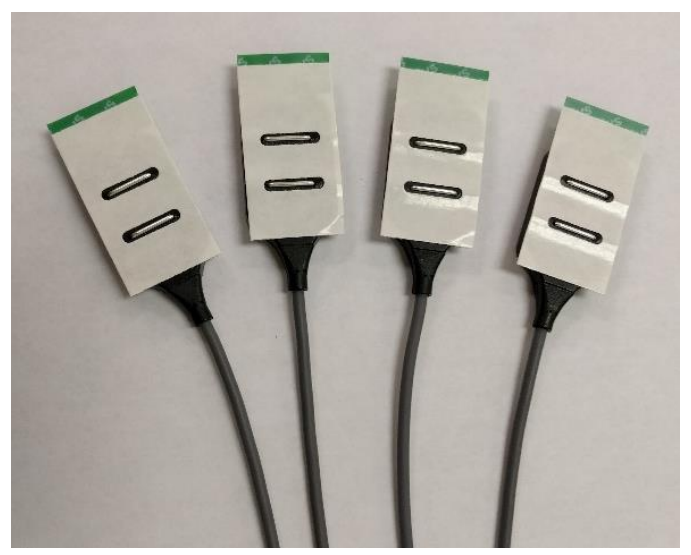

Figure 17: Surface EMG sensor with adhesive 


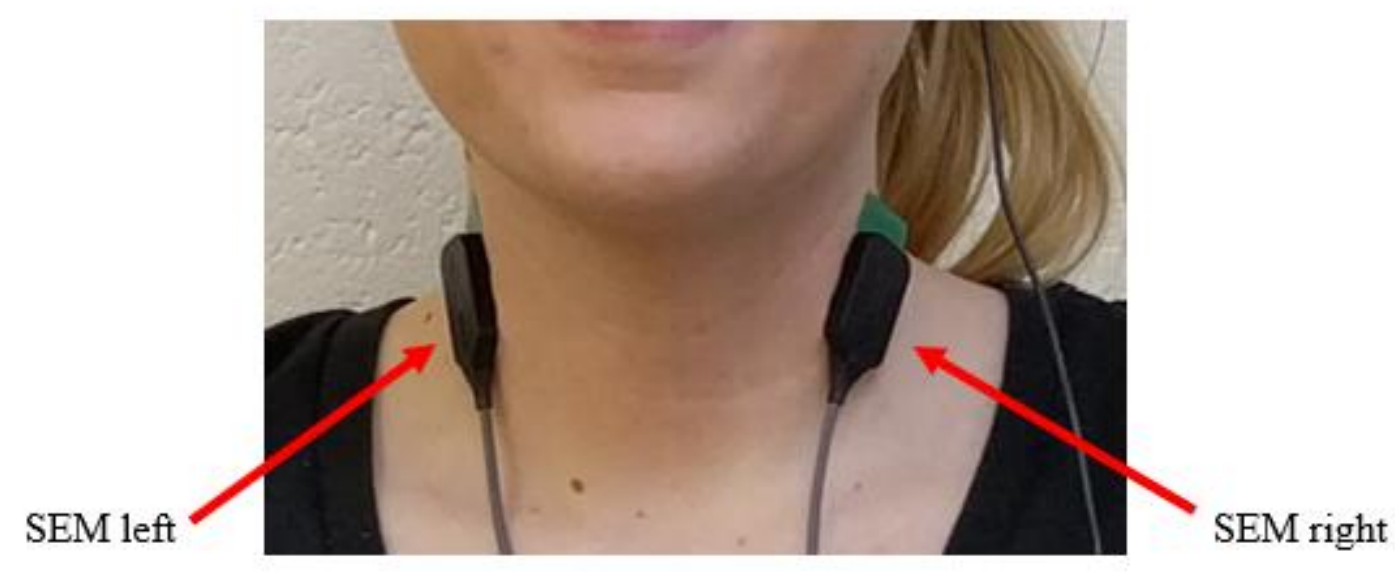

Figure 18: EMG sensors on the left and right SEM muscles

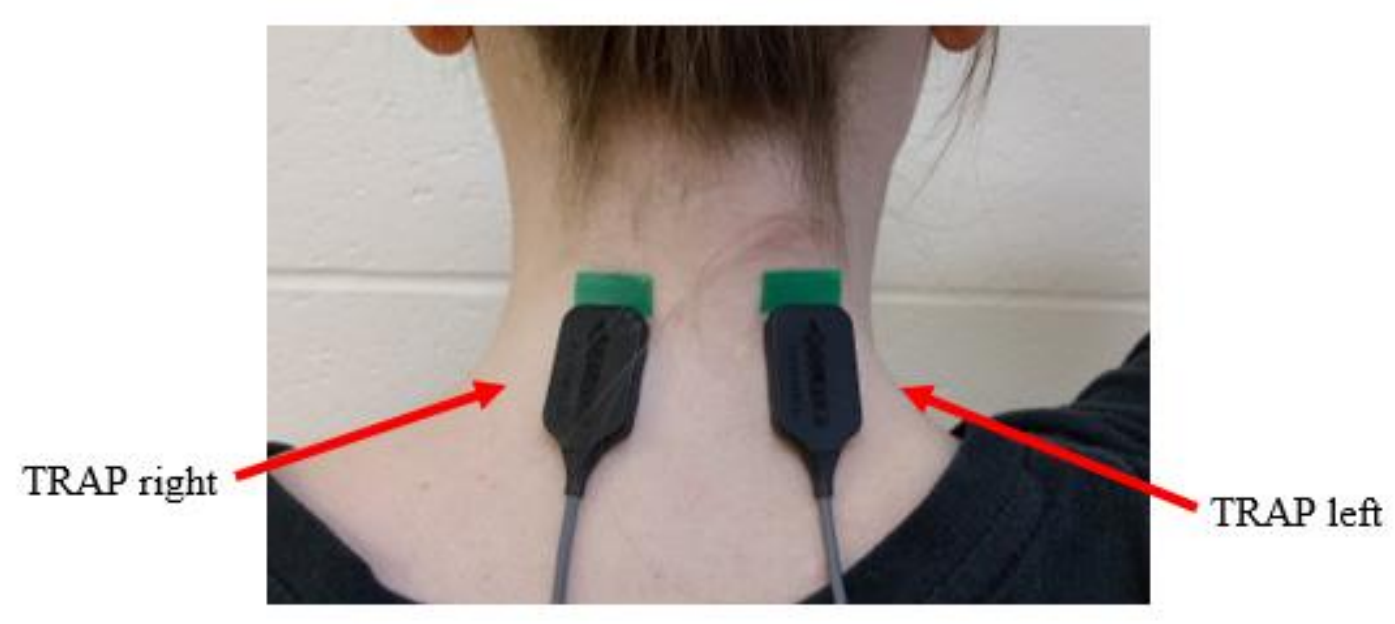

Figure 19: EMG sensors on the right and left trapezius muscles

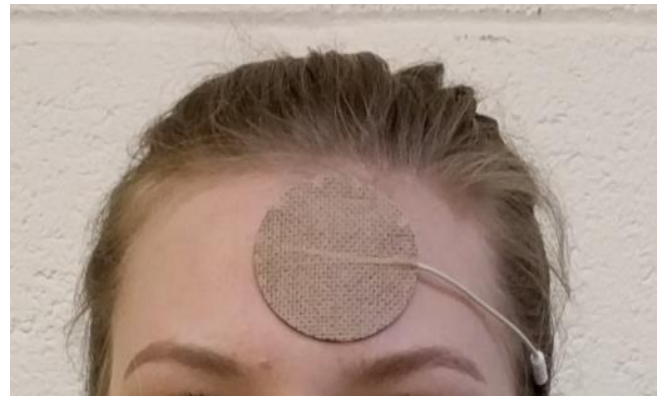

Figure 20: Ground electrode for EMG 


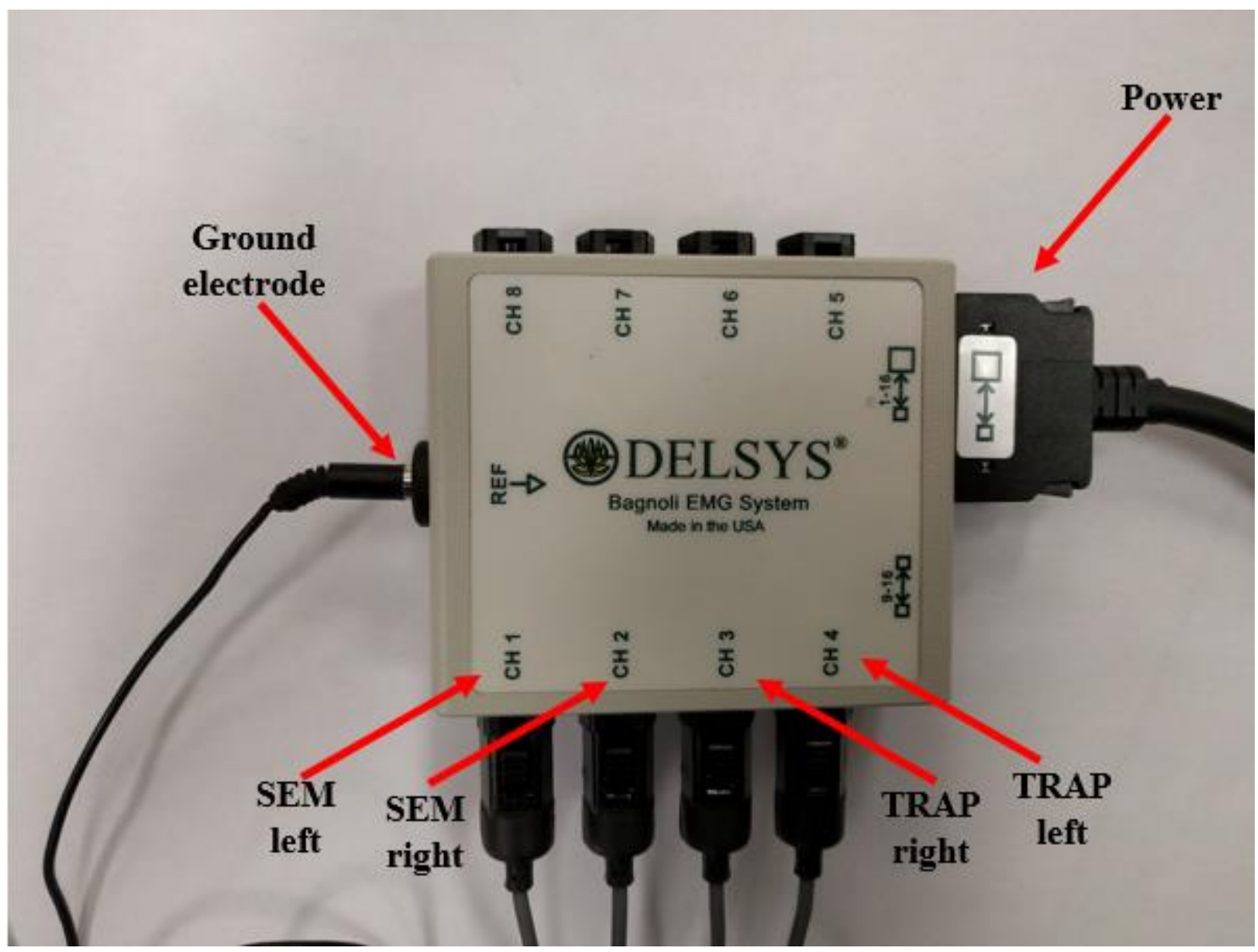

Figure 21: EMG Box with slot numbers and wires

Table 3: Slot number with muscle name used for each participant

\begin{tabular}{|c|c|}
\hline Slot number & Muscle \\
\hline 1 & SEM left \\
\hline 2 & SEM right \\
\hline 3 & TRAP right \\
\hline 4 & TRAP left \\
\hline
\end{tabular}

Once the EMG sensors were on, a maximum voluntary contraction (MVC) trial was completed. An MVC is conducted in order to normalize the data to better compare tasks which reduces variance between participants. This was done by having the participant push their head back as hard as they could against a padded area. Since there are two muscles to be analyzed, two MVC trials were necessary. The MVC trial for the SEM muscles required the patient to push their head forward as hard as they voluntarily could. This was done by using a stationary 
apparatus that could be moved and tilted to accommodate multiple heights and angles. As shown in Figure 22, the participant's body is straight with their head tilted down at a 20 degree angle, this allowed for sufficient muscle exertion. A belt was wrapped around their waist to push against, allowing more muscle exertion. The participant was instructed to push their head against the padded headrest for 3 seconds as hard as they could without straining their neck or body. The participant was instructed when to go and when to stop. The researcher would continually encourage the participant as they completed the MVC trial for the 3 seconds. This helped assure the participant was doing the trial properly, thus they would exert more force.

The second MVC trial activated the left and right TRAP muscles. This was completed similarly to the SEM MVC trial. The participant was positioned in the same device, this time with their back against the apparatus. Again, their body was positioned with straight posture and head tilted down at a 20 degree angle. A belt was wrapped around their waist and was instructed to push their head back as hard as they could. Figure 23 displays the participant in the position ready to complete the MVC trial. This again was done for about 3 seconds while the researcher encouraged the participant to exert more force. In some cases, participants were too tall to use this device, a wall and a soft cushion was used to form the same posture, so the same action could be repeated; this is, however, less secure and may cause a lesser MVC. 


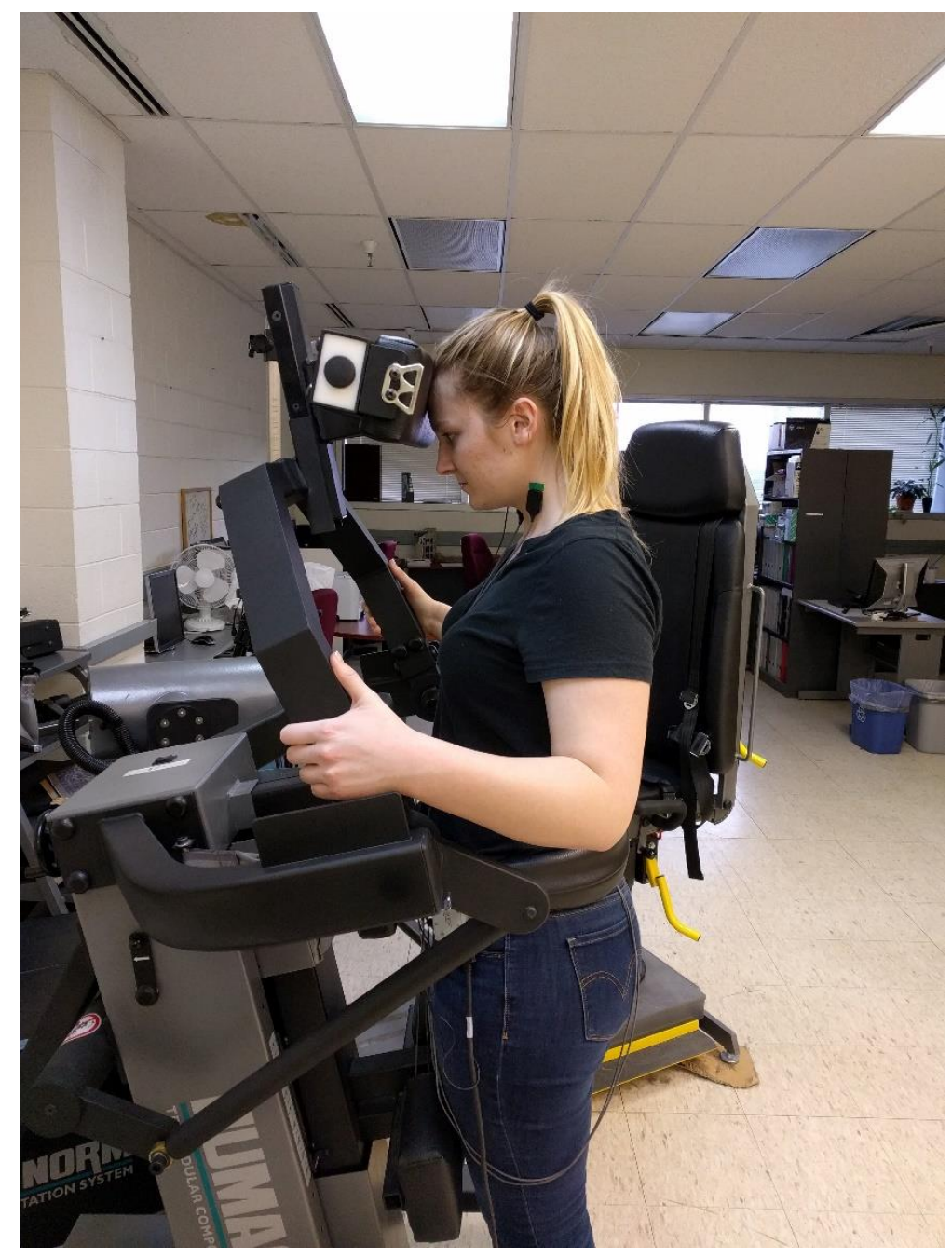

Figure 22: MVC trial for SEM muscles 


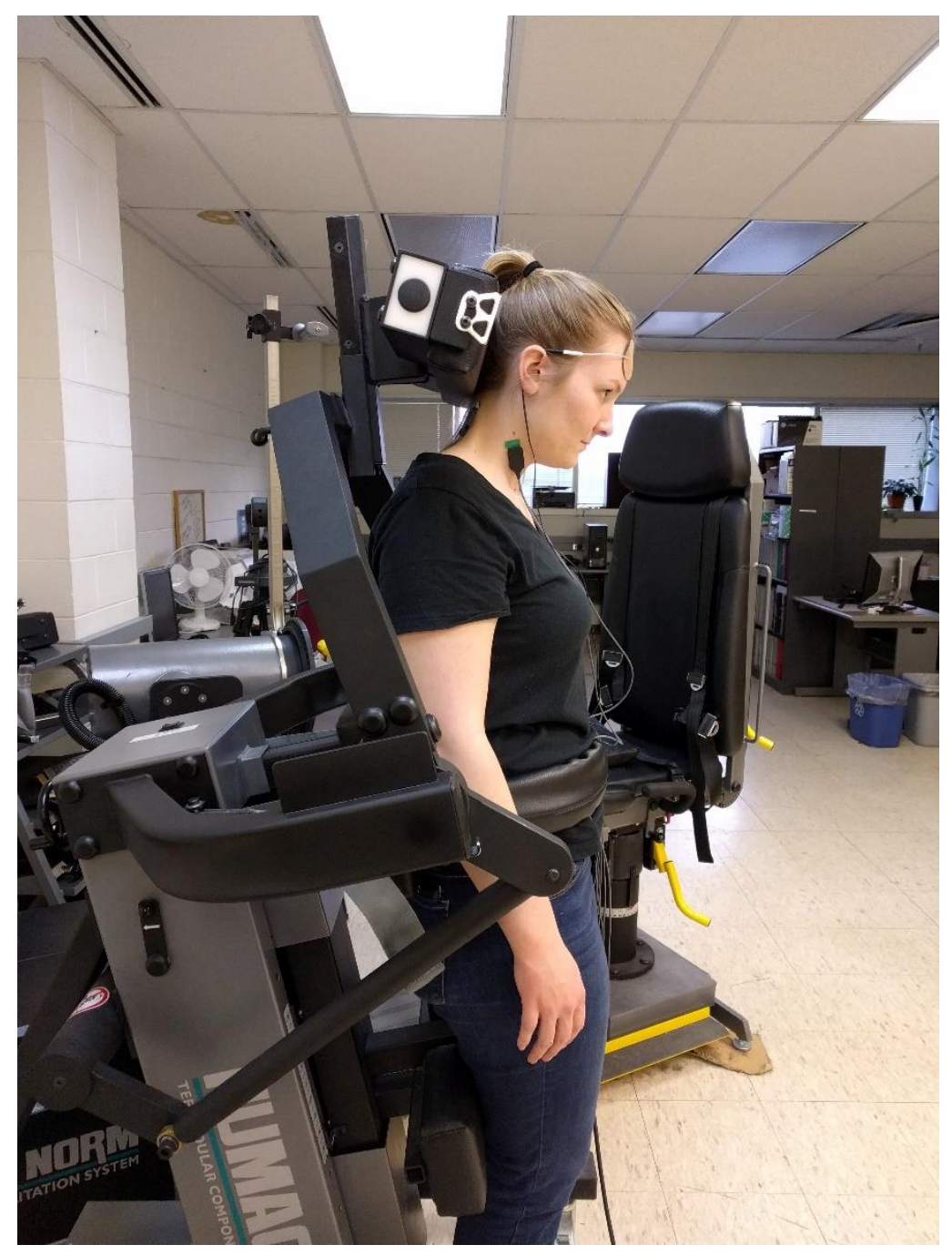

Figure 23: MVC trial for TRAP muscles

\subsubsection{Vicon}

The Vicon motion capture system is composed of eight cameras. These cameras are positioned around the testing area. Figure 24 displays five of the eight cameras used in the testing room (circled). These cameras sense the reflective markers that were placed on the participant (Figure 25). Note, it is important to enclose all shiny areas of the system and testing area to ensure the Vicon cameras do not mistake a shiny piece of metal for a marker; this will help with extracting data from the Nexus software system. 


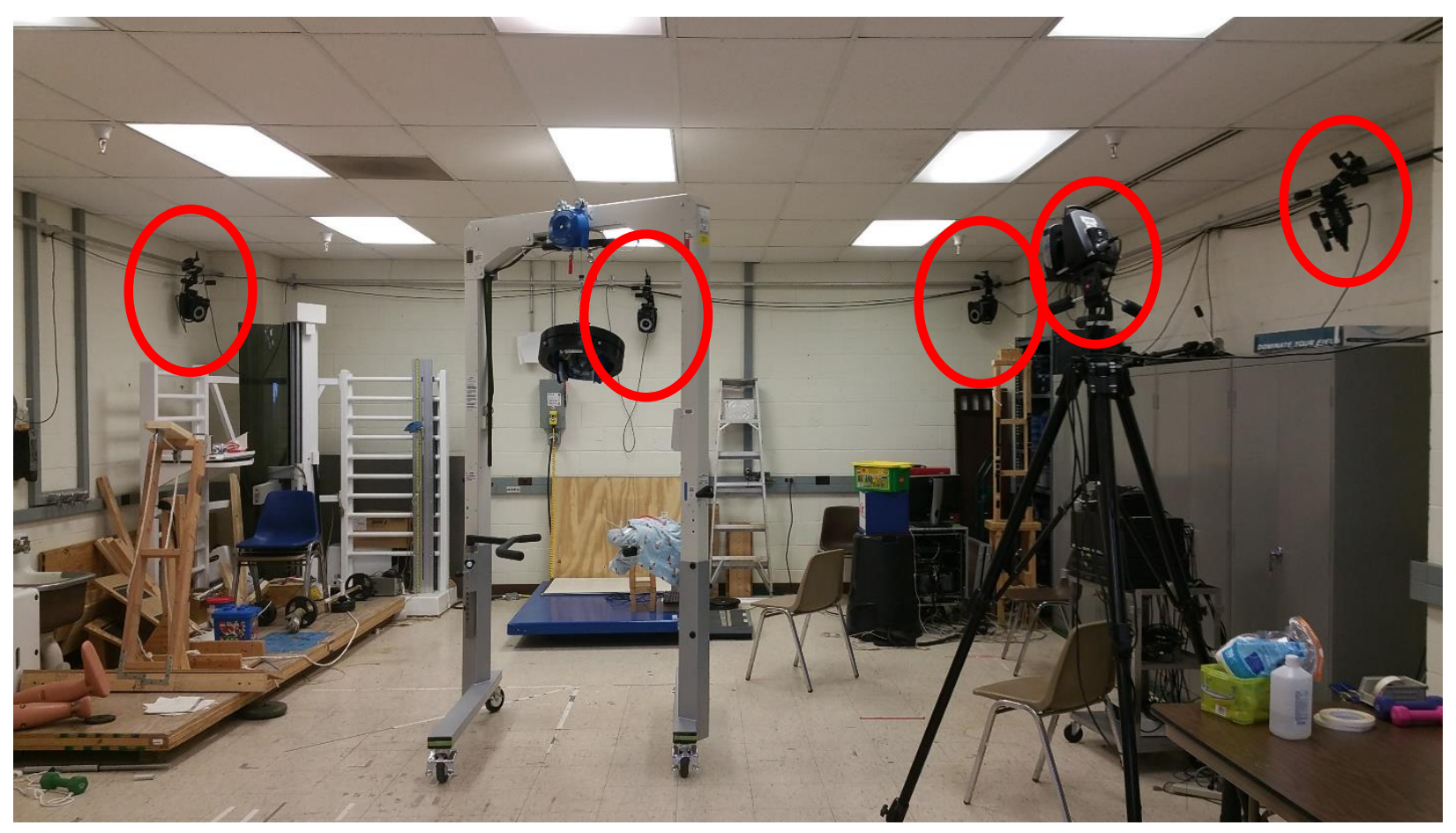

Figure 24: Image of testing room Vicon cameras (circled)

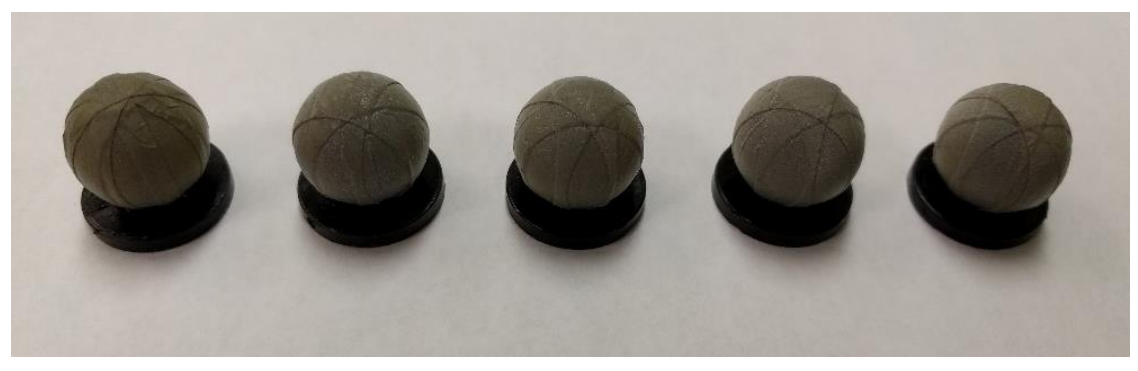

Figure 25: Vicon markers

Figure 26 displays the positioning of the markers on the participant's cheeks and shoulders. The cheek markers were used to analyze the head motion to calculate speed, acceleration and range of motion of the participants head. The shoulder sensors are in place to differentiate the head movements to the torso movements. Sensors were also place on the mockup helmet, however, that data was not used in this study. 


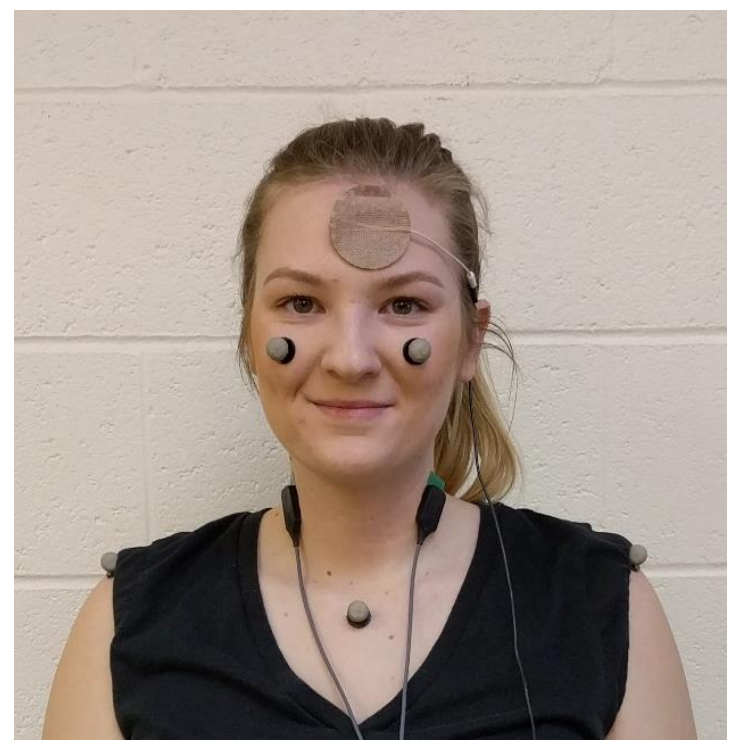

Figure 26: EMG and Vicon sensors in place on participant

If at any time an EMG sensor or Vicon marker became loose or fell off, a new piece of tape was applied to the sensor/marker and the skin was again cleaned to get rid of oils and placed back on the same spot. This may happen because the area was not properly cleaned or due to moisture.

\subsection{Protocol}

Six tasks were completed during each test and repeated a total of 5 times. The tasks in order are: 1) nodding head, 2) tapping foot on floor, 3) walking in place, 4) clapping hands, 5) turning head side to side and 6) shaking head. Figure 27 displays these tasks. Each task was demonstrated to the participant and was asked to perform it for five seconds. 


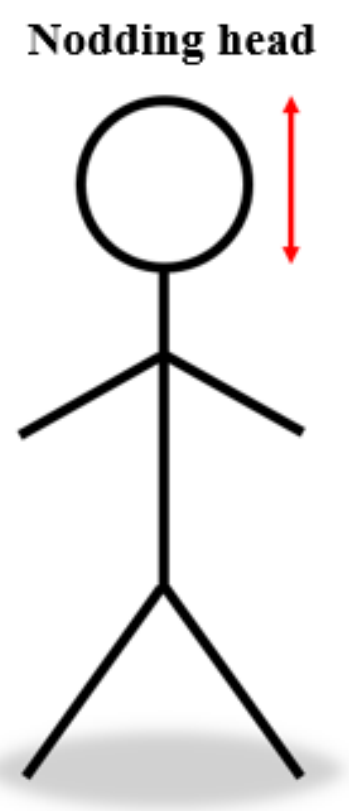

(1)
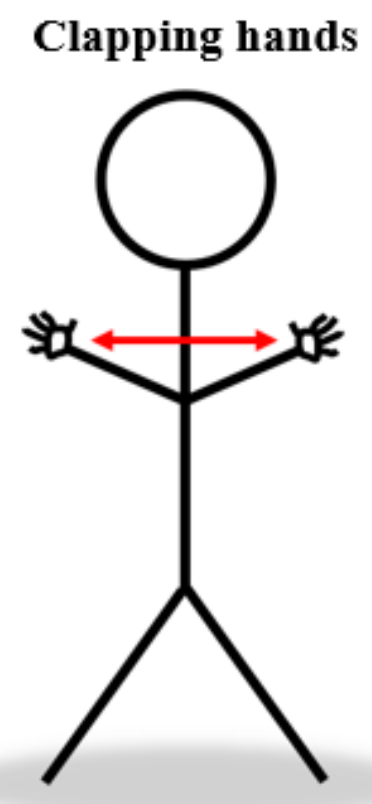

(4)

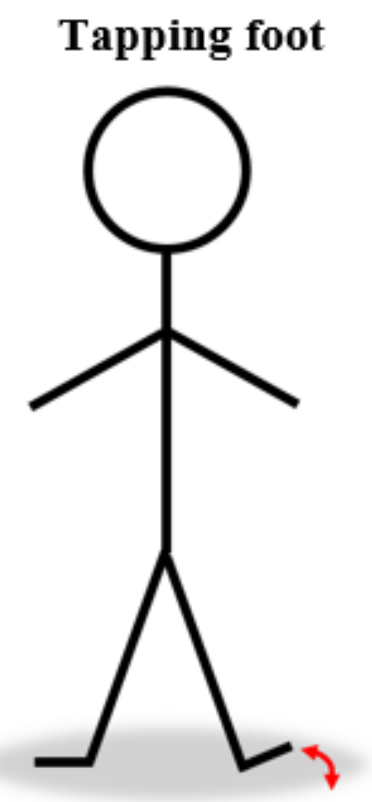

(2)

\section{Walking in place}

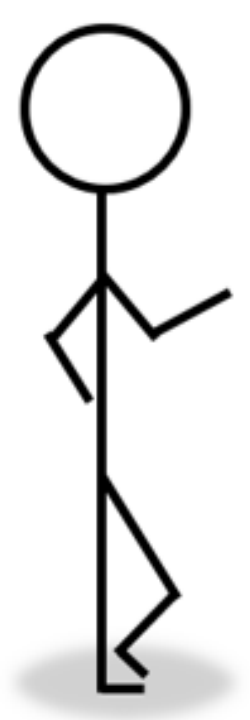

(3)

Turning head side to side

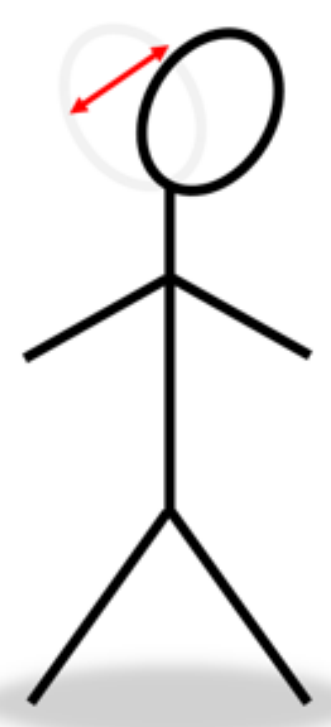

(5)

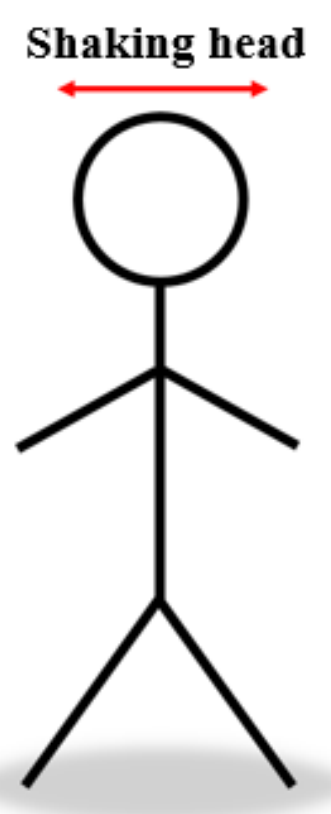

(6)

Figure 27: Schematic of tasks performed in the study

The first repetition set was completed without the helmet. The participant was asked to stand in a designated spot and nod their head for five seconds while the tester collected EMG and 
Vicon data. The tester would guide the participant when to start the task and when to stop the task by counting to five out loud in accordance to the Nexus collection software, which includes a built-in stopwatch. Once the first set of repetitions were complete the helmet was placed on for repetitions 2-4 then taken off for the fifth repetition. Figure 28 displays the order in which the tasks and repetitions were complete. A real AM-PET brain scans duration is 30 minutes, therefore the helmet will be on for no less than 30 minutes.

\section{0 minutes}

Helmet off

Repetition 1

1. Nod head

2. Tap foot

3. Walk in place

4. Clap hands

5. Turn head

6. Shake head
Helmet on

Repetition 2

1. Nod head

2. Tap foot

3. Walk in place

4. Clap hands

5. Turn head

6. Shake head

\section{Helmet on}

Repetition 3

1. Nod head

2. Tap foot

3. Walk in place

4. Clap hands

5. Turn head

6. Shake head
Helmet on

Repetition 4

1. Nod head

2. Tap foot

3. Walk in place

4. Clap hands

5. Turn head

6. Shake head

\section{Helmet off}

Repetition 5

1. Nod head

2. Tap foot

3. Walk in place

4. Clap hands

5. Turn head

6. Shake head

Figure 28: Visual representation of repetitions and tasks

As shown in Figure 28, six tasks are completed for each repetition. Beginning after the first repetition, the participant was asked what their comfort level was on a scale from 1-10, where 1 is comfortable and 10 is uncomfortable. The Biodex support system was then wheeled to the participant and was placed in the designated spot and wheels were locked (see Figure 29). 
The participant was directed how to place on the helmet by pulling the helmet over their head and were advised not to make any sudden movements until they were comfortable with the system. The participant can touch the helmet to readjust at any time but was urged not to while completing a task. Once the participant placed the helmet on, a timer was set for 30 minutes and they were asked what their comfort level was on a scale to 1-10 with 1 being comfortable. Three sets of repetitions were completed over the 30 minute time period with the helmet on. After each task with the helmet on, the participant was asked their comfort level. The tasks alone do not take the full 30 minutes, so regular conversation with normal stationary movements helped spread out the tasks and fill the 30 minutes. 


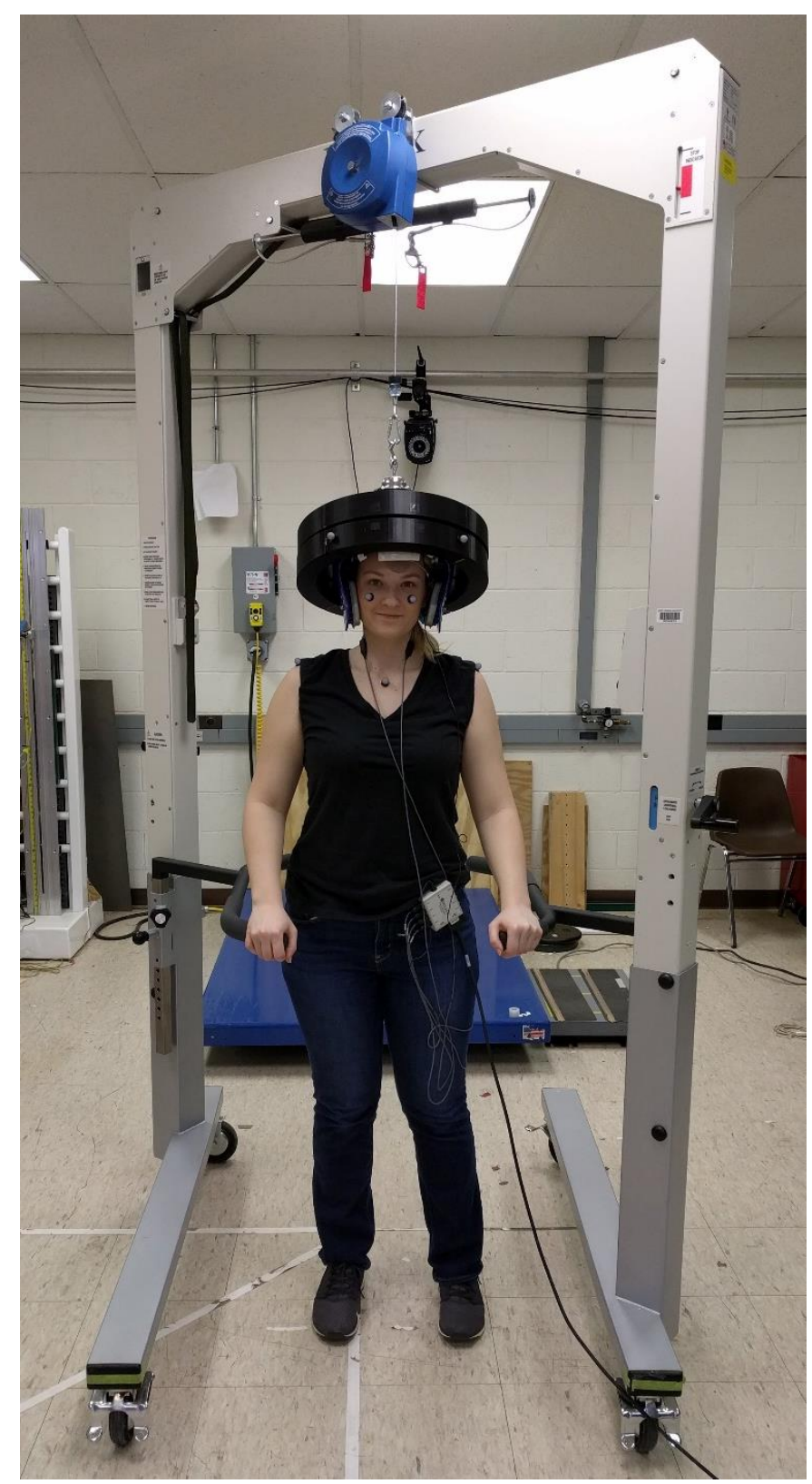

Figure 29: Participant with Biodex support and helmet on in the designated position

After 30 minutes, the helmet was taken off and the Biodex system was moved out of the testing area. The participant was asked to stand back in the designated spot and the six tasks were completed while measuring the EMG and Vicon data. This was to be completed the same as before, again for five seconds each. 


\subsection{Data Analysis}

T-tests are used to relate two population sets and determine if they are similar. In this case, there are two dependent variables: 1) without helmet and 2) with helmet. This method will determine if two population sets are considered similar. If the data is similar, the helmet has no effect on the patient with the given variables. Five sets of t-tests were completed to determine the safety and mechanics of the device including 1) EMG before and after the 30 minute helmet session, 2) EMG with and without the helmet, 3) speed with and without the helmet, 4) acceleration with and without the helmet and 5) range of motion with and without helmet for nodding head, turning head and shaking head. Table 4 displays the five t-tests with their respective repetitions for each population.

Table 4: The five sets of $t$-tests with populations to be compared

\begin{tabular}{|c|c|c|c|c|}
\hline & \# & Description of task & Population 1 & Population 2 \\
\hline \multirow[t]{2}{*}{ EMG } & 1 & $\begin{array}{l}\text { Before and after } 30 \text { minutes with } \\
\text { helmet }\end{array}$ & repetition 1 & repetition 5 \\
\hline & 2 & With and without helmet & repetitions 1 and 5 & repetitions 2,3 and 4 \\
\hline \multirow{3}{*}{ Vicon } & 3 & Speed with and without helmet & repetitions 1 and 5 & repetitions 2,3 and 4 \\
\hline & 4 & $\begin{array}{l}\text { Acceleration with and without } \\
\text { helmet }\end{array}$ & repetitions 1 and 5 & repetitions 2,3 and 4 \\
\hline & 5 & $\begin{array}{l}\text { Range of motion with and without } \\
\text { helmet for nodding head, turning } \\
\text { head and shaking head }\end{array}$ & repetitions 1 and 5 & repetitions 2,3 and 4 \\
\hline
\end{tabular}

To complete this method a degree of freedom $(v)$ is calculated and a t-statistic $\left(T^{\prime}\right)$ is obtained to determine if the two populations can be considered similar. A hypothesis is created to determine if the population sets are similar, $H_{o}$ representing similarity and $H_{1}$ representing difference between the two populations.

$$
H_{o}: \mu_{1}=\mu_{2}
$$




$$
H_{1}: \mu_{1} \neq \mu_{2}
$$

The degree of freedom $(v)$ was calculated using Equation 1. This is needed to find the critical values in the t-distribution table.

$$
v=\frac{\left(s_{1}^{2} / n_{1}+s_{2}^{2} / n_{2}\right)^{2}}{\left[\left(s_{1}^{2} / n_{1}\right)^{2} /\left(n_{1}-1\right)\right]+\left[\left(s_{2}^{2} / n_{2}\right)^{2} /\left(n_{2}-1\right)\right]} \quad \text { Equation } 1
$$

Where $s_{1}^{2}$ is the variance of population $1, s_{2}^{2}$ is the variance of population $2, n_{1}$ is the number of data points in population 1 and $n_{2}$ is the number of data points in population 2 .

Equation 2 displays the t-statistic which is used to determine if the critical value is within the bounds or not.

$$
T^{\prime}=\frac{\left(\bar{X}_{1}-\bar{X}_{2}\right)-\left(\mu_{1}-\mu_{2}\right)}{\sqrt{\left(s_{1}^{2} / n_{1}\right)+\left(s_{2}^{2} / n_{2}\right)}}
$$

Where $\bar{X}_{1}$ is the mean of population $1, \bar{X}_{2}$ is the mean of population $2, \mu_{1}$ and $\mu_{2}$ are the populations mean, in this case, zero.

A $95 \%$ confidence interval was chosen, or $\alpha=0.95$. Using a two-sided t-distribution table, the critical value can be obtained; this is shown in Equation 3. If the t-statistic is within the bounds of this equation, the two data sets are considered similar.

$$
P\left(-t_{\alpha / 2}<T^{\prime}<t_{\alpha / 2}\right) \approx 1-\alpha \quad \text { Equation } 3
$$

\subsubsection{EMG Analysis}

The Nexus software outputs a graph for each muscle showing the muscles activity 1000 times per second. This data is filtered using a Matlab program to reduce noise that occurs in the testing room such as cell phone and computer frequencies. The data was normalized using the 
MVC trials of each participant and muscle. In some cases the participant's max MVC was smaller than the EMG readings during a task; if this occurred, the larger value would be the new MVC. This could be due to the muscle not being activated enough during the MVC trial or there could have been an error in the EMG sensors that created a spike, amongst other possibilities. Normalization of data was completed using the MVC in order to better compare the participants. In order to do this, the average of each task was divided by the MVC trial and formed into a percentage.

\subsubsection{Vicon Analysis}

The Vicon motion capture analysis was completed by calculating the speed, acceleration and range of motion between the points in $3 \mathrm{D}$ space. The Nexus data collection software outputs data points in 3D space of markers 100 times per second. This can be translated into speed, acceleration and range of motion. The speed $(s)$ calculation is computed using the distance $(d)$ in Equation 4, shown in Equation 5. The acceleration (a) calculation is shown in Equation 6. The range of motion was captured by determining the maximum and minimum values in the $\mathrm{z}$ direction (nodding and turning head) and y-direction (shaking head).

$$
\begin{array}{cc}
d=\sqrt{\left(x_{i}-x_{j}\right)^{2}+\left(y_{i}-y_{j}\right)^{2}+\left(z_{i}-z_{j}\right)^{2}} & \text { Equation 4 } \\
s=\frac{d}{\Delta t} & \text { Equation 5 } \\
a=\Delta s / \Delta t & \text { Equation 6 }
\end{array}
$$

Where $x_{i}-x_{j}$ is the distance between two x-axis points, $y_{i}-y_{j}$ between $\mathrm{y}$-axis and $z_{i}-$ $z_{j}$ between z-axis. And $\Delta t$ is the difference in time and $\Delta s$ is the difference in speed. 


\section{CHAPTER FIVE: RESEARCH RESULTS}

The t-test from EMG and Vicon data is presented. The t-test results for all compared populations are shown in Table 5-Table 32. The qualitative data from the comfort questionnaire is presented at the end. A discussion of the results will be discussed following the results.

\subsection{EMG}

\subsubsection{T-test Before and After 30 Minute Helmet Test}

Table 5-Table 10 display the calculated values from the t-test for EMG signals before and after the 30 minute helmet session (repetition 1 versus repetition 5). Appendix A displays the normalized data.

Notice values for SEM right are shaded gray. There was an unknown error in the EMG data the created consistently high numbers for SEM right values. The following chapter addresses this in detail.

Table 5: EMG statistical calculations for nodding head comparing before and after 30 minute helmet session

\begin{tabular}{|c|c|c|c|c|}
\hline Variable & $\begin{array}{c}\text { Values for SEM } \\
\text { left }\end{array}$ & $\begin{array}{c}\text { Values for SEM } \\
\text { right }\end{array}$ & $\begin{array}{c}\text { Values for TRAP } \\
\text { right }\end{array}$ & $\begin{array}{c}\text { Values for TRAP } \\
\text { left }\end{array}$ \\
\hline $\bar{X}_{1}$ & $7.6 \%$ & $33.5 \%$ & $10.8 \%$ & $18.5 \%$ \\
\hline $\bar{X}_{2}$ & $3.6 \%$ & $27.1 \%$ & $11.8 \%$ & $12.3 \%$ \\
\hline$S_{1}^{2}$ & $3.3 \%$ & $7.0 \%$ & $0.5 \%$ & $3.5 \%$ \\
\hline$S_{2}^{2}$ & $0.1 \%$ & $5.2 \%$ & $0.9 \%$ & $0.8 \%$ \\
\hline$n_{1}$ & 20 & 20 & 20 & 20 \\
\hline$n_{2}$ & 20 & 20 & 20 & 20 \\
\hline$v$ & 26628.8 & 52.1 & 23.7 & 292.7 \\
\hline$t-$ statistic & 1.0 & 0.8 & -0.4 & 1.3 \\
\hline critical value & 2.0 & 2.0 & 2.1 & 2.0 \\
\hline
\end{tabular}

Table 6: EMG statistical calculations for tapping foot comparing before and after 30 minute helmet session

\begin{tabular}{|c|c|c|c|c|}
\hline Variable & $\begin{array}{c}\text { Values for SEM } \\
\text { left }\end{array}$ & $\begin{array}{c}\text { Values for SEM } \\
\text { right }\end{array}$ & $\begin{array}{c}\text { Values for TRAP } \\
\text { right }\end{array}$ & $\begin{array}{c}\text { Values for TRAP } \\
\text { left }\end{array}$ \\
\hline $\bar{X}_{1}$ & $3.4 \%$ & $28.6 \%$ & $8.5 \%$ & $9.3 \%$ \\
\hline $\bar{X}_{2}$ & $2.7 \%$ & $26.8 \%$ & $7.6 \%$ & $7.9 \%$ \\
\hline
\end{tabular}




\begin{tabular}{|c|c|c|c|c|}
\hline$S_{1}^{2}$ & $0.1 \%$ & $4.9 \%$ & $0.4 \%$ & $0.5 \%$ \\
\hline$S_{2}^{2}$ & $0.0 \%$ & $5.2 \%$ & $0.4 \%$ & $0.3 \%$ \\
\hline$n_{1}$ & 20 & 20 & 20 & 20 \\
\hline$n_{2}$ & 20 & 20 & 20 & 20 \\
\hline$v$ & 81.6 & 35.9 & 42.2 & 57.6 \\
\hline$t-$ statistic & 1.0 & 0.2 & 0.5 & 0.7 \\
\hline critical value & 2.0 & 2.0 & 2.0 & 2.0 \\
\hline
\end{tabular}

Table 7: EMG statistical calculations for walking in place comparing before and after 30 minute helmet session

\begin{tabular}{|c|c|c|c|c|}
\hline Variable & $\begin{array}{c}\text { Values for SEM } \\
\text { left }\end{array}$ & $\begin{array}{c}\text { Values for SEM } \\
\text { right }\end{array}$ & $\begin{array}{c}\text { Values for TRAP } \\
\text { right }\end{array}$ & $\begin{array}{c}\text { Values for TRAP } \\
\text { left }\end{array}$ \\
\hline $\bar{X}_{1}$ & $5.0 \%$ & $27.7 \%$ & $10.5 \%$ & $12.8 \%$ \\
\hline $\bar{X}_{2}$ & $3.4 \%$ & $27.3 \%$ & $8.2 \%$ & $9.4 \%$ \\
\hline$S_{1}^{2}$ & $0.2 \%$ & $5.3 \%$ & $0.7 \%$ & $1.2 \%$ \\
\hline$S_{2}^{2}$ & $0.1 \%$ & $5.3 \%$ & $0.4 \%$ & $0.4 \%$ \\
\hline$n_{1}$ & 20 & 20 & 20 & 20 \\
\hline$n_{2}$ & 20 & 20 & 20 & 20 \\
\hline$v$ & 112.0 & 37.8 & 78.3 & 123.4 \\
\hline$t-$ statistic & 1.4 & 0.1 & 1.0 & 1.2 \\
\hline critical value & 2.0 & 2.0 & 2.0 & 2.0 \\
\hline
\end{tabular}

Table 8: EMG statistical calculations for clapping hands comparing before and after 30 minute helmet session

\begin{tabular}{|c|c|c|c|c|}
\hline Variable & $\begin{array}{c}\text { Values for SEM } \\
\text { left }\end{array}$ & $\begin{array}{c}\text { Values for SEM } \\
\text { right }\end{array}$ & $\begin{array}{c}\text { Values for TRAP } \\
\text { right }\end{array}$ & $\begin{array}{c}\text { Values for TRAP } \\
\text { left }\end{array}$ \\
\hline $\bar{X}_{1}$ & $4.7 \%$ & $28.9 \%$ & $11.8 \%$ & $11.9 \%$ \\
\hline $\bar{X}_{2}$ & $5.5 \%$ & $28.0 \%$ & $9.0 \%$ & $9.7 \%$ \\
\hline$S_{1}^{2}$ & $0.2 \%$ & $5.0 \%$ & $1.0 \%$ & $0.9 \%$ \\
\hline$S_{2}^{2}$ & $0.4 \%$ & $5.2 \%$ & $0.5 \%$ & $0.5 \%$ \\
\hline$n_{1}$ & 20 & 20 & 20 & 20 \\
\hline$n_{2}$ & 20 & 20 & 20 & 20 \\
\hline$v$ & 19.4 & 36.9 & 96.3 & 70.0 \\
\hline$t-$ statistic & -0.5 & 0.1 & 1.0 & 0.8 \\
\hline critical value & 2.1 & 2.0 & 2.0 & 2.0 \\
\hline
\end{tabular}

Table 9: EMG statistical calculations for turning head comparing before and after 30 minute helmet session

\begin{tabular}{|c|c|c|c|c|}
\hline Variable & $\begin{array}{c}\text { Values for SEM } \\
\text { left }\end{array}$ & $\begin{array}{c}\text { Values for SEM } \\
\text { right }\end{array}$ & $\begin{array}{c}\text { Values for TRAP } \\
\text { right }\end{array}$ & $\begin{array}{c}\text { Values for TRAP } \\
\text { left }\end{array}$ \\
\hline $\bar{X}_{1}$ & $14.0 \%$ & $33.4 \%$ & $17.0 \%$ & $16.0 \%$ \\
\hline $\bar{X}_{2}$ & $10.5 \%$ & $29.1 \%$ & $13.3 \%$ & $16.7 \%$ \\
\hline$S_{1}^{2}$ & $1.6 \%$ & $6.1 \%$ & $1.8 \%$ & $1.3 \%$ \\
\hline$S_{2}^{2}$ & $1.3 \%$ & $5.9 \%$ & $1.4 \%$ & $1.8 \%$ \\
\hline$n_{1}$ & 20 & 20 & 20 & 20 \\
\hline$n_{2}$ & 20 & 20 & 20 & 20 \\
\hline
\end{tabular}




\begin{tabular}{|c|c|c|c|c|}
\hline$v$ & 48.9 & 39.2 & 50.0 & 28.1 \\
\hline$t-$ statistic & 0.9 & 0.6 & 1.0 & -0.2 \\
\hline critical value & 2.0 & 2.0 & 2.0 & 2.1 \\
\hline
\end{tabular}

Table 10: EMG statistical calculations for shaking head comparing before and after 30 minute helmet session

\begin{tabular}{|c|c|c|c|c|}
\hline Variable & $\begin{array}{c}\text { Values for SEM } \\
\text { left }\end{array}$ & $\begin{array}{c}\text { Values for SEM } \\
\text { right }\end{array}$ & $\begin{array}{c}\text { Values for TRAP } \\
\text { right }\end{array}$ & $\begin{array}{c}\text { Values for TRAP } \\
\text { left }\end{array}$ \\
\hline $\bar{X}_{1}$ & $10.7 \%$ & $32.6 \%$ & $18.8 \%$ & $16.6 \%$ \\
\hline $\bar{X}_{2}$ & $7.8 \%$ & $28.6 \%$ & $16.2 \%$ & $16.9 \%$ \\
\hline$S_{1}^{2}$ & $1.3 \%$ & $5.5 \%$ & $2.7 \%$ & $1.6 \%$ \\
\hline$S_{2}^{2}$ & $0.7 \%$ & $5.7 \%$ & $3.6 \%$ & $2.0 \%$ \\
\hline$n_{1}$ & 20 & 20 & 20 & 20 \\
\hline$n_{2}$ & 20 & 20 & 20 & 20 \\
\hline$v$ & 84.0 & 37.0 & 28.9 & 30.7 \\
\hline$t-$ statistic & 0.9 & 0.5 & 0.5 & -0.1 \\
\hline critical value & 2.0 & 2.0 & 2.0 & 2.0 \\
\hline
\end{tabular}

\subsubsection{EMG T-test With and Without Helmet}

Table 11-Table 16 display the t-test of population sets with and without the helmet (repetitions 1 and 5 versus 2, 3 and 4). Appendix B displays the normalized data.

Notice Table 11 only has $59 n_{2}$ values. This is due to one of the EMG not collecting data for one task completed. This is a glitch in the Nexus data collection software.

Table 11: EMG statistical calculations for nodding head comparing with and without helmet

\begin{tabular}{|c|c|c|c|c|}
\hline Variable & $\begin{array}{c}\text { Values for SEM } \\
\text { left }\end{array}$ & $\begin{array}{c}\text { Values for SEM } \\
\text { right }\end{array}$ & $\begin{array}{c}\text { Values for TRAP } \\
\text { right }\end{array}$ & $\begin{array}{c}\text { Values for TRAP } \\
\text { left }\end{array}$ \\
\hline $\bar{X}_{1}$ & $5.6 \%$ & $30.3 \%$ & $11.3 \%$ & $15.4 \%$ \\
\hline $\bar{X}_{2}$ & $5.5 \%$ & $28.4 \%$ & $14.6 \%$ & $15.4 \%$ \\
\hline$S_{1}^{2}$ & $1.7 \%$ & $6.0 \%$ & $0.7 \%$ & $2.2 \%$ \\
\hline$S_{2}^{2}$ & $0.6 \%$ & $5.1 \%$ & $1.2 \%$ & $1.2 \%$ \\
\hline$n_{1}$ & 40 & 40 & 40 & 40 \\
\hline$n_{2}$ & 59 & 59 & 59 & 59 \\
\hline$v$ & 58.8 & 78.9 & 95.5 & 66.3 \\
\hline$t-$ statistic & 0.1 & 0.4 & -1.7 & 0.0 \\
\hline critical value & 2.0 & 2.0 & 2.0 & 2.0 \\
\hline
\end{tabular}


Table 12: EMG statistical calculations for tapping foot comparing with and without helmet

\begin{tabular}{|c|c|c|c|c|}
\hline Variable & $\begin{array}{c}\text { Values for SEM } \\
\text { left }\end{array}$ & $\begin{array}{c}\text { Values for SEM } \\
\text { right }\end{array}$ & $\begin{array}{c}\text { Values for TRAP } \\
\text { right }\end{array}$ & Values for TRAP left \\
\hline $\bar{X}_{1}$ & $3.0 \%$ & $27.7 \%$ & $8.1 \%$ & $8.6 \%$ \\
\hline $\bar{X}_{2}$ & $3.2 \%$ & $27.3 \%$ & $10.4 \%$ & $10.8 \%$ \\
\hline$S_{1}^{2}$ & $0.0 \%$ & $4.9 \%$ & $0.4 \%$ & $0.4 \%$ \\
\hline$S_{2}^{2}$ & $0.1 \%$ & $4.9 \%$ & $1.2 \%$ & $0.8 \%$ \\
\hline$n_{1}$ & 40 & 40 & 40 & 40 \\
\hline$n_{2}$ & 60 & 60 & 60 & 60 \\
\hline$v$ & 97.2 & 83.6 & 96.5 & 97.6 \\
\hline$t-$ statistic & -0.4 & 0.1 & -1.4 & -1.5 \\
\hline critical value & 2.0 & 2.0 & 2.0 & 2.0 \\
\hline
\end{tabular}

Table 13: EMG statistical calculations for walking in place comparing with and without helmet

\begin{tabular}{|c|c|c|c|c|}
\hline Variable & $\begin{array}{c}\text { Values for SEM } \\
\text { left }\end{array}$ & $\begin{array}{c}\text { Values for SEM } \\
\text { right }\end{array}$ & $\begin{array}{c}\text { Values for TRAP } \\
\text { right }\end{array}$ & $\begin{array}{c}\text { Values for TRAP } \\
\text { left }\end{array}$ \\
\hline $\bar{X}_{1}$ & $4.2 \%$ & $27.5 \%$ & $9.4 \%$ & $11.1 \%$ \\
\hline $\bar{X}_{2}$ & $4.2 \%$ & $27.4 \%$ & $10.0 \%$ & $11.7 \%$ \\
\hline$S_{1}^{2}$ & $0.1 \%$ & $5.1 \%$ & $0.6 \%$ & $0.8 \%$ \\
\hline$S_{2}^{2}$ & $0.2 \%$ & $5.0 \%$ & $0.5 \%$ & $0.7 \%$ \\
\hline$n_{1}$ & 40 & 40 & 40 & 40 \\
\hline$n_{2}$ & 60 & 60 & 60 & 60 \\
\hline$v$ & 94.0 & 83.0 & 82.6 & 77.7 \\
\hline$t-$ statistic & 0.0 & 0.0 & -0.4 & -0.3 \\
\hline critical value & 2.0 & 2.0 & 2.0 & 2.0 \\
\hline
\end{tabular}

Table 14: EMG statistical calculations for clapping hands comparing with and without helmet

\begin{tabular}{|c|c|c|c|c|}
\hline Variable & $\begin{array}{c}\text { Values for SEM } \\
\text { left }\end{array}$ & $\begin{array}{c}\text { Values for SEM } \\
\text { right }\end{array}$ & $\begin{array}{c}\text { Values for TRAP } \\
\text { right }\end{array}$ & $\begin{array}{c}\text { Values for TRAP } \\
\text { left }\end{array}$ \\
\hline $\bar{X}_{1}$ & $5.1 \%$ & $28.6 \%$ & $10.4 \%$ & $10.8 \%$ \\
\hline $\bar{X}_{2}$ & $4.0 \%$ & $27.1 \%$ & $10.5 \%$ & $12.3 \%$ \\
\hline$S_{1}^{2}$ & $0.3 \%$ & $5.0 \%$ & $0.8 \%$ & $0.7 \%$ \\
\hline$S_{2}^{2}$ & $0.2 \%$ & $5.1 \%$ & $0.8 \%$ & $1.3 \%$ \\
\hline$n_{1}$ & 40 & 40 & 40 & 40 \\
\hline$n_{2}$ & 60 & 60 & 60 & 60 \\
\hline$v$ & 77.5 & 84.5 & 87.1 & 96.2 \\
\hline$t-$ statistic & 1.1 & 0.3 & -0.1 & -0.8 \\
\hline critical value & 2.0 & 2.0 & 2.0 & 2.0 \\
\hline
\end{tabular}

Table 15: EMG statistical calculations for turning head comparing with and without helmet

\begin{tabular}{|l|c|c|c|c|} 
Variable & $\begin{array}{c}\text { Values for SEM } \\
\text { left }\end{array}$ & $\begin{array}{c}\text { Values for SEM } \\
\text { right }\end{array}$ & $\begin{array}{c}\text { Values for TRAP } \\
\text { right }\end{array}$ & $\begin{array}{c}\text { Values for TRAP } \\
\text { left }\end{array}$ \\
\hline
\end{tabular}




\begin{tabular}{|c|c|c|c|c|}
\hline $\bar{X}_{1}$ & $12.2 \%$ & $31.3 \%$ & $15.1 \%$ & $16.4 \%$ \\
\hline $\bar{X}_{2}$ & $18.0 \%$ & $30.9 \%$ & $14.3 \%$ & $16.0 \%$ \\
\hline$S_{1}^{2}$ & $1.4 \%$ & $5.9 \%$ & $1.6 \%$ & $1.5 \%$ \\
\hline$S_{2}^{2}$ & $1.1 \%$ & $5.3 \%$ & $1.0 \%$ & $1.2 \%$ \\
\hline$n_{1}$ & 40 & 40 & 40 & 40 \\
\hline$n_{2}$ & 60 & 60 & 60 & 60 \\
\hline$v$ & 77.0 & 80.5 & 71.3 & 77.2 \\
\hline$t-$ statistic & -2.5 & 0.1 & 0.3 & 0.1 \\
\hline critical value & 2.0 & 2.0 & 2.0 & 2.0 \\
\hline
\end{tabular}

Table 16: EMG statistical calculations for shaking head comparing with and without helmet

\begin{tabular}{|c|c|c|c|c|}
\hline Variable & $\begin{array}{c}\text { Values for SEM } \\
\text { left }\end{array}$ & $\begin{array}{c}\text { Values for SEM } \\
\text { right }\end{array}$ & $\begin{array}{c}\text { Values for TRAP } \\
\text { right }\end{array}$ & $\begin{array}{c}\text { Values for TRAP } \\
\text { left }\end{array}$ \\
\hline $\bar{X}_{1}$ & $9.3 \%$ & $30.6 \%$ & $17.5 \%$ & $16.8 \%$ \\
\hline $\bar{X}_{2}$ & $7.8 \%$ & $28.5 \%$ & $15.3 \%$ & $17.0 \%$ \\
\hline$S_{1}^{2}$ & $1.0 \%$ & $5.5 \%$ & $3.1 \%$ & $1.8 \%$ \\
\hline$S_{2}^{2}$ & $0.5 \%$ & $5.0 \%$ & $1.1 \%$ & $1.4 \%$ \\
\hline$n_{1}$ & 40 & 40 & 40 & 40 \\
\hline$n_{2}$ & 60 & 60 & 60 & 60 \\
\hline$v$ & 63.1 & 81.0 & 58.0 & 77.3 \\
\hline$t-$ statistic & 0.8 & 0.4 & 0.7 & -0.1 \\
\hline critical value & 2.0 & 2.0 & 2.0 & 2.0 \\
\hline
\end{tabular}

\subsection{Speed}

Table 17-Table 22 display the t-test calculations for the speed of the populations with and without the helmet (repetitions 1 and 5 versus 2, 3 and 4). Appendix $C$ displays the normalized speed data.

Table 17: Speed statistical analysis of nodding head

\begin{tabular}{|c|c|}
\hline Variable & Calculated number \\
\hline $\bar{X}_{1}$ & 95.2 \\
\hline $\bar{X}_{2}$ & 61.2 \\
\hline$S_{1}^{2}$ & 2036.8 \\
\hline$S_{2}^{2}$ & 420.0 \\
\hline$n_{1}$ & 40 \\
\hline$n_{2}$ & 60 \\
\hline$v$ & 49.8 \\
\hline$t-$ statistic & 4.5 \\
\hline critical value & 2.0 \\
\hline
\end{tabular}


Table 18: Speed statistical analysis of tapping foot

\begin{tabular}{|c|c|}
\hline Variable & Calculated number \\
\hline $\bar{X}_{1}$ & 28.0 \\
\hline $\bar{X}_{2}$ & 15.8 \\
\hline$S_{1}^{2}$ & 341.1 \\
\hline$S_{2}^{2}$ & 31.4 \\
\hline$n_{1}$ & 40 \\
\hline$n_{2}$ & 60 \\
\hline$v$ & 43.8 \\
\hline$t-$ statistic & 4.1 \\
\hline critical value & 2.0 \\
\hline
\end{tabular}

Table 19: Speed statistical analysis of walking in place

\begin{tabular}{|c|c|}
\hline Variable & Calculated number \\
\hline $\bar{X}_{1}$ & 122.3 \\
\hline $\bar{X}_{2}$ & 56.8 \\
\hline$S_{1}^{2}$ & 1553.4 \\
\hline$S_{2}^{2}$ & 518.3 \\
\hline$n_{1}$ & 40 \\
\hline$n_{2}$ & 60 \\
\hline$v$ & 56.4 \\
\hline$t-$ statistic & 9.5 \\
\hline critical value & 2.0 \\
\hline
\end{tabular}

Table 20: Speed statistical analysis of clapping hands

\begin{tabular}{|c|c|}
\hline Variable & Calculated number \\
\hline $\bar{X}_{1}$ & 37.1 \\
\hline $\bar{X}_{2}$ & 14.3 \\
\hline$S_{1}^{2}$ & 1568.7 \\
\hline$S_{2}^{2}$ & 18.1 \\
\hline$n_{1}$ & 40 \\
\hline$n_{2}$ & 60 \\
\hline$v$ & 39.6 \\
\hline$t-$ statistic & 3.6 \\
\hline critical value & 2.0 \\
\hline
\end{tabular}

Table 21: Speed statistical analysis of tuning head

\begin{tabular}{|c|c|}
\hline Variable & Calculated number \\
\hline $\bar{X}_{1}$ & 141.7 \\
\hline $\bar{X}_{2}$ & 68.2 \\
\hline$S_{1}^{2}$ & 4833.5 \\
\hline$S_{2}^{2}$ & 15271.1 \\
\hline
\end{tabular}




\begin{tabular}{|c|c|}
\hline$n_{1}$ & 40 \\
\hline$n_{2}$ & 60 \\
\hline$v$ & 95.7 \\
\hline$t-$ statistic & 3.8 \\
\hline critical value & 2.0 \\
\hline
\end{tabular}

Table 22: Speed statistical analysis of shaking head

\begin{tabular}{|c|c|}
\hline Variable & Calculated number \\
\hline $\bar{X}_{1}$ & 205.8 \\
\hline $\bar{X}_{2}$ & 92.2 \\
\hline$S_{1}^{2}$ & 5659.8 \\
\hline$S_{2}^{2}$ & 1814.0 \\
\hline$n_{1}$ & 40 \\
\hline$n_{2}$ & 60 \\
\hline$v$ & 55.8 \\
\hline$t-$ statistic & 8.7 \\
\hline critical value & 2.0 \\
\hline
\end{tabular}

\subsection{Acceleration}

Table 23-Table 28 display the acceleration for Vicon data with and without the helmet being on (repetitions 1 and 5 versus 2, 3 and 4). Appendix D displays the normalized acceleration data.

Table 23: Acceleration statistical analysis of nodding head

\begin{tabular}{|c|c|}
\hline Variable & Calculated number \\
\hline $\bar{X}_{1}$ & 543.7 \\
\hline $\bar{X}_{2}$ & 383.3 \\
\hline$S_{1}^{2}$ & 82997.5 \\
\hline$S_{2}^{2}$ & 24031.0 \\
\hline$n_{1}$ & 40 \\
\hline$n_{2}$ & 60 \\
\hline$v$ & 54.2 \\
\hline$t-$ statistic & 3.2 \\
\hline critical value & 2.0 \\
\hline
\end{tabular}

Table 24: Acceleration statistical analysis of tapping foot

\begin{tabular}{|c|c|}
\hline Variable & Calculated number \\
\hline $\bar{X}_{1}$ & 100.5 \\
\hline $\bar{X}_{2}$ & 72.4 \\
\hline
\end{tabular}




\begin{tabular}{|c|c|}
\hline$S_{1}^{2}$ & 2448.8 \\
\hline$S_{2}^{2}$ & 1263.0 \\
\hline$n_{1}$ & 40 \\
\hline$n_{2}$ & 60 \\
\hline$v$ & 65.3 \\
\hline$t-$ statistic & 3.1 \\
\hline critical value & 2.0 \\
\hline
\end{tabular}

Table 25: Acceleration statistical analysis of walking in place

\begin{tabular}{|c|c|}
\hline Variable & Calculated number \\
\hline $\bar{X}_{1}$ & 535.0 \\
\hline $\bar{X}_{2}$ & 235.6 \\
\hline$S_{1}^{2}$ & 44150.3 \\
\hline$S_{2}^{2}$ & 13896.1 \\
\hline$n_{1}$ & 40 \\
\hline$n_{2}$ & 60 \\
\hline$v$ & 55.5 \\
\hline$t-$ statistic & 8.2 \\
\hline critical value & 2.0 \\
\hline
\end{tabular}

Table 26: Acceleration statistical analysis of clapping hands

\begin{tabular}{|c|c|}
\hline Variable & Calculated number \\
\hline $\bar{X}_{1}$ & 135.1 \\
\hline $\bar{X}_{2}$ & 75.2 \\
\hline$S_{1}^{2}$ & 6842.1 \\
\hline$S_{2}^{2}$ & 1810.8 \\
\hline$n_{1}$ & 40 \\
\hline$n_{2}$ & 60 \\
\hline$v$ & 52.9 \\
\hline$t-$ statistic & 4.2 \\
\hline critical value & 2.0 \\
\hline
\end{tabular}

Table 27: Acceleration statistical analysis of turning head

\begin{tabular}{|c|c|}
\hline Variable & Calculated number \\
\hline $\bar{X}_{1}$ & 510.8 \\
\hline $\bar{X}_{2}$ & 202.1 \\
\hline$S_{1}^{2}$ & 102305.0 \\
\hline$S_{2}^{2}$ & 12956.8 \\
\hline$n_{1}$ & 40 \\
\hline$n_{2}$ & 60 \\
\hline$v$ & 45.6 \\
\hline$t-$ statistic & 5.9 \\
\hline critical value & 2.0 \\
\hline
\end{tabular}


Table 28: Acceleration statistical analysis of shaking head

\begin{tabular}{|c|c|}
\hline Variable & Calculated number \\
\hline $\bar{X}_{1}$ & 1259.7 \\
\hline $\bar{X}_{2}$ & 344.7 \\
\hline$S_{1}^{2}$ & 292661.1 \\
\hline$S_{2}^{2}$ & 45382.4 \\
\hline$n_{1}$ & 40 \\
\hline$n_{2}$ & 60 \\
\hline$v$ & 47.1 \\
\hline$t-$ statistic & 10.2 \\
\hline critical value & 2.0 \\
\hline
\end{tabular}

\subsection{Range of Motion}

Table 29-Table 32 display the t-test results comparing the range of motion with and without the helmets for the three head moving tasks: nodding head (x-direction), turning head (x and z-directions), and shaking head (z-direction.) Appendix E displays the normalized data for range of motion.

Table 29: Angle statistical analysis of nodding head

\begin{tabular}{|c|c|}
\hline Variable & Calculated number \\
\hline $\bar{X}_{1}$ & 59.5 \\
\hline $\bar{X}_{2}$ & 29.2 \\
\hline$S_{1}^{2}$ & 1047.3 \\
\hline$S_{2}^{2}$ & 222.0 \\
\hline$n_{1}$ & 40 \\
\hline$n_{2}$ & 60 \\
\hline$v$ & 50.1 \\
\hline$t-$ statistic & 5.6 \\
\hline critical value & 2.0 \\
\hline
\end{tabular}

Table 30: Angle statistical analysis of turning head (y-axis)

\begin{tabular}{|c|c|}
\hline Variable & Calculated number \\
\hline $\bar{X}_{1}$ & 122.3 \\
\hline $\bar{X}_{2}$ & 51.7 \\
\hline$S_{1}^{2}$ & 3403.8 \\
\hline$S_{2}^{2}$ & 656.2 \\
\hline
\end{tabular}




\begin{tabular}{|c|c|}
\hline$n_{1}$ & 40 \\
\hline$n_{2}$ & 60 \\
\hline$v$ & 49.1 \\
\hline$t-$ statistic & 7.2 \\
\hline critical value & 2.0 \\
\hline
\end{tabular}

Table 31: Angle statistical analysis of turning head (z-axis)

\begin{tabular}{|c|c|}
\hline Variable & Calculated number \\
\hline $\bar{X}_{1}$ & 66.2 \\
\hline $\bar{X}_{2}$ & 28.2 \\
\hline$S_{1}^{2}$ & 763.8 \\
\hline$S_{2}^{2}$ & 109.3 \\
\hline$n_{1}$ & 40 \\
\hline$n_{2}$ & 60 \\
\hline$v$ & 46.5 \\
\hline$t-$ statistic & 8.3 \\
\hline critical value & 2.0 \\
\hline
\end{tabular}

Table 32: Angle statistical analysis of shaking head

\begin{tabular}{|c|c|}
\hline Variable & Calculated number \\
\hline $\bar{X}_{1}$ & 100.8 \\
\hline $\bar{X}_{2}$ & 99.6 \\
\hline$S_{1}^{2}$ & 1106.1 \\
\hline$S_{2}^{2}$ & 2317.7 \\
\hline$n_{1}$ & 40 \\
\hline$n_{2}$ & 60 \\
\hline$v$ & 97.8 \\
\hline$t-$ statistic & 0.1 \\
\hline critical value & 2.0 \\
\hline
\end{tabular}

\subsection{Qualitative Results}

Table 33 displays the qualitative comfort questionnaire where participants were asked on a scale from 1 to 10 what their comfort level was, where 1 is comfortable and 10 is uncomfortable. The comfort level before helmet is the time directly before the helmet was placed on, after repetition 1, and comfort level with helmet is when the helmet was first placed on. 


\begin{tabular}{|c|c|c|c|c|c|c|c|c|c|c|c|c|c|c|c|c|c|c|c|c|c|}
\hline \multicolumn{22}{|c|}{ Recorded Comfort Values } \\
\hline & & & \multicolumn{6}{|c|}{ Repetition 2} & \multicolumn{6}{|c|}{$\begin{array}{r}\text { Repetition } 3 \\
\end{array}$} & \multicolumn{7}{|c|}{ Repetition 4} \\
\hline Participant & $\begin{array}{l}\text { Comfort } \\
\text { before } \\
\text { helmet }\end{array}$ & $\begin{array}{l}\text { Comfort } \\
\text { with } \\
\text { helmet }\end{array}$ & task 1 & task 2 & task 3 & task 4 & task 5 & 5 task 6 & task 1 & task 2 & task 3 & task 4 & 4 task 5 & task 6 & task 1 & task 2 & task 3 & task 4 & task 5 & task 6 & \\
\hline 1 & 1 & 3 & 3 & 3 & 4 & $\begin{array}{l}4 \quad 3 \\
\end{array}$ & 4 & $\begin{array}{ll}4 & 5\end{array}$ & 4 & 3 & 4 & $\begin{array}{l}43 \\
+1\end{array}$ & $\begin{array}{l}3 \quad 5 \\
\end{array}$ & 54 & 3 & 3 & 4 & $\begin{array}{ll}4 & 4\end{array}$ & 6 & & 5 \\
\hline 2 & 2 & 4 & 4 & 4 & 4 & 4 & 4 & 4 & 4 & 4 & 4 & 4 & 5 & 5 & 5 & 5 & 5 & 5 & 5 & & 5 \\
\hline 3 & 1 & 4 & 4 & 4 & 5 & 4 & 6 & 4 & 5 & 5 & 5 & 4 & 6 & 6 & 5 & 5 & 5 & 5 & 6 & & 6 \\
\hline 4 & 1 & 5 & 5 & 5 & 5 & 5 & 6 & 6 & 6 & 5 & 5 & 5 & 6 & 6 & 6 & 5 & 5 & 5 & 7 & & 6 \\
\hline 5 & 1 & 2 & 2 & 2 & 2 & 2 & 2 & 2 & 2 & 2 & 3 & 2 & 2 & 2 & 3 & 3 & 2 & 3 & 3 & & 3 \\
\hline 6 & 1 & 1 & 2 & 1 & 2 & 1 & 3 & 3 & 2 & 1 & 2 & 1 & 3 & 3 & 2 & 1 & 3 & 1 & 3 & & 3 \\
\hline 7 & 2 & 4 & 4 & 4 & 4 & 4 & 5 & 4 & 4 & 4 & 4 & 4 & 6 & 5 & 5 & 5 & 5 & 5 & 6 & & 6 \\
\hline 8 & 1 & 1 & 2 & 2 & 3 & 2 & 4 & 4 & 2 & 2 & 2 & 2 & 3 & 4 & 2 & 2 & 2 & 2 & 3 & & 3 \\
\hline 9 & 1 & 3 & 3 & 3 & 3 & 3 & 3 & 3 & 3 & 3 & 3 & 3 & 3 & 3 & 3 & 3 & 3 & 3 & 3 & & 3 \\
\hline 10 & 1 & 5 & 5 & 4 & 7 & 4 & 4 & 4 & 5 & 5 & 5 & 4 & 5 & 3 & 3 & 3 & 4 & 3 & 5 & & 4 \\
\hline 11 & 1 & 5 & 5 & 2 & 3 & 2 & 6 & 4 & 3 & 1 & 3 & 1 & 5 & 4 & 4 & 1 & 1 & 1 & 4 & & 4 \\
\hline 12 & 1 & 1 & 2 & 2 & 2 & 2 & 4 & 4 & 3 & 2 & 3 & 2 & 5 & 4 & 4 & 4 & 4 & 4 & 5 & & 6 \\
\hline 13 & 1 & 1 & 2 & 1 & 3 & 1 & 5 & 5 & 5 & 1 & 4 & 1 & 6 & 5 & 5 & 1 & 3 & 1 & 5 & & 5 \\
\hline 14 & 1 & 1 & 2 & 1 & 1 & 1 & 3 & 2 & 1 & 1 & 1 & 1 & 2 & 1 & 1 & 1 & 1 & 1 & 2 & & 1 \\
\hline 15 & 1 & 1 & 2 & 1 & 1 & 1 & 2 & 2 & 1 & 1 & 1 & 1 & 2 & 2 & 1 & 1 & 1 & 1 & 2 & & 2 \\
\hline 16 & 1 & 4 & 4 & 4 & 4 & 4 & 5 & 5 & 5 & 5 & 5 & 5 & 5 & 5 & 6 & 6 & 6 & 6 & 6 & & 6 \\
\hline 17 & 1 & 3 & 4 & 2 & 5 & 2 & 5 & 4 & 3 & 1 & 3 & 1 & 3 & 3 & 4 & 1 & 3 & 1 & 4 & & 4 \\
\hline 18 & 2 & 3 & 4 & 4 & 5 & 4 & 6 & 5 & 5 & 6 & 7 & 3 & 4 & 4 & 5 & 6 & 7 & 4 & 5 & & 6 \\
\hline 19 & 1 & 3 & 3 & 1 & 4 & 3 & 6 & 6 & 4 & 2 & 3 & 2 & 4 & 5 & 5 & 3 & 3 & 2 & 5 & & 4 \\
\hline 20 & 2 & 4 & 4 & 3 & 3 & 3 & 4 & 3 & 3 & 2 & 3 & 2 & 4 & 3 & 3 & 2 & 2 & 2 & 4 & & 2 \\
\hline
\end{tabular}

task 1: nodding head

task 2: tapping foot

task 3: walking in place

task 4: clapping hands

task 5: turning head

task 6: shaking head 
Through observation, there was minimal discomfort. Standing in place had more of an effect on the person's fatigue than moving one's head.

An email was sent to the participants the day after the test to see if there were any prolonged or forthcoming pain. Of the 20 participants, no one claimed to have neck pain after the experiment (until today 40 days after the experiment), therefore we can safely assume there is no delayed effect. 


\section{CHAPTER SIX: RESEARCH DISCUSSION AND RECOMMENDATIONS}

\subsection{EMG}

The t-test completed before and after the 30 minute helmet session shows there is no difference in EMG activity. That means if there were any increased muscle activity in the measured SEM or TRAP muscles, it would only be temporary and only last until the helmet was taken off, see Table 5-Table 10.

To further identify the safety of the test, another t-test was computed comparing having the helmet on and having the helmet off. The t-test showed that there is no difference between the helmet being on and the helmet being off except for the SEM left muscle for turning one's head. This creates a limitation which includes avoiding tasks that involve turning one's head side to side, see Table 11-Table 16.

To conclude the EMG outputs before and after the 30 minute helmet test, we do not reject $H_{0}$ in any of the tasks. When comparing EMG muscle activity with and without the helmet we do not reject $H_{0}$ for nodding head, tapping foot, walking in place clapping hands or shaking head. We do, however, accept $H_{1}$ for turning one's head on the SEM muscles when comparing with and without helmet (see Table 15).

\subsection{Vicon}

The t-test was again used to identify if there was a difference between having the helmet on versus having the helmet off. In this case, there was a difference for all the moves in both speed and acceleration. This may positively affect the EMG result because a participant's head motion is limited. 
Notice the average of population $2\left(\bar{X}_{2}\right)$ is consistently lower than $\bar{X}_{1}$, in both speed and acceleration. This shows that speed and acceleration decrease once the helmet is placed on a patients head.

The range of motion of nodding head, turning head and shaking head were analyzed by comparing the difference between having the helmet on versus having the helmet off. In this case nodding one's head and turning one's head had an effect on whether the helmet is on or off while shaking one's head did not have an effect if the helmet was on or off.

To conclude both speed and acceleration t-test, we accept $H_{1}$ resulting in a change of speed and acceleration with and without the helmet on. This creates a limitation when it comes to speed and acceleration, this can be associated with slower patient reaction time during a real AM-PET scan.

We also accept $H_{1}$ for the range of motion of nodding one's head and turning one's head. We do not reject $H_{0}$ when it comes to shaking one's head. These result in limited head movements in the sagittal and frontal planes as expected.

Please not in t-tests, we cannot accept the null hypothesis $\left(H_{0}\right)$ because of insufficient evidence to support $H_{1}$.

\subsection{Increased Movement}

Based on this design it was found more efficient to change the pivot point from the center of gravity on the top of the helmet to a improve design, where there are multiple pivot points and allow for more range of motion. The degree of freedom around shaking ones' head was reduced due to the simplicity of the support design. This design only had one point of support around the center of gravity of the helmet. This movement could be increased by making the support on 
either side of the helmet (near the ears). This would allow the patient to easily nod their head. As shown in the t-test, the range of motion from shaking one's head did not change with and without the helmet. This shows that if the support system design is free from obscurities, the range of motion may not change when the helmet is placed on. More explanation of design improvement can be read in section 6.8, Improved Design.

\subsection{Counterbalancer}

The counterbalancer used in this study was analog and the tension of the counterbalancer could only be measured using an outside source. Friction occurred in this counterbalancer that allowed the helmet to move up, but slight downward force had to be applied to move the helmet down. If the tension in the counterbalancer was lowered, the participant would have to support some of the helmets weight. It is recommended to build a digital counterbalancer to better monitor the tension and diagnose possible malfunctions. This also easily allows researchers to quickly change the tension for future research.

\subsection{Weight Reduction}

In order to reduce weight of the helmet there are multiple recommendations that can be made, mechanically. The football helmet weighs around 2.5 kilograms and can be reduced by creating a helmet specially designed for an AM-PET scan. There is no need for the protective outer casing of a football helmet other than for structural purposes. If this was removed the weight could be reduced by $\sim 10 \%$. The $3 \mathrm{D}$ printed structural material could be reduced by using carbon fiber or some other light weight but, strong material. The modules that are encased use a semi-hollow plastic that increases the weight and bulkiness of the helmet. This could be removed and replaced with carbon fiber or some other light weight, thin material. 


\subsection{Risk Assessment}

A risk assessment was completed to reduce risk using Failure Modes and Effects Analysis (FMEA). FMEA uses the Raytheon method which assesses a risk priority number (RPN) using the combination of severity, occurrence and detection. Severity (SEV) is based on a scale from 1 to 10 where 1 has no impact and 10 has catastrophic impact. Occurrence (Occ.) uses a scale from 1 to 10 where 1 is less than 3 defects per million is predicted and 10 is greater than 500,000 defects per million. Again, the detectability (Det.) uses the scale from 1 to 10 where 1 is always detected by current control plan and 10 is unable to detect. The scales from 1 to 10 are based off of Automotive Industry Action Group (AIAG) shown in Table 34 (Harris). Using these scales, the RPN value is calculated by multiplying them together. This [RPN] number will range between 1 and 1000, the smaller the RPN value the better the product/process, see Equation 7.

$$
R P N=\text { severity } * \text { occurance } * \text { detectability } \quad \text { Equation } 7
$$

Table 34: AIAG Compiled Ratings (Harris)

\begin{tabular}{|c|c|c|c|}
\hline \multicolumn{4}{|c|}{ AIAG Compiled Ratings } \\
\hline Rating & Severity of effect & Likelihood of Occurrence & Ability to Detect \\
\hline 10 & $\begin{array}{l}\text { Hazardous and without } \\
\text { warning }\end{array}$ & \multirow[t]{2}{*}{$\begin{array}{l}\text { Very high; failure is almost } \\
\text { inevitable }\end{array}$} & Cannot detect \\
\hline 9 & $\begin{array}{l}\text { Hazardous and with } \\
\text { warning }\end{array}$ & & $\begin{array}{l}\text { Very remote chance of } \\
\text { detection }\end{array}$ \\
\hline 8 & Loss of primary function & \multirow[t]{2}{*}{ High; repeated failures } & $\begin{array}{l}\text { Remote chance of } \\
\text { detection }\end{array}$ \\
\hline 7 & $\begin{array}{l}\text { Reduced primary function } \\
\text { performance }\end{array}$ & & $\begin{array}{l}\text { Very low chance of } \\
\text { detection }\end{array}$ \\
\hline 6 & $\begin{array}{l}\text { Loss of secondary } \\
\text { function }\end{array}$ & \multirow[t]{3}{*}{$\begin{array}{l}\text { Moderate; occasional } \\
\text { failures }\end{array}$} & Low chance of detection \\
\hline 5 & $\begin{array}{l}\text { Reduced secondary } \\
\text { function performance }\end{array}$ & & $\begin{array}{l}\text { Moderate chance of } \\
\text { detection }\end{array}$ \\
\hline 4 & $\begin{array}{l}\text { Minor defect notice by } \\
\text { most customers }\end{array}$ & & $\begin{array}{l}\text { Moderately high chance } \\
\text { of detection }\end{array}$ \\
\hline 3 & $\begin{array}{l}\text { Minor defect noticed by } \\
\text { some customers }\end{array}$ & Low; relatively few failures & \\
\hline
\end{tabular}




\begin{tabular}{|l|l|l|l|}
\hline 2 & $\begin{array}{l}\text { Minor defect noticed by } \\
\text { discriminating customers }\end{array}$ & Remote; failure is unlikely & Almost certain detection \\
\hline 1 & No effect & .
\end{tabular}

When assessing the FMEA, the RPN displays a quantitative value that can be compared to other components/functions which can easily detect which is a high priority to assess safety. The larger the RPN value the more severe the component/function.

There are qualitative columns included in this assessment which include: component/function, failure mode, failure cause, failure effect and recommendations in addition to the RPN calculation. The component/function describes a piece of a product or process to be described, the failure mode describes what can happen to the component, the failure cause describes why it happened, failure effect describes why it occurred and recommendations uses the hierarchy of control to give suggestions on how to reduce the RPN value (Hierarchy of Controls). Table 35 displays the FMEA analysis with the following components: counterbalancer failure, sudden acceleration, pulley failure and patient falls. 
Table 35: FMEA of AM-PET 10kg helmet and support system

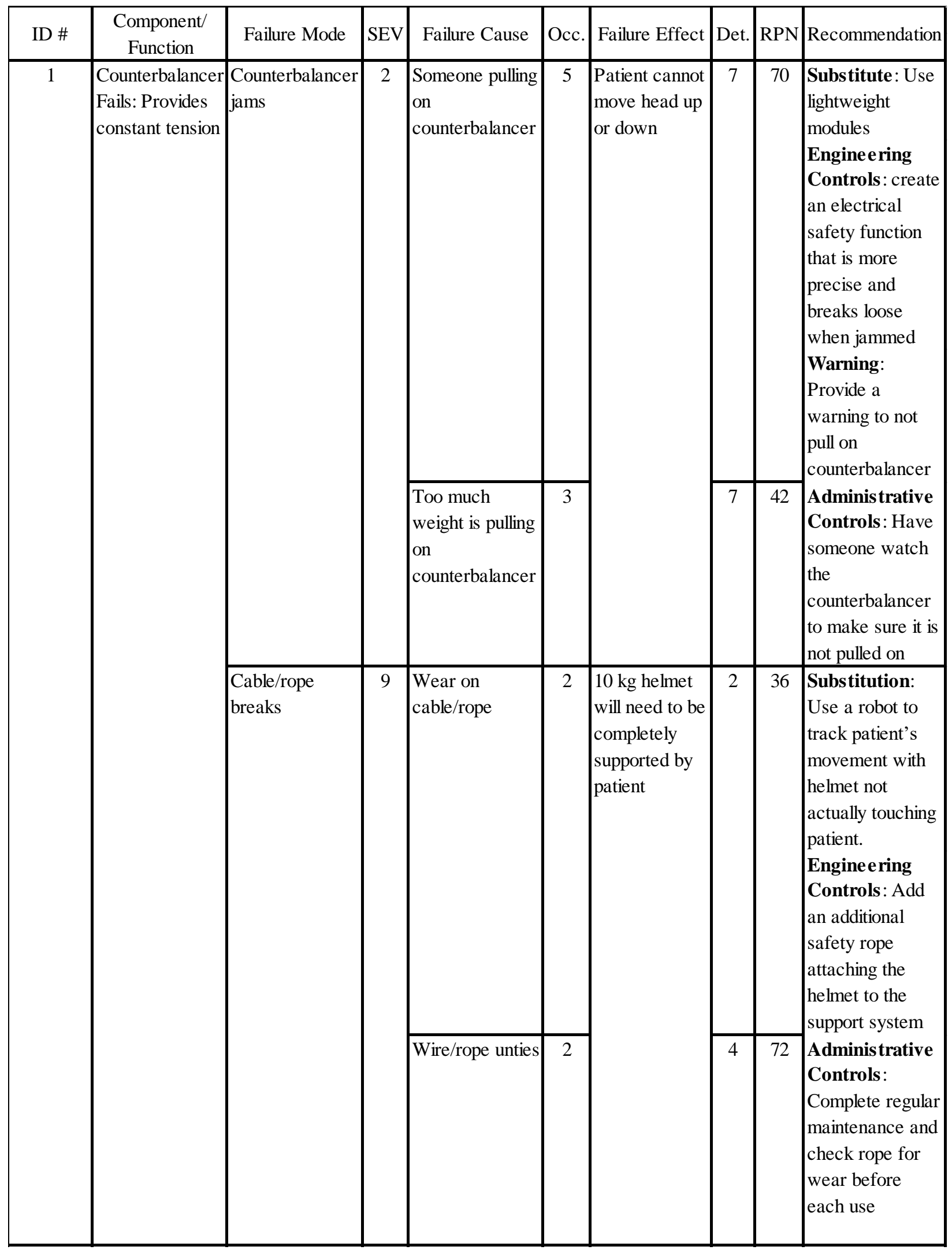




\begin{tabular}{|c|c|c|c|c|c|c|c|c|c|}
\hline 2 & $\begin{array}{l}\text { Biodex/support } \\
\text { system suddenly } \\
\text { stops or slows }\end{array}$ & $\begin{array}{l}\text { Running into } \\
\text { object }\end{array}$ & 4 & $\begin{array}{l}\text { Object was not } \\
\text { seen on ceiling } \\
\text { or ground }\end{array}$ & 4 & $\begin{array}{l}\text { Slight }(-) \\
\text { acceleration }\end{array}$ & 1 & 16 & $\begin{array}{l}\text { Eliminate: } \\
\text { Remove all } \\
\text { objects around } \\
\text { patient when } \\
\text { walking } \\
\text { Enginee ring } \\
\text { controls: Have a } \\
\text { proximity sensor } \\
\text { that will slow } \\
\text { down the system } \\
\text { before it hits } \\
\text { something } \\
\text { Administrative } \\
\text { Controls: Have } \\
\text { someone nearby } \\
\text { to watch patient } \\
\text { so they don't run } \\
\text { into anything }\end{array}$ \\
\hline & & Wheels lock & & $\begin{array}{l}\text { Dupris on floor } \\
\text { that stuck to the } \\
\text { wheels }\end{array}$ & 2 & & 2 & 16 & $\begin{array}{l}\text { Eliminate: Take } \\
\text { wheels away and } \\
\text { make system } \\
\text { stationary } \\
\text { Administrative } \\
\text { Controls: } \\
\text { Sweep area } \\
\text { around where } \\
\text { patient will be } \\
\text { walking } \\
\text { PPE: Have } \\
\text { patient wear } \\
\text { booties to reduce } \\
\text { dirt and debris } \\
\text { from getting into } \\
\text { wheels } \\
\end{array}$ \\
\hline & Pulley fails & $\begin{array}{l}\text { Pulley directly } \\
\text { overhead or } \\
\text { bottom pulley } \\
\text { falls off }\end{array}$ & 8 & Loose screws & 2 & $\begin{array}{l}\text { Patients head } \\
\text { is quickly } \\
\text { swung }\end{array}$ & 3 & 48 & $\begin{array}{l}\text { Eliminate: } \\
\text { Eliminate pulley, } \\
\text { place } \\
\text { counterbalancer } \\
\text { directly above } \\
\text { patient's head }\end{array}$ \\
\hline
\end{tabular}




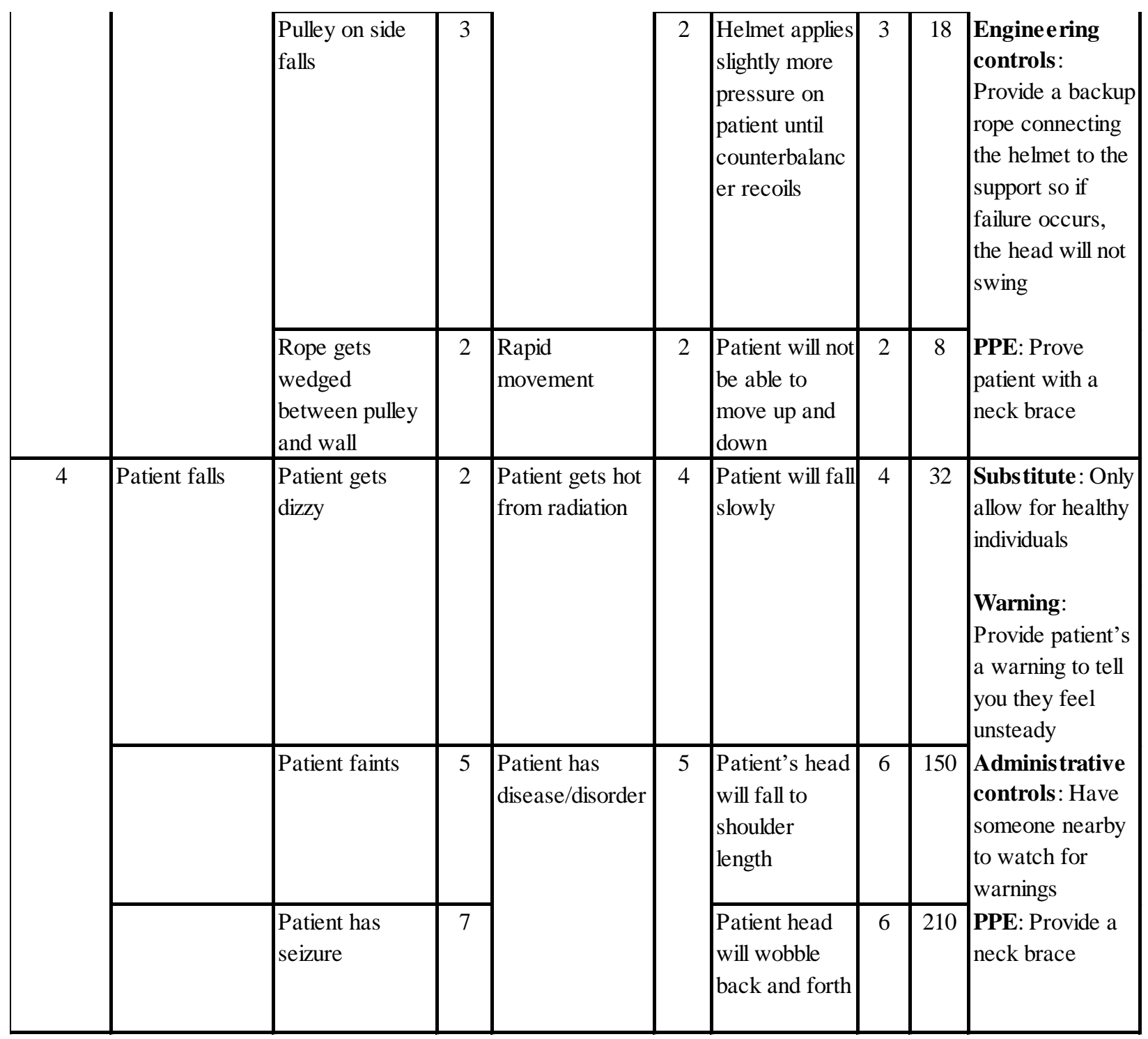

Notice the most at risk from using the FMEA is when a patient faints or has a seizure.

There is a loss of muscle control of the neck, the occurrence is high because of the clientele and detection is low; it has the highest RPN value. An RPN value of 72 was given with the chance of the wire rope and the extended rope unties and no longer is being supported. A solution was proposed to eliminate the extended rope and reconfigure the counterbalancer to be directly over the patients head. This would also eliminate the use of pulleys and further improve upon the design. Figure 30 displays the modified Biodex system before the risk assessment was complete 
and Figure 31 displays the modified Biodex system after the risk assessment was complete and changes were made. 


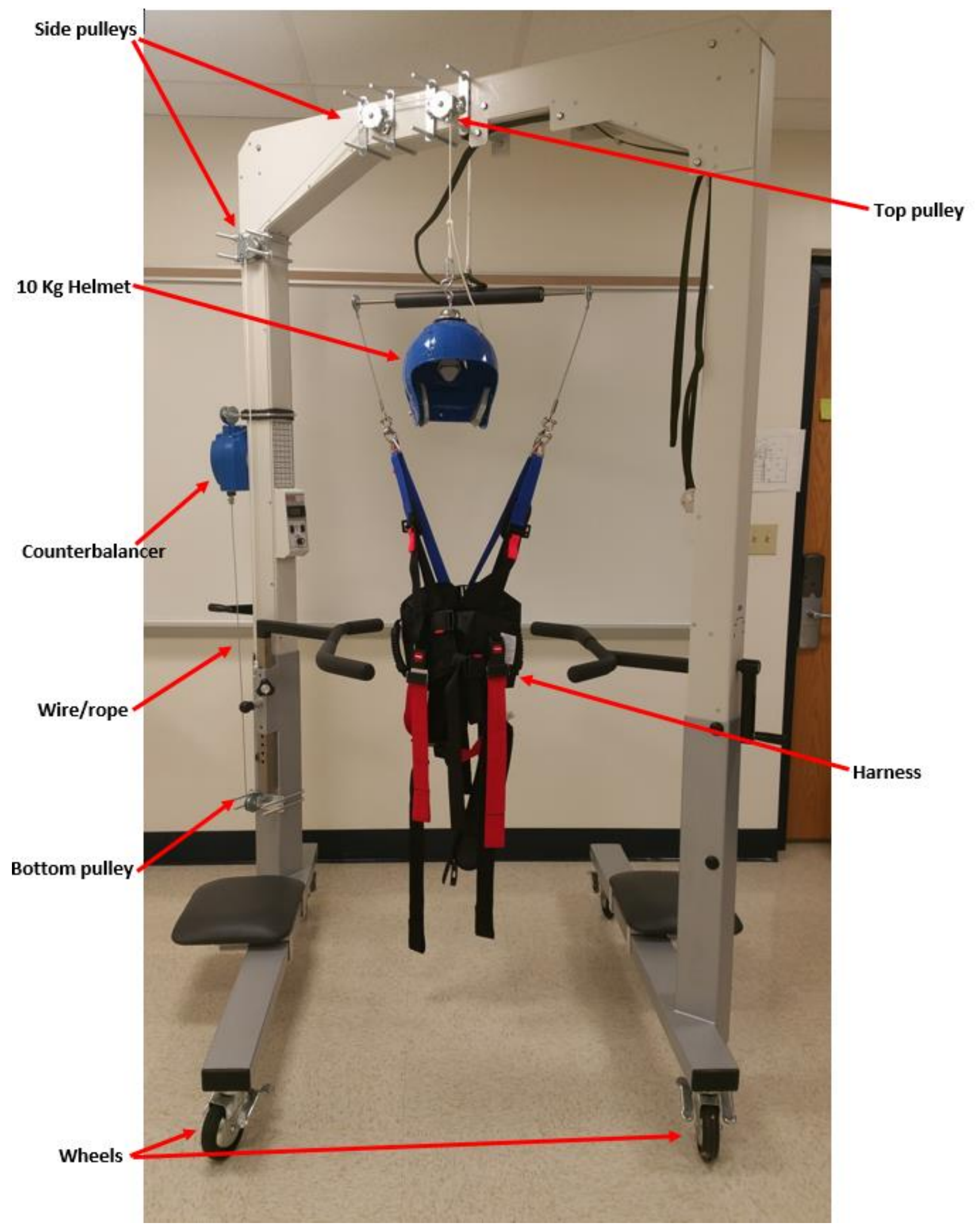

Figure 30: Modified Biodex before safety assessment 


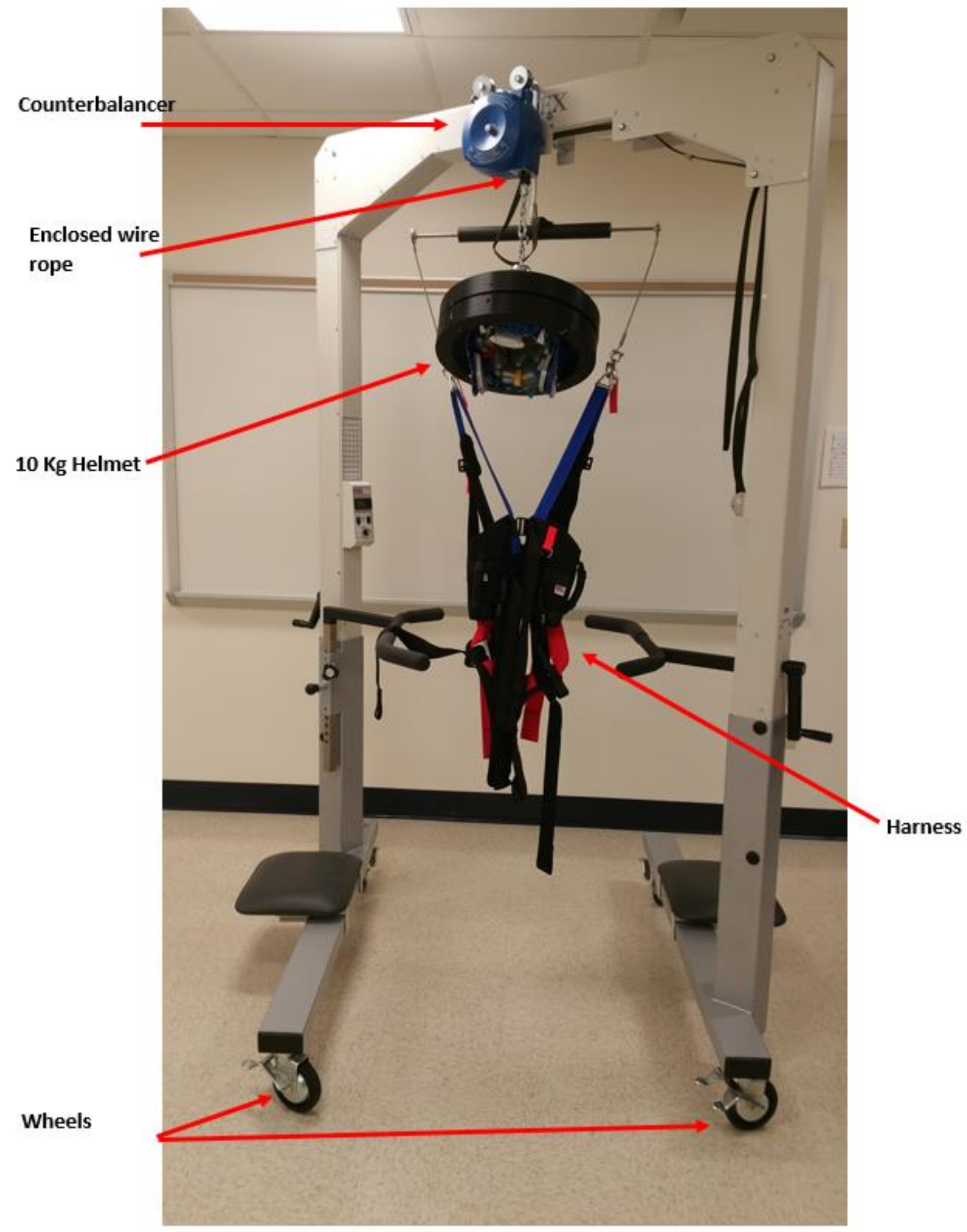

Figure 31: Modified Biodex design after safety assessment 


\subsubsection{Preventative Maintenance}

To prevent mechanical complications during a test, checks should be completed before each test. The counterbalancer should be checked to make sure the hardware has not come loose from the Biodex system. This should be completed before each use to ensure the counterbalancer will not fall off during a rigorous movement. The counterbalancer wire should also be checked for overuse by pulling the wire down and checking to see if there are any frayed wires, this should be done as the counterbalancer directions describe. It is important that the wire does not break, this could cause serious injury or death.

Before the helmet is placed on the patient the administrators should inform them not to make any rigorous movements until they are comfortable with the helmet. The helmet itself precludes quick movements but this should be stated anyways.

\subsection{Testing Limitations and Recommendations}

Limitations of this device include reduced head movement and limited to stationary movements. Although there were no injuries or pain from participants, it is unknown if this system is safe to use on those who are frail or have abnormal movements (i.e., Parkinson's). It is advised to use a neck brace for those at risk for injury until more tests have been completed with frail individuals and always being monitored to watch for signs of pain. The harness should be used for those who are at risk for falling. If a fall does occur, the helmet easily slips off their head and the harness catches them.

From both qualitative and qualitative data, muscle activity and discomfort was higher when the participant turned their head from ear to shoulder. This is not a common motion, as it does not mean anything like shaking one's head means yes and nodding one's head means no. 
Those performing the test should refrain from initiating movements that make the participant move turn their head side to side.

Minor discomfort arose while standing for an extended amount of time. Due to the stationary movements, this can be easily reduced by placing a rug where the patient will be standing to cushion the floor as they are standing. Another way this can be reduced is by placing a short stool for the patient's foot to rest on. This allows the patient to align their spine for better posture.

A trained professional should be near the patient at all times monitoring movements and signs for distress such as discomfort, heat exhaustion, lightheadedness and others that can be detected. The trained professional should urge the patient not to make any sudden movements while the helmet is on. The patient should know how to take the helmet off in case of an emergency, this also gives them a sense of control over the test. Stretches are proven to help reduce neck strain and should be completed before placing the helmet on.

\subsubsection{Results Limitations}

Limitations arose when analyzing the data including how the speed, acceleration and range of motion was calculated. To determine speed, acceleration and range of motion, the left cheek marker was used to track movements in 3D space. Typically the mid-point between the two cheek markers are used, however, occasionally an error occurred in the data where the cheek right marker was tracked incorrectly or the Vicon system did not pick up the marker for a short period of time. This could be due to the helmet covering the marker or the Vicon system could have mistaken a shiny part for the marker (possible from perspiring), thus the use of the cheek left marker to calculate speed, acceleration and range of motion. 
Occasional drastic increase in movement from the Vicon data output occurred. This could be due to the marker being mistaken by a shiny piece. Where this occurs, the data was eliminated, this "jumping" was verified visually using the Nexus data collection software to confirm "jumping" markers. This didn't occur often, when it did, only for a short amount a time.

Notice there are consistent high SEM right values for tasks in Table 5-Table 16 of the results section. SEM right and left should be similar to each other like the TRAP left and right values. Table 6 displays the calculations for tapping one's foot. This should show little muscle activity, however the SEM right $\bar{X}_{1}$ is $28.6 \%$ which is extremely large, while the SEM left $\bar{X}_{2}$ is $3.4 \%$ which appears to be more correct. The reason for the SEM right values is unknown. SEM right values are also very similar for each task ( 30\%). Many assumptions as to why the data seems incorrect include the amount of noise in the data. There was a noticeable difference between the SEM right and the SEM left, TRAP right and left channels. Figure 32 and Figure 33 display raw (un-filtered) EMG data of a participant turning their head. There is a noticeable difference between the two data sets. Figure 33 shows increased muscle activity shown as "spikes" of data, whereas Figure 33 shows consistent muscle activity with no noticeable "spikes". The noise shown in Figure 33 may not have been appropriately filtered by the Matlab program. Notice, Figure 33 also had a much lower amplitude than Figure 32. The SEM left muscle seems to be a more appropriate output than SEM right. Thus values for SEM right are shaded because there is an unknown error for those values. 


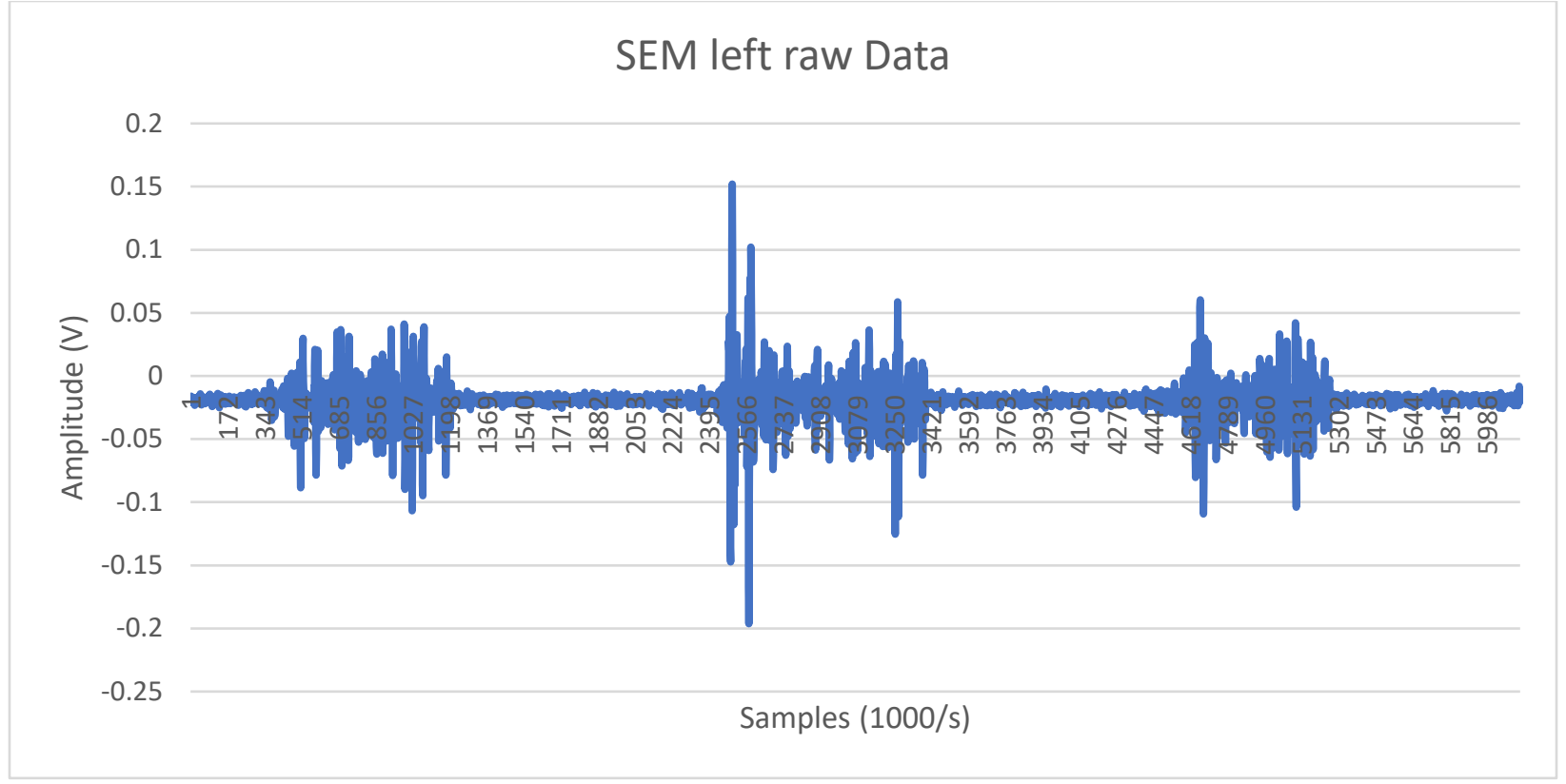

Figure 32: SEM left raw EMG data

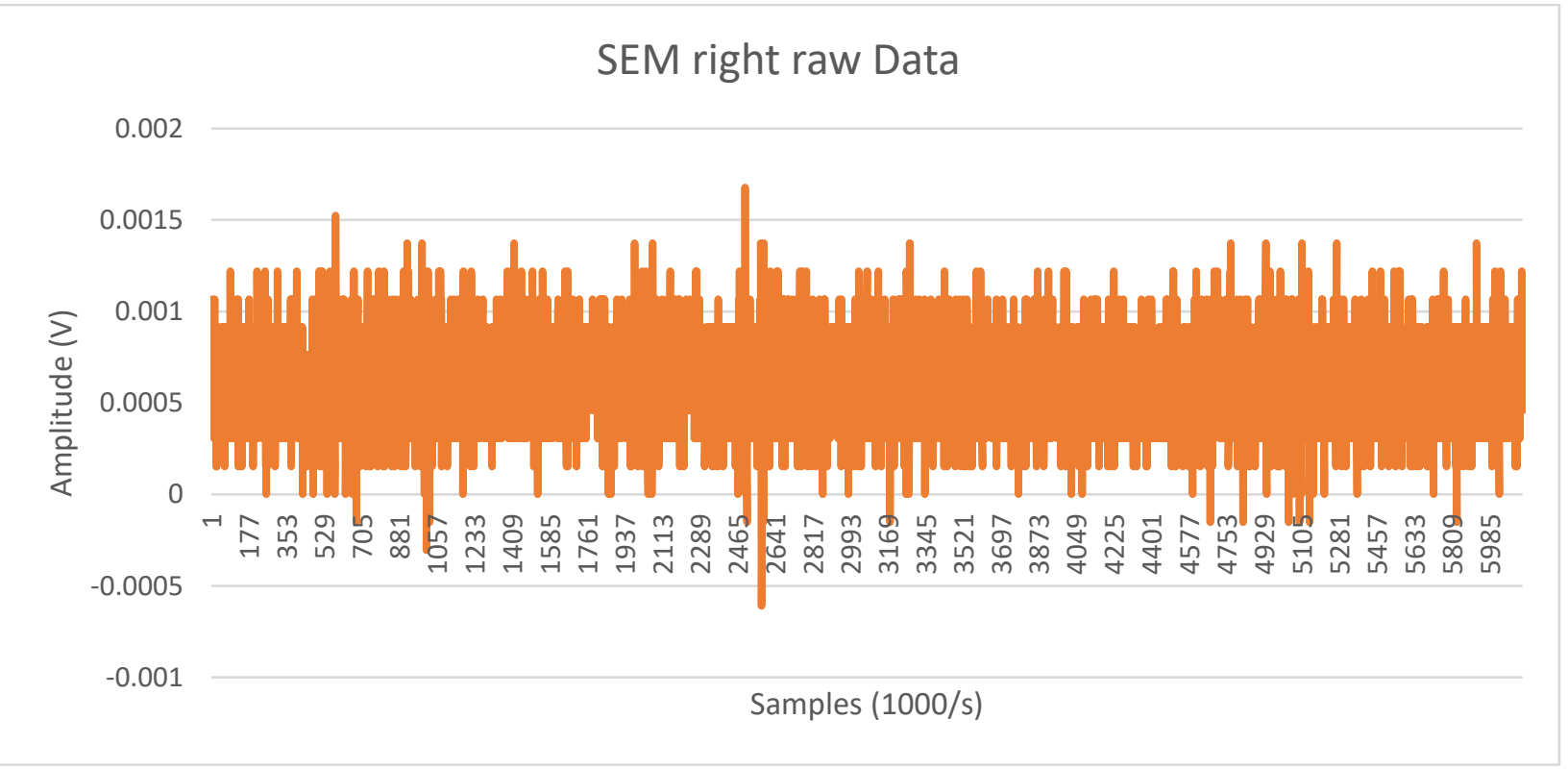

Figure 33: SEM right raw EMG data

Age of participants limited the results. Young pediatrics were not tested in this devise and the mean age of participants was $\sim 25$ years old. Most participants were in their early 20 s, there was one participant who was 68 and claimed to feel no pain or discomfort during the test. 


\subsection{Improved Design}

Design of the $10 \mathrm{~kg}$ mock-up helmet was created to test muscle activity and how the helmet has an effect on a person's head movements. Through the results section, a limitation was created in the SEM muscle when turning one's head side to side. Also there was a noticeable decrease in range of motion for both nodding head and turning head. Figure 34 displays an improved design of the system. It was learned that the participant did not support the helmet with their head or neck, thus eliminating the need for a full helmet, a ring shape will suffice eliminating non-essential weight on top. Also, to increase the range of motion for nodding one's head, the rotational axis was moved to allow for more rotational movement. There is also no need for the extra padding the football helmet comes with that dampens hits to the head, this will allow the ring to be closer the brain, thus less radiation needed. This system, shown in Figure 34, can be made in the facilities available at WVU. A more complex design could use a gyroscope system shown in Figure 35. This will allow for full use of degrees of freedom common to head movements. This design, however, would require increased time and cost to create.

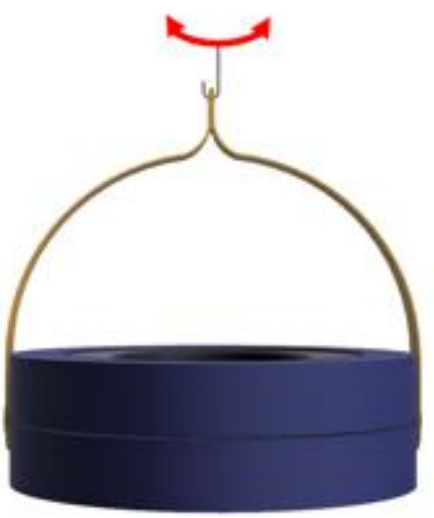

Front View

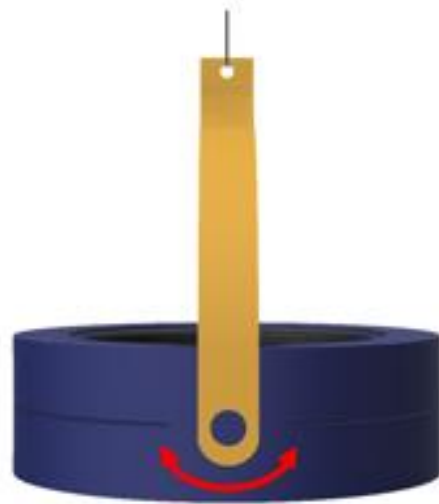

Side View

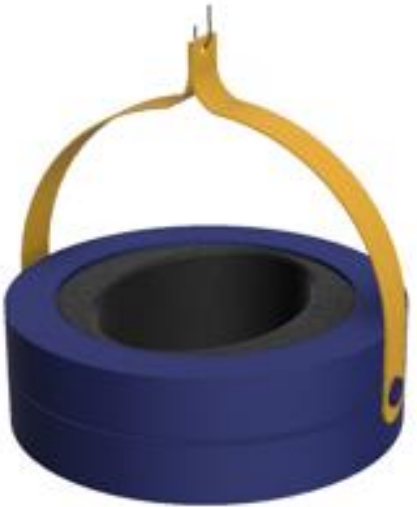

Isometric View

Figure 34: Improved design 


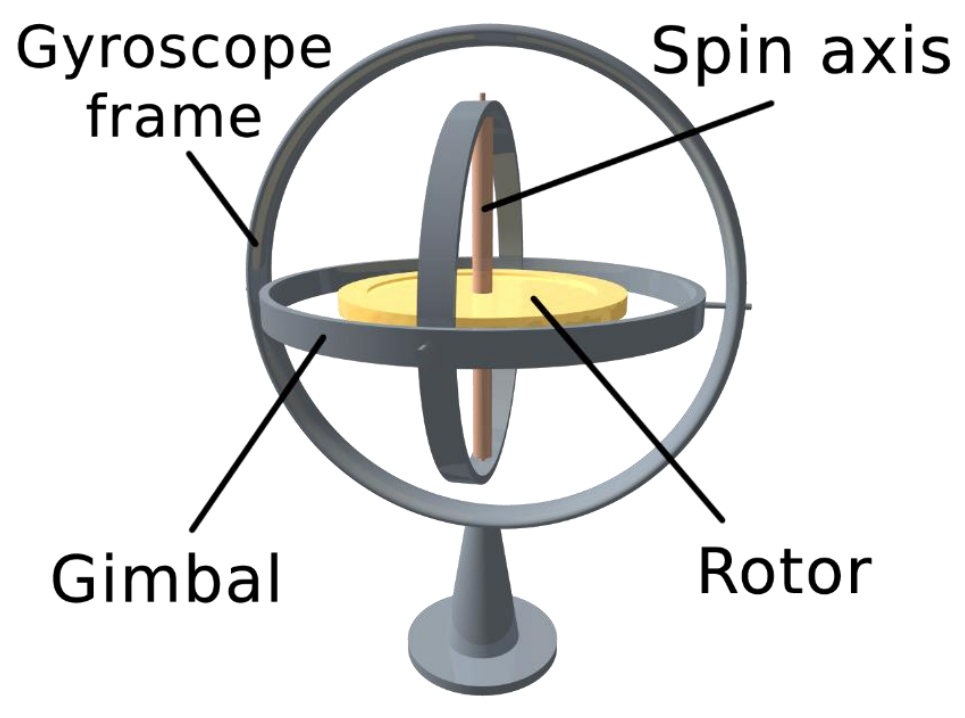

Figure 35: Gyroscope design (File:3D Gyroscope.pn)

If the AM-PET helmet was improved by using a gyroscope design, there should not be an effect on range of motion on the patients head. This is because the gyroscope would not limit rotational movements. If we turn Figure 35 so the spin access is horizontal, the AM-PET helmet would be placed where the rotor is and connected to the spin axis through the sides of the helmet. The spin axis would then be connected to the gimbals and finally to the gyroscope frame (or the support structure). Stoppers should be used to limit the angles at which a patient can turn their head, for instance nodding head, rotation should be limited to 180 degrees which will reduce risk of injury. The joints on the AM-PET gyroscope design would be closer to the heads natural rotational axes allowing the movement to be much easier for the patient. The material used must be strong, not only to support the $10 \mathrm{~kg}$ but also because the gyroscope design must be modified so the patient's vision is not reduced due to a ring being in front of their eyes. Thus some of the gyroscope rings must be modified by creating a half circle ring.

To manufacture an AM-PET gyroscope design, bearings can be used to reduce friction and allow for rotational head movements. These bearings can be made from a lightweight metal 
(often aluminum) and should have a very low tolerance value when ready to manufacture due to the precision needed in a gyroscope design (Gyroscope). This increases both the design time and cost of the helmet to allow for turning head side to side. 


\section{CHAPTER SEVEN: CONCLUSIONS AND OUTLOOK}

AM-PET has the potential to increase the knowledge about the brain, however, placing a $10 \mathrm{~kg}$ helmet on a patients head could potentially be dangerous. The neck was the primary risk factor when placing a 10kg helmet on a subject head so this study was conducted to show if it will be safe for patients to wear. The test completed was to prove the system is safe while wearing the 10kg mock-up helmet for 30 minutes and see if there is an effect the helmet has on the subject using EMG and Vicon motion capture technology. T-tests were used to compare data before and after the 30 minute helmet session and with and without the helmet. With this, it was shown that this system has no increased muscle activity on the SEM and TRAP muscle with the exception of turning one's head. This system has an effect of a participants head speed and acceleration and degreased the range of motion for nodding head and turning head. There is not difference in the range of motion for shaking one's head. Recommendations were made in order to ensure safety of a patient including continuous monitoring of a patient for any signs of distress and limiting movements that require someone to move their head on the frontal plane.

Future outlook for AM-PET involves the creation of a robotic system that will follow a patient around an area to complete non-stationary tasks. This would include walking, jumping, and skipping around a room. A backpack system of AM-PET is also under development where a patient can walk around in any terrain, drive a car and be more active while wearing an AM-PET helmet. A gyroscope design can be implemented into the backpack system and future AM-PET designs. 


\section{WORKS CITED}

Anandkumar, S. (2015). The effect of sustained natural apophyseal glide (SNAG) combined with neurodynamics in the management of a patient with cervical radiculopathy: a case report. Physiother Theory Practice, 31(2), 140-145.

Bauer, C., Brefczynski-Lewis, J., Marano, G., Mandich, M.-B., Stolin, A., Martone, P., ... Maje, S. (2016). Concept of an upright wearable positron emission tomography imager in humans. Brain and Behavior, 6(9).

Birchard, K. R., Busireddy, K. R., \& Semelka, R. C. (2015). Critical Observations in Radiology for Medical Students. Wiley-Blackwell.

Brandt, L., Andersen, J., Lassen, C., Kryger, A., Overgaard, E., Vilstrup, I., \& Mikkelsen, S. (2004). Neck and shoulder symptoms and disorders among Danish computer workers. Scand. J. Work Environ. Health, 30(5), 399-409.

Burton, R. (1999, February). Cervical Spinal Injury from Repeated Exposures to Sustained Acceleration. Cedex, France: Neuilly-sur-Seine.

Carroll, L., Hogg-Johnson, S., \& van der Velde, G. (2008). Course and Prognostic Factors for Neck Pain in the General Population: Results of the Bone and Joint Decade 2000-2010 Task Force on Neck Pain and Its Associated Disorders. Spine, 33, S75-S82.

Clancy, W. G., Brand, R. L., \& Bergfield, J. A. (1977, September 1). Upper trunk brachial plexus injuries in contact sports. The American Journal of Sports Medicine.

Coakwell, M. R., Bloswick, D. S., \& Moser, R. (2004, January). High-Risk Head and Neck Movements at High G and Interventions to Reduce Associated Neck Injury. Aviation, Space, and Environmental Medicine, 75(1), 68-80.

Cusick, J. F., Pintar, F. A., \& Yoganandan, N. (2001). Whiplash syndrome: kinematic factors influencing pain patterns. Spine, 1252-1258.

Delsys. (2017). Surface EMG Sensors. Retrieved July 27, 2017, from http://www.delsys.com/products/desktop-emg/surface-emg-sensors/

Durbin, E. (1957). Fracture-Dislocations of the Cervical Spine. THE JOURNAL OF BONE AND JOINT SURGERY, 39(1), 23-38.

Eltayeb, S., Staal, J., Hassan, A., \& De Bie, R. (2009). Work Related Risk Factors for Neck, Shoulder and Arms Complaints: A Cohort Study Among Dutch Computer Office Workers. Journal of Occupational Rehabilitation, 19(4), 315-322.

File:3D Gyroscope.png. (2006, October 4). Retrieved April 18, 2018, from Wikimedia Commons: https://commons.wikimedia.org/wiki/File:3D_Gyroscope.png

File:Musculi coli base.svg. (2007, July 2). Retrieved April 17, 2018, from Wikimedia Commons: https://commons.wikimedia.org/wiki/File:Musculi_coli_base.svg 
Funk, M., \& Schuppel, J. (2003). Strangulation Injuries. Wisconsin Medical Journal, 102(3), 41-45.

Grush, L. (2016, October 25). Astronauts' spinal muscles shrink and weaken after long stays in space. Retrieved July 19, 2017, from The Verge: https://www.theverge.com/2016/10/25/13392824/astronauts-back-pain-health-space-spinalmuscles

Guiberteau, M. (2017, January 23). Positron Emission Tomography - Computed Tomography (PET/CT). (Radiologylnfo.org) Retrieved April 6, 2017, from https://www.radiologyinfo.org/en/info.cfm?pg=pet

Gyroscope. (n.d.). Retrieved April 18, 2018, from How products are made: http://www.madehow.com/Volume-6/Gyroscope.html

Hagström, Y. \&. (1996). Prolonged functional impairments after whiplash injury. Scand. J. Rehabil. Med, $28,139-146$.

Haibin, C. L. (2013). Clinical and Biomechanical Analysis of Whiplash Injuries. IEEE, 368-371.

Harris, J. (2017, October 17). Lecture 8 - Failure Modes and Effects Analysis (FMEA). Morgantown, West Virginia.

Haylen, P. (2004). Spinal injuries in rugby union, 1970-2003: lessons and responsibilities. Medical Journal of Australia, 181, 48-51.

Hierarchy of Controls. (2016, July 18). (NIOSH, Producer) Retrieved January 19, 2018, from Centers for Disease Control and Prevention: https://www.cdc.gov/niosh/topics/hierarchy/default.html

Hu, B., \& Ning, X. (2016). Cervical spine biomechanics and task performance during touchscreen computer operations. International Journal of Industrial Ergonomics, 56, 41-50.

Hult, L. (1954). The Munkfors Investigation. In A study of the Frequency and Causes of the Stiff Neck Brachialgia and Lumbago-Sciatica Syndromes, as well as observations on certain Signs and Symptoms from the Dorsal Spine and the Joints of the Extremities in Industrial and Forest Workers. Denmark: Ejnar Munksaard.

Jensen, C. (2003). Development of neck and hand-wrist symptoms in relation to duration of computer use at work. Scandinavian Journal of Work, Environment \& Health, 29(3), 197-205.

Johnston, V. B., Jull, G., Souvlis, T., \& Jimmieson, N. L. (2008). Neck Movement and Muscle Activity Characteristics in Female Office Workers With Neck Pain. Spine, 33(5), 197-205.

Kalyani, R. R., Corriere, M., \& Ferrucci, L. (2014). Age-related and disease-related muscle loss: the effect of diabetes, obesity, and other diseases. Lancet Diabetes \& Endocrinology, 2(10), 819-829.

Kulin, J., \& Reaston, M. (2011). Musculoskeletal disorders early diagnosis: A retrospective study in the occupational medicine setting. Journal of occupational Medicine and Toxicology, 6(1).

Kumdee, O., \& Ritthipravat, P. (2015). Repetitive Motion Detection for Human Behavior Understanding From Video Images. International Symposium on Signal Processing and Information Technology (ISSPIT), 484-489. 
Majewski, S., \& Proffitt, J. (2008). United States of America Patent No. 7,884,331.

Mäkela, M., Heliövaara, M., Sievers, K., Impivaara, O., Kekt, P., \& Aromma, A. (1991). Prevalence, Determinants, and Consequences of Chronic Neck Pain in Finland. American Journal of Epidemiology, 134(11), 1356-1367.

Maloiy, G. M., Heglund, N. C., Prager, L. M., Cavagna, G. A., \& Taylor, C. R. (1986). Energetic cost of carrying loads: have African women discovered an economic way? Nature, 319, 668-669.

Melroy, S., Bauer, C., McHugh, M., Carden, G., Stolin, A., Majewski, S., . . Wuest, T. (2017).

Development and Design of Next-Generation Head-Mounted Ambulatory Microdose PositronEmission Tomography (AM-PET) System. Sensors, 17(1164).

Murray, G. C., \& Persellin, R. H. (1981, May). Cervical Fracture Complicating Ankylosing Spondylitis: A Report of Eight Cases and Review of the Literature. The American Journal of Medicine, 70, 10331041.

NASCAR. (2015, January 5). SAVING LIVES WITH THE HANS DEVICE. Retrieved August 15, 2017, from http://www.nascar.com/en_us/monster-energy-nascar-cup-series/nascar-nation/nascaredu/nascar-basic/HANS-Device.html

Ning, X., Huang, Y., Hu, B., \& Nimbarte, A. D. (2015). Neck kinematics and muscle activity during mobile device operations. International Journal of Industrial Ergonomics, 48, 10-15.

Nouma, Y., Ammar, B. S., Bardaa, S., Hammami, Z., \& Maatoug, S. (2016). Accidental hanging among children and adults: A report of two cases and review of the literature. Egyptian Journal of Forensic Sciences, 6(3), 310-314.

Ogiela, D. (n.d.). 5 Exercises to Prevent an Aching Neck. Retrieved July 23, 2017, from Health Encyclopedia: https://www.urmc.rochester.edu/encyclopedia/content.aspx?contenttypeid=1\&contentid=745

Öhberg, F. G. (2003). Chronic Whiplash Associated Disorders and Neck Movement Measurements: An Instantaneous Helical Axis Approach. IEEE, 7(4), 274-282.

Rubin, G. D. (2016, May 24). Magnetic Resonance Imaging (MRI) - Body. (Radiologylnfo) Retrieved April 7, 2017, from https://www.radiologyinfo.org/en/info.cfm?pg=bodymr\#experience

S. Majewski, J. P.-L. (n.d.). HelmetPET: A Silicon Photomultiplier Based Wearable Brain Imager. IEEE Explore, 4030-4034.

Sagittal Plane Definition. (n.d.). Retrieved April 11, 2018, from Biology Dictionary: https://biologydictionary.net/sagittal-plane/

Sharma, V. K., Rango, J., Connaughton, A. J., Lombardo, D. J., \& Sabesan, V. J. (2015). The Current State of Head and Neck Injuries in Extreme Sports. The Orthopedic Journal of Sports Medicine.

Shikdar, A. K.-H. (2008). An Ergonomics Intervention Study of Reducing Health Complaints among Office Employees. IEEE, 1966-1970. 
Sirikantharajah, S. V. (2015). Analysis of Neck Muscle Activity and Comparison of Head Movement and Body Movement during Rotational Motion. IEEE, 3509-3512.

Spitzer, W. O. (1995). Scientific monograpgh of the Quebec Task Force on whiplash associated disorders: redefining "whiplash" and its management. Spine, 20, 1-73.

Staff, M. C. (2015, January 20). Whiplash. Retrieved April 9, 2018, from Mayo Clinic: https://www.mayoclinic.org/diseases-conditions/whiplash/symptoms-causes/syc-20378921

Stemper, B., Yoganandan, N., Gennarelli, T., \& Pintar, F. (2005). Localized cervical facet joint kinematics under physiological and whiplash loading. J Neurosurg Spine, 3(6).

Suissa, S. H. (2001). The relation between initial symptoms and signs and the prognosis of whiplash. Europ. Spine, 10, 44-49.

Thatte, M. R., Babhulkar, S., \& Hiremath, A. (2013). Brachial plexus injury in adults: Diagnosis and surgical treatment strategies. Journal of Indian Academy of Neurology, 16(1), 26-33.

Vanderbeek, R. (1988). Period prevalence of acute neck injury in U.S. Air Force pilots exposed to high G forces. 59(1176-80). Aviation Space Environment Med.

Vaska, P., Schlyer, D. J., Shokouhi, S., S. P. Stoll, J.-F. P., O'Connor, P., Junnarkar, S. S., . . Fontaine, R. (2004). RatCAP: Miniaturized Head-Mounted PET for Conscious Rodent Brain Imaging. IEEE Transactions on Nuclear Science, 51(5), 2718-2722. Retrieved from http://ieeexplore.ieee.org/stamp/stamp.jsp?arnumber=1344399

Vetroczky, N., \& Lauber, C. A. (2017). Do Patients With Cervical Radiculopathy Benefit From the Addition of Cervical Traction to a Rehabilitation Program? A Critically Appraised Topic. Human Kinetics, 22(3), 18-25.

Vicon. (2017). Vicon. Retrieved 18 July, 2017, from https://www.vicon.com/

Wald, C. (2016, March 16). Computed Tomography (CT) - Body. (RadiologyInfo.org) Retrieved April 6, 2017, from https://www.radiologyinfo.org/en/info.cfm?pg=bodyct

Wen, J.-J., \& Chou, H.-M. (2016). Dimensional Acupuncture Therapy in Clinical Application of Brachial Plexus Injury. IEEE International Conference on Advanced Materials for Science and Engineering, 309-312.

Winslow, J., Martinez, A., \& Thomas, C. K. (2015, March). Automatic Identification and Classification of Muscle Spasms in Long-Term EMG Recordings. IEEE JOURNAL OF BIOMEDICAL AND HEALTH INFORMATICS, 19(20), 464-470. 


\section{APPENDIX A}

Table 36: Normalized EMG data of nodding head (population 1 - gray, population 2 - white)

\begin{tabular}{|c|c|c|c|c|c|c|c|c|}
\hline \multicolumn{9}{|c|}{ Nodding head } \\
\hline & \multicolumn{4}{|c|}{ Before } & \multicolumn{4}{|c|}{ After } \\
\hline Subject \# & SEM left & SEM right & TRAP right & TRAP left & SEM left & SEM right & TRAP right & TRAP left \\
\hline 1 & $1.3 \%$ & $10.8 \%$ & $9.0 \%$ & $8.6 \%$ & $0.9 \%$ & $10.6 \%$ & $7.9 \%$ & $7.4 \%$ \\
\hline 2 & $2.1 \%$ & $35.9 \%$ & $12.2 \%$ & $12.2 \%$ & $4.9 \%$ & $37.8 \%$ & $19.3 \%$ & $17.5 \%$ \\
\hline 3 & $84.3 \%$ & $82.7 \%$ & $4.4 \%$ & $51.7 \%$ & $0.7 \%$ & $4.5 \%$ & $0.1 \%$ & $1.1 \%$ \\
\hline 4 & $1.1 \%$ & $13.9 \%$ & $15.1 \%$ & $14.5 \%$ & $0.7 \%$ & $13.8 \%$ & $14.3 \%$ & $19.5 \%$ \\
\hline 5 & $5.7 \%$ & $2.9 \%$ & $10.0 \%$ & $20.2 \%$ & $5.8 \%$ & $3.0 \%$ & $37.8 \%$ & $18.5 \%$ \\
\hline 6 & $4.6 \%$ & $51.6 \%$ & $13.8 \%$ & $10.1 \%$ & $7.1 \%$ & $52.4 \%$ & $12.9 \%$ & $9.3 \%$ \\
\hline 7 & $0.2 \%$ & $2.9 \%$ & $3.3 \%$ & $8.3 \%$ & $0.2 \%$ & $2.7 \%$ & $2.2 \%$ & $2.2 \%$ \\
\hline 8 & $3.8 \%$ & $69.3 \%$ & $16.3 \%$ & $82.6 \%$ & $3.9 \%$ & $13.6 \%$ & $12.9 \%$ & $0.3 \%$ \\
\hline 9 & $6.1 \%$ & $30.9 \%$ & $10.1 \%$ & $10.4 \%$ & $2.1 \%$ & $30.7 \%$ & $11.6 \%$ & $11.1 \%$ \\
\hline 10 & $0.8 \%$ & $10.8 \%$ & $0.8 \%$ & $0.5 \%$ & $1.4 \%$ & $11.4 \%$ & $1.5 \%$ & $0.9 \%$ \\
\hline 11 & $4.1 \%$ & $2.7 \%$ & $0.4 \%$ & $20.0 \%$ & $5.6 \%$ & $2.9 \%$ & $0.8 \%$ & $28.8 \%$ \\
\hline 12 & $1.0 \%$ & $10.5 \%$ & $3.7 \%$ & $3.5 \%$ & $1.5 \%$ & $10.6 \%$ & $4.2 \%$ & $4.9 \%$ \\
\hline 13 & $4.0 \%$ & $38.1 \%$ & $27.2 \%$ & $29.0 \%$ & $5.6 \%$ & $39.4 \%$ & $25.2 \%$ & $28.6 \%$ \\
\hline 14 & $7.7 \%$ & $66.4 \%$ & $6.2 \%$ & $6.5 \%$ & $9.1 \%$ & $67.6 \%$ & $6.4 \%$ & $7.3 \%$ \\
\hline 15 & $2.7 \%$ & $2.8 \%$ & $0.6 \%$ & $20.0 \%$ & $2.2 \%$ & $2.8 \%$ & $0.1 \%$ & $15.5 \%$ \\
\hline 16 & $1.4 \%$ & $20.2 \%$ & $13.6 \%$ & $14.9 \%$ & $1.6 \%$ & $21.6 \%$ & $13.0 \%$ & $15.8 \%$ \\
\hline 17 & $8.0 \%$ & $69.1 \%$ & $16.7 \%$ & $7.8 \%$ & $6.3 \%$ & $67.4 \%$ & $14.2 \%$ & $10.6 \%$ \\
\hline 18 & $3.5 \%$ & $41.4 \%$ & $12.1 \%$ & $11.2 \%$ & $3.2 \%$ & $41.5 \%$ & $9.7 \%$ & $8.4 \%$ \\
\hline 19 & $5.0 \%$ & $58.2 \%$ & $22.7 \%$ & $23.8 \%$ & $4.7 \%$ & $56.9 \%$ & $23.3 \%$ & $24.2 \%$ \\
\hline 20 & $4.1 \%$ & $49.8 \%$ & $17.1 \%$ & $13.5 \%$ & $4.6 \%$ & $50.3 \%$ & $17.7 \%$ & $14.1 \%$ \\
\hline
\end{tabular}

Table 37: Normalized EMG data of tapping foot (population 1 - gray, population 2 - white)

\begin{tabular}{|c|rrrr|rrrr|}
\hline \multicolumn{8}{|c|}{ Tapping foot } \\
\hline & \multicolumn{7}{|c|}{ Before } & \multicolumn{5}{c|}{ After } \\
\hline Subject \# & SEM left & SEM right & TRAP right & TRAP left & SEM left & SEM right & TRAP right & TRAP left \\
\hline 1 & $0.8 \%$ & $10.7 \%$ & $7.2 \%$ & $6.4 \%$ & $0.9 \%$ & $10.9 \%$ & $6.5 \%$ & $5.7 \%$ \\
2 & $1.9 \%$ & $36.1 \%$ & $8.5 \%$ & $8.1 \%$ & $2.1 \%$ & $35.7 \%$ & $8.5 \%$ & $7.9 \%$ \\
3 & $0.3 \%$ & $4.5 \%$ & $0.3 \%$ & $0.9 \%$ & $0.9 \%$ & $4.6 \%$ & $0.1 \%$ & $0.6 \%$ \\
4 & $1.2 \%$ & $13.8 \%$ & $15.5 \%$ & $12.7 \%$ & $0.7 \%$ & $13.8 \%$ & $11.0 \%$ & $9.6 \%$ \\
5 & $3.4 \%$ & $2.8 \%$ & $8.8 \%$ & $19.1 \%$ & $3.8 \%$ & $2.8 \%$ & $6.3 \%$ & $15.0 \%$ \\
6 & $4.4 \%$ & $50.5 \%$ & $8.2 \%$ & $6.3 \%$ & $4.4 \%$ & $51.1 \%$ & $8.3 \%$ & $5.8 \%$ \\
7 & $0.3 \%$ & $38.4 \%$ & $4.0 \%$ & $9.1 \%$ & $0.1 \%$ & $2.7 \%$ & $1.0 \%$ & $1.3 \%$ \\
8 & $3.3 \%$ & $13.6 \%$ & $11.1 \%$ & $0.5 \%$ & $3.5 \%$ & $13.6 \%$ & $13.9 \%$ & $0.2 \%$ \\
9 & $6.8 \%$ & $30.5 \%$ & $5.1 \%$ & $4.7 \%$ & $1.9 \%$ & $30.0 \%$ & $4.9 \%$ & $4.6 \%$
\end{tabular}




\begin{tabular}{|r|rrrr|rrrr|}
10 & $0.8 \%$ & $10.9 \%$ & $0.8 \%$ & $0.4 \%$ & $0.8 \%$ & $10.9 \%$ & $0.8 \%$ & $0.4 \%$ \\
11 & $8.0 \%$ & $2.7 \%$ & $0.2 \%$ & $11.1 \%$ & $3.9 \%$ & $2.6 \%$ & $0.2 \%$ & $12.3 \%$ \\
12 & $1.1 \%$ & $10.5 \%$ & $3.3 \%$ & $3.2 \%$ & $1.2 \%$ & $10.8 \%$ & $4.2 \%$ & $4.9 \%$ \\
13 & $3.2 \%$ & $38.9 \%$ & $25.4 \%$ & $29.7 \%$ & $3.1 \%$ & $38.9 \%$ & $24.3 \%$ & $23.8 \%$ \\
14 & $5.9 \%$ & $65.8 \%$ & $7.2 \%$ & $6.3 \%$ & $7.4 \%$ & $66.7 \%$ & $5.9 \%$ & $5.8 \%$ \\
15 & $2.0 \%$ & $2.8 \%$ & $0.4 \%$ & $14.3 \%$ & $2.0 \%$ & $2.8 \%$ & $0.1 \%$ & $10.8 \%$ \\
16 & $1.4 \%$ & $20.5 \%$ & $9.4 \%$ & $10.1 \%$ & $1.4 \%$ & $20.5 \%$ & $6.6 \%$ & $9.0 \%$ \\
17 & $8.0 \%$ & $69.8 \%$ & $14.7 \%$ & $7.1 \%$ & $4.5 \%$ & $68.6 \%$ & $12.9 \%$ & $6.9 \%$ \\
18 & $5.5 \%$ & $42.1 \%$ & $10.8 \%$ & $9.2 \%$ & $3.2 \%$ & $41.2 \%$ & $9.4 \%$ & $8.1 \%$ \\
19 & $5.1 \%$ & $56.9 \%$ & $16.9 \%$ & $16.2 \%$ & $3.5 \%$ & $58.5 \%$ & $15.0 \%$ & $14.5 \%$ \\
20 & $3.9 \%$ & $50.1 \%$ & $12.6 \%$ & $10.4 \%$ & $4.4 \%$ & $50.1 \%$ & $12.2 \%$ & $9.8 \%$ \\
\hline
\end{tabular}

Table 38: Normalized EMG data for walking in place (population 1 gray, population 2 - white)

\begin{tabular}{|c|c|c|c|c|c|c|c|c|}
\hline \multicolumn{9}{|c|}{ Walking in Place } \\
\hline \multirow[b]{2}{*}{ Subject \# } & \multicolumn{4}{|c|}{ Before } & \multicolumn{4}{|c|}{ After } \\
\hline & SEM left & SEM right & TRAP right & TRAP left & SEM left & SEM right & TRAP right & TRAP left \\
\hline 1 & $0.9 \%$ & $10.6 \%$ & $8.4 \%$ & $9.4 \%$ & $0.9 \%$ & $10.8 \%$ & $8.1 \%$ & $8.4 \%$ \\
\hline 2 & $2.5 \%$ & $35.6 \%$ & $9.4 \%$ & $11.2 \%$ & $2.3 \%$ & $36.3 \%$ & $11.6 \%$ & $11.0 \%$ \\
\hline 3 & $1.0 \%$ & $4.5 \%$ & $0.3 \%$ & $0.7 \%$ & $0.5 \%$ & $4.6 \%$ & $0.1 \%$ & $0.8 \%$ \\
\hline 4 & $2.1 \%$ & $14.8 \%$ & $32.0 \%$ & $25.2 \%$ & $1.4 \%$ & $14.0 \%$ & $17.3 \%$ & $17.7 \%$ \\
\hline 5 & $3.0 \%$ & $2.8 \%$ & $9.0 \%$ & $19.1 \%$ & $7.1 \%$ & $2.9 \%$ & $9.0 \%$ & $19.9 \%$ \\
\hline 6 & $4.5 \%$ & $52.4 \%$ & $10.7 \%$ & $8.2 \%$ & $4.5 \%$ & $52.3 \%$ & $9.6 \%$ & $6.3 \%$ \\
\hline 7 & $0.2 \%$ & $2.8 \%$ & $1.2 \%$ & $45.8 \%$ & $0.1 \%$ & $2.7 \%$ & $0.9 \%$ & $1.0 \%$ \\
\hline 8 & $3.4 \%$ & $13.6 \%$ & $13.0 \%$ & $0.3 \%$ & $3.7 \%$ & $14.0 \%$ & $11.9 \%$ & $0.2 \%$ \\
\hline 9 & $6.7 \%$ & $31.0 \%$ & $6.0 \%$ & $5.4 \%$ & $2.0 \%$ & $29.9 \%$ & $6.0 \%$ & $5.6 \%$ \\
\hline 10 & $7.3 \%$ & $19.5 \%$ & $9.5 \%$ & $4.9 \%$ & $1.0 \%$ & $11.1 \%$ & $0.8 \%$ & $0.5 \%$ \\
\hline 11 & $10.1 \%$ & $2.7 \%$ & $0.2 \%$ & $15.1 \%$ & $10.5 \%$ & $3.0 \%$ & $0.3 \%$ & $13.4 \%$ \\
\hline 12 & $1.3 \%$ & $10.7 \%$ & $3.6 \%$ & $3.3 \%$ & $1.4 \%$ & $11.4 \%$ & $2.3 \%$ & $3.2 \%$ \\
\hline 13 & $3.6 \%$ & $40.2 \%$ & $28.1 \%$ & $29.1 \%$ & $3.1 \%$ & $40.9 \%$ & $21.3 \%$ & $22.2 \%$ \\
\hline 14 & $12.7 \%$ & $67.5 \%$ & $7.6 \%$ & $6.8 \%$ & $8.5 \%$ & $67.3 \%$ & $5.4 \%$ & $5.9 \%$ \\
\hline 15 & $7.6 \%$ & $3.2 \%$ & $0.5 \%$ & $15.9 \%$ & $2.1 \%$ & $2.8 \%$ & $0.1 \%$ & $15.7 \%$ \\
\hline 16 & $1.4 \%$ & $20.7 \%$ & $11.6 \%$ & $12.0 \%$ & $1.4 \%$ & $20.7 \%$ & $7.5 \%$ & $10.7 \%$ \\
\hline 17 & $16.9 \%$ & $70.5 \%$ & $17.4 \%$ & $8.2 \%$ & $4.9 \%$ & $67.8 \%$ & $10.8 \%$ & $7.4 \%$ \\
\hline 18 & $5.1 \%$ & $42.1 \%$ & $11.6 \%$ & $9.6 \%$ & $3.4 \%$ & $42.7 \%$ & $11.3 \%$ & $9.9 \%$ \\
\hline 19 & $5.3 \%$ & $58.3 \%$ & $18.2 \%$ & $15.7 \%$ & $3.7 \%$ & $59.0 \%$ & $16.2 \%$ & $15.9 \%$ \\
\hline 20 & $4.0 \%$ & $50.6 \%$ & $12.5 \%$ & $9.8 \%$ & $4.3 \%$ & $51.1 \%$ & $13.0 \%$ & $12.7 \%$ \\
\hline
\end{tabular}

Table 39: Normalized EMG data for clapping hands (population 1 gray, population 2 - white)

\begin{tabular}{|c|c|c|c|c|c|c|c|c|}
\hline \multicolumn{9}{|c|}{ Clapping hands } \\
\hline & \multicolumn{4}{|c|}{ Before } & \multicolumn{4}{|c|}{ After } \\
\hline Subject \# & SEM left & SEM right & TRAP right & TRAP left & SEM left & SEM right & TRAP right & TRAP left \\
\hline
\end{tabular}




\begin{tabular}{r|rrrr|rrrr|}
\hline 1 & $1.1 \%$ & $10.8 \%$ & $8.8 \%$ & $11.7 \%$ & $0.9 \%$ & $10.7 \%$ & $9.0 \%$ & $10.8 \%$ \\
2 & $9.8 \%$ & $38.4 \%$ & $32.0 \%$ & $34.8 \%$ & $22.1 \%$ & $48.2 \%$ & $24.2 \%$ & $27.0 \%$ \\
3 & $1.3 \%$ & $4.6 \%$ & $0.3 \%$ & $1.0 \%$ & $0.4 \%$ & $4.4 \%$ & $0.1 \%$ & $0.7 \%$ \\
4 & $1.3 \%$ & $14.1 \%$ & $18.9 \%$ & $16.8 \%$ & $0.8 \%$ & $13.8 \%$ & $12.9 \%$ & $14.8 \%$ \\
5 & $3.6 \%$ & $38.5 \%$ & $24.5 \%$ & $22.6 \%$ & $9.4 \%$ & $2.8 \%$ & $8.4 \%$ & $16.1 \%$ \\
6 & $4.7 \%$ & $51.9 \%$ & $11.2 \%$ & $8.5 \%$ & $4.5 \%$ & $50.9 \%$ & $9.0 \%$ & $5.8 \%$ \\
7 & $0.2 \%$ & $2.7 \%$ & $1.1 \%$ & $1.5 \%$ & $0.2 \%$ & $2.7 \%$ & $1.0 \%$ & $1.1 \%$ \\
8 & $3.6 \%$ & $13.6 \%$ & $13.8 \%$ & $0.3 \%$ & $3.8 \%$ & $13.9 \%$ & $13.2 \%$ & $0.2 \%$ \\
9 & $8.8 \%$ & $32.1 \%$ & $6.3 \%$ & $5.9 \%$ & $2.1 \%$ & $30.2 \%$ & $5.1 \%$ & $5.1 \%$ \\
10 & $1.0 \%$ & $10.9 \%$ & $1.0 \%$ & $0.6 \%$ & $17.6 \%$ & $29.3 \%$ & $5.1 \%$ & $3.0 \%$ \\
11 & $4.4 \%$ & $2.6 \%$ & $0.2 \%$ & $11.5 \%$ & $8.6 \%$ & $2.8 \%$ & $0.3 \%$ & $9.5 \%$ \\
12 & $2.2 \%$ & $10.8 \%$ & $3.4 \%$ & $3.7 \%$ & $1.6 \%$ & $10.9 \%$ & $2.9 \%$ & $4.4 \%$ \\
13 & $3.6 \%$ & $37.5 \%$ & $31.2 \%$ & $31.7 \%$ & $3.3 \%$ & $38.6 \%$ & $21.8 \%$ & $25.1 \%$ \\
14 & $10.8 \%$ & $66.4 \%$ & $7.0 \%$ & $7.3 \%$ & $14.6 \%$ & $66.6 \%$ & $7.0 \%$ & $7.6 \%$ \\
15 & $5.4 \%$ & $2.8 \%$ & $0.6 \%$ & $19.3 \%$ & $2.3 \%$ & $2.7 \%$ & $0.1 \%$ & $12.6 \%$ \\
16 & $2.0 \%$ & $20.4 \%$ & $11.7 \%$ & $13.6 \%$ & $1.3 \%$ & $20.3 \%$ & $6.6 \%$ & $9.4 \%$ \\
17 & $16.2 \%$ & $70.5 \%$ & $24.4 \%$ & $10.6 \%$ & $4.8 \%$ & $67.4 \%$ & $12.3 \%$ & $6.7 \%$ \\
18 & $3.9 \%$ & $41.9 \%$ & $10.9 \%$ & $10.1 \%$ & $3.3 \%$ & $42.0 \%$ & $9.9 \%$ & $8.6 \%$ \\
19 & $5.2 \%$ & $59.0 \%$ & $17.7 \%$ & $16.5 \%$ & $3.9 \%$ & $58.5 \%$ & $15.9 \%$ & $16.1 \%$ \\
20 & $4.3 \%$ & $49.4 \%$ & $11.7 \%$ & $9.6 \%$ & $4.3 \%$ & $50.1 \%$ & $14.5 \%$ & $9.2 \%$ \\
\hline
\end{tabular}

Table 40: Normalized EMG data for turning head (population 1 gray, population 2 - white)

\begin{tabular}{|c|c|c|c|c|c|c|c|c|}
\hline \multicolumn{9}{|c|}{ Turning head } \\
\hline & \multicolumn{4}{|c|}{ Before } & \multicolumn{4}{|c|}{ After } \\
\hline Subject \# & SEM left & SEM right & TRAP right & TRAP left & SEM left & SEM right & TRAP right & TRAP left \\
\hline 1 & $4.8 \%$ & $11.8 \%$ & $15.6 \%$ & $10.4 \%$ & $9.6 \%$ & $15.0 \%$ & $14.3 \%$ & $10.0 \%$ \\
\hline 2 & $5.2 \%$ & $36.7 \%$ & $13.7 \%$ & $13.3 \%$ & $2.8 \%$ & $37.0 \%$ & $12.6 \%$ & $13.4 \%$ \\
\hline 3 & $10.9 \%$ & $56.5 \%$ & $50.4 \%$ & $2.0 \%$ & $8.4 \%$ & $9.1 \%$ & $0.1 \%$ & $1.5 \%$ \\
\hline 4 & $1.9 \%$ & $14.2 \%$ & $20.1 \%$ & $22.1 \%$ & $5.8 \%$ & $16.2 \%$ & $22.9 \%$ & $15.7 \%$ \\
\hline 5 & $13.8 \%$ & $3.0 \%$ & $9.0 \%$ & $13.6 \%$ & $12.2 \%$ & $3.0 \%$ & $10.1 \%$ & $13.6 \%$ \\
\hline 6 & $27.8 \%$ & $57.0 \%$ & $23.2 \%$ & $16.5 \%$ & $18.8 \%$ & $54.2 \%$ & $15.0 \%$ & $10.6 \%$ \\
\hline 7 & $4.1 \%$ & $5.5 \%$ & $5.1 \%$ & $5.7 \%$ & $0.9 \%$ & $3.1 \%$ & $2.9 \%$ & $3.4 \%$ \\
\hline 8 & $20.6 \%$ & $15.4 \%$ & $13.9 \%$ & $0.3 \%$ & $12.9 \%$ & $14.2 \%$ & $12.0 \%$ & $0.2 \%$ \\
\hline 9 & $7.2 \%$ & $31.0 \%$ & $10.0 \%$ & $11.1 \%$ & $3.7 \%$ & $30.1 \%$ & $7.2 \%$ & $7.8 \%$ \\
\hline 10 & $25.9 \%$ & $38.5 \%$ & $3.7 \%$ & $3.3 \%$ & $1.7 \%$ & $10.9 \%$ & $1.2 \%$ & $0.7 \%$ \\
\hline 11 & $19.2 \%$ & $3.1 \%$ & $0.6 \%$ & $39.6 \%$ & $12.3 \%$ & $2.9 \%$ & $0.5 \%$ & $28.7 \%$ \\
\hline 12 & $2.7 \%$ & $11.2 \%$ & $6.0 \%$ & $4.6 \%$ & $5.0 \%$ & $12.5 \%$ & $6.3 \%$ & $5.0 \%$ \\
\hline 13 & $4.4 \%$ & $38.3 \%$ & $29.2 \%$ & $29.5 \%$ & $3.5 \%$ & $39.1 \%$ & $23.4 \%$ & $26.4 \%$ \\
\hline 14 & $39.0 \%$ & $76.3 \%$ & $10.8 \%$ & $11.4 \%$ & $52.9 \%$ & $80.3 \%$ & $12.8 \%$ & $14.6 \%$ \\
\hline 15 & $6.2 \%$ & $2.9 \%$ & $0.6 \%$ & $20.3 \%$ & $3.3 \%$ & $2.7 \%$ & $0.1 \%$ & $45.7 \%$ \\
\hline 16 & $3.5 \%$ & $22.1 \%$ & $23.8 \%$ & $24.2 \%$ & $6.5 \%$ & $23.5 \%$ & $19.0 \%$ & $32.8 \%$ \\
\hline 17 & $8.1 \%$ & $67.7 \%$ & $15.9 \%$ & $11.8 \%$ & $6.3 \%$ & $67.6 \%$ & $13.8 \%$ & $25.3 \%$ \\
\hline
\end{tabular}




\begin{tabular}{|r|rrrr|rrrr|}
18 & $45.3 \%$ & $62.3 \%$ & $14.2 \%$ & $15.1 \%$ & $15.7 \%$ & $45.9 \%$ & $10.4 \%$ & $8.9 \%$ \\
19 & $23.3 \%$ & $62.4 \%$ & $39.6 \%$ & $38.9 \%$ & $14.8 \%$ & $60.7 \%$ & $36.0 \%$ & $31.5 \%$ \\
20 & $6.0 \%$ & $52.1 \%$ & $35.1 \%$ & $27.3 \%$ & $12.6 \%$ & $54.5 \%$ & $44.4 \%$ & $38.3 \%$ \\
\hline
\end{tabular}

Table 41: Normalized EMG data for shaking head (population 1 gray, population 2 - white)

\begin{tabular}{|c|c|c|c|c|c|c|c|c|}
\hline \multicolumn{9}{|c|}{ Shaking head } \\
\hline & \multicolumn{4}{|c|}{ Before } & \multicolumn{4}{|c|}{ After } \\
\hline Subject \# & SEM left & SEM right & TRAP right & TRAP left & SEM left & SEM right & TRAP right & TRAP left \\
\hline 1 & $1.5 \%$ & $10.7 \%$ & $7.2 \%$ & $6.4 \%$ & $1.1 \%$ & $10.7 \%$ & $6.3 \%$ & $5.6 \%$ \\
\hline 2 & $5.3 \%$ & $36.4 \%$ & $22.0 \%$ & $17.3 \%$ & $7.6 \%$ & $36.7 \%$ & $17.3 \%$ & $14.4 \%$ \\
\hline 3 & $0.4 \%$ & $63.9 \%$ & $60.4 \%$ & $2.0 \%$ & $2.2 \%$ & $4.9 \%$ & $0.1 \%$ & $2.0 \%$ \\
\hline 4 & $1.0 \%$ & $13.9 \%$ & $16.4 \%$ & $11.7 \%$ & $2.4 \%$ & $14.2 \%$ & $16.8 \%$ & $11.1 \%$ \\
\hline 5 & $10.8 \%$ & $2.9 \%$ & $8.9 \%$ & $17.6 \%$ & $11.4 \%$ & $3.0 \%$ & $27.3 \%$ & $16.8 \%$ \\
\hline 6 & $8.5 \%$ & $52.2 \%$ & $26.5 \%$ & $22.3 \%$ & $9.5 \%$ & $52.1 \%$ & $22.0 \%$ & $15.0 \%$ \\
\hline 7 & $47.5 \%$ & $32.1 \%$ & $4.8 \%$ & $6.4 \%$ & $0.4 \%$ & $2.8 \%$ & $2.9 \%$ & $3.1 \%$ \\
\hline 8 & $4.8 \%$ & $13.8 \%$ & $13.9 \%$ & $0.3 \%$ & $4.1 \%$ & $13.6 \%$ & $15.0 \%$ & $0.2 \%$ \\
\hline 9 & $3.3 \%$ & $30.3 \%$ & $11.3 \%$ & $18.5 \%$ & $3.1 \%$ & $30.2 \%$ & $8.3 \%$ & $12.2 \%$ \\
\hline 10 & $8.8 \%$ & $15.5 \%$ & $2.3 \%$ & $1.5 \%$ & $15.3 \%$ & $21.6 \%$ & $2.5 \%$ & $2.4 \%$ \\
\hline 11 & $16.1 \%$ & $2.8 \%$ & $0.4 \%$ & $37.7 \%$ & $13.8 \%$ & $2.8 \%$ & $0.4 \%$ & $33.8 \%$ \\
\hline 12 & $1.4 \%$ & $10.5 \%$ & $5.2 \%$ & $4.6 \%$ & $3.7 \%$ & $11.3 \%$ & $4.4 \%$ & $5.8 \%$ \\
\hline 13 & $5.4 \%$ & $38.8 \%$ & $27.1 \%$ & $39.5 \%$ & $5.0 \%$ & $37.5 \%$ & $19.3 \%$ & $22.5 \%$ \\
\hline 14 & $15.3 \%$ & $66.9 \%$ & $7.7 \%$ & $18.8 \%$ & $12.5 \%$ & $68.3 \%$ & $8.4 \%$ & $10.4 \%$ \\
\hline 15 & $25.5 \%$ & $3.1 \%$ & $0.6 \%$ & $17.6 \%$ & $2.2 \%$ & $2.7 \%$ & $0.1 \%$ & $46.7 \%$ \\
\hline 16 & $4.5 \%$ & $22.4 \%$ & $32.6 \%$ & $31.7 \%$ & $4.6 \%$ & $22.2 \%$ & $31.2 \%$ & $47.0 \%$ \\
\hline 17 & $10.5 \%$ & $73.8 \%$ & $45.1 \%$ & $11.2 \%$ & $8.3 \%$ & $68.2 \%$ & $21.0 \%$ & $35.6 \%$ \\
\hline 18 & $9.3 \%$ & $42.9 \%$ & $15.1 \%$ & $12.7 \%$ & $7.6 \%$ & $41.9 \%$ & $11.4 \%$ & $9.3 \%$ \\
\hline 19 & $5.7 \%$ & $59.1 \%$ & $41.2 \%$ & $42.5 \%$ & $4.4 \%$ & $58.6 \%$ & $22.6 \%$ & $23.4 \%$ \\
\hline 20 & $29.2 \%$ & $59.3 \%$ & $27.6 \%$ & $12.3 \%$ & $37.6 \%$ & $67.8 \%$ & $86.0 \%$ & $21.1 \%$ \\
\hline
\end{tabular}


APPENDIX B 
Table 42: Normalized EMG data for nodding head with and without the helmet (population 1-gray, population 2-white)

\begin{tabular}{|c|c|c|c|c|c|c|c|c|c|c|}
\hline \multicolumn{11}{|c|}{ Nodding head } \\
\hline & \multirow[b]{2}{*}{ Subject \# } & \multicolumn{4}{|c|}{ Without helmet } & & \multicolumn{4}{|c|}{ With helmet } \\
\hline & & SEM right & SEM left & TRAP left & TRAP right & & SEM right & SEM left & TRAP left & TRAP right \\
\hline \multirow{20}{*}{ Rep 1} & 1 & $1.3 \%$ & $10.8 \%$ & $9.0 \%$ & $8.6 \%$ & \multirow{20}{*}{ Rep 2} & $1.0 \%$ & $10.8 \%$ & $10.2 \%$ & $12.6 \%$ \\
\hline & 2 & $2.1 \%$ & $35.9 \%$ & $12.2 \%$ & $12.2 \%$ & & $2.7 \%$ & $35.6 \%$ & $11.5 \%$ & $10.4 \%$ \\
\hline & 3 & $84.3 \%$ & $82.7 \%$ & $4.4 \%$ & $51.7 \%$ & & $0.6 \%$ & $44.2 \%$ & $48.3 \%$ & $1.2 \%$ \\
\hline & 4 & $1.1 \%$ & $13.9 \%$ & $15.1 \%$ & $14.5 \%$ & & $1.3 \%$ & $13.9 \%$ & $30.6 \%$ & $44.3 \%$ \\
\hline & 5 & $5.7 \%$ & $2.9 \%$ & $10.0 \%$ & $20.2 \%$ & & $3.4 \%$ & $2.9 \%$ & $13.8 \%$ & $25.8 \%$ \\
\hline & 6 & $4.6 \%$ & $51.6 \%$ & $13.8 \%$ & $10.1 \%$ & & $7.7 \%$ & $52.1 \%$ & $18.3 \%$ & $14.1 \%$ \\
\hline & 7 & $0.2 \%$ & $2.9 \%$ & $3.3 \%$ & $8.3 \%$ & & $0.5 \%$ & $2.9 \%$ & $4.4 \%$ & $5.3 \%$ \\
\hline & 8 & $3.8 \%$ & $69.3 \%$ & $16.3 \%$ & $82.6 \%$ & & $3.5 \%$ & $13.8 \%$ & $13.3 \%$ & $0.3 \%$ \\
\hline & 9 & $6.1 \%$ & $30.9 \%$ & $10.1 \%$ & $10.4 \%$ & & $2.3 \%$ & $32.1 \%$ & $20.2 \%$ & $17.4 \%$ \\
\hline & 10 & $0.8 \%$ & $10.8 \%$ & $0.8 \%$ & $0.5 \%$ & & $0.8 \%$ & $11.3 \%$ & $1.5 \%$ & $1.0 \%$ \\
\hline & 11 & $4.1 \%$ & $2.7 \%$ & $0.4 \%$ & $20.0 \%$ & & $5.2 \%$ & $36.0 \%$ & $34.1 \%$ & $32.7 \%$ \\
\hline & 12 & $1.0 \%$ & $10.5 \%$ & $3.7 \%$ & $3.5 \%$ & & $2.1 \%$ & $11.0 \%$ & $6.7 \%$ & $5.5 \%$ \\
\hline & 13 & $4.0 \%$ & $38.1 \%$ & $27.2 \%$ & $29.0 \%$ & & $4.3 \%$ & $38.4 \%$ & $40.9 \%$ & $37.4 \%$ \\
\hline & 14 & $7.7 \%$ & $66.4 \%$ & $6.2 \%$ & $6.5 \%$ & & $20.2 \%$ & $72.6 \%$ & $13.4 \%$ & $12.9 \%$ \\
\hline & 15 & $2.7 \%$ & $2.8 \%$ & $0.6 \%$ & $20.0 \%$ & & $53.7 \%$ & $4.0 \%$ & $0.1 \%$ & $17.9 \%$ \\
\hline & 16 & $1.4 \%$ & $20.2 \%$ & $13.6 \%$ & $14.9 \%$ & & $1.5 \%$ & $20.5 \%$ & $12.0 \%$ & $16.4 \%$ \\
\hline & 17 & $8.0 \%$ & $69.1 \%$ & $16.7 \%$ & $7.8 \%$ & & $25.4 \%$ & $70.1 \%$ & $28.7 \%$ & $19.2 \%$ \\
\hline & 18 & $3.5 \%$ & $41.4 \%$ & $12.1 \%$ & $11.2 \%$ & & $3.2 \%$ & $42.2 \%$ & $12.0 \%$ & $11.0 \%$ \\
\hline & 19 & $5.0 \%$ & $58.2 \%$ & $22.7 \%$ & $23.8 \%$ & & $5.8 \%$ & $58.0 \%$ & $28.3 \%$ & $31.1 \%$ \\
\hline & 20 & $4.1 \%$ & $49.8 \%$ & $17.1 \%$ & $13.5 \%$ & & $7.4 \%$ & $53.1 \%$ & $36.6 \%$ & $28.6 \%$ \\
\hline \multirow{40}{*}{ Rep 5} & 1 & $0.9 \%$ & $10.6 \%$ & $7.9 \%$ & $7.4 \%$ & \multirow{20}{*}{ Rep 3} & $3.5 \%$ & $12.6 \%$ & $9.6 \%$ & $12.7 \%$ \\
\hline & 2 & $4.9 \%$ & $37.8 \%$ & $19.3 \%$ & $17.5 \%$ & & - & - & - & - \\
\hline & 3 & $0.7 \%$ & $4.5 \%$ & $0.1 \%$ & $1.1 \%$ & & $0.4 \%$ & $4.5 \%$ & $0.1 \%$ & $1.1 \%$ \\
\hline & 4 & $0.7 \%$ & $13.8 \%$ & $14.3 \%$ & $19.5 \%$ & & $1.3 \%$ & $14.0 \%$ & $23.1 \%$ & $37.0 \%$ \\
\hline & 5 & $5.8 \%$ & $3.0 \%$ & $37.8 \%$ & $18.5 \%$ & & $6.4 \%$ & $2.9 \%$ & $10.9 \%$ & $22.4 \%$ \\
\hline & 6 & $7.1 \%$ & $52.4 \%$ & $12.9 \%$ & $9.3 \%$ & & $6.5 \%$ & $52.4 \%$ & $16.3 \%$ & $10.5 \%$ \\
\hline & 7 & $0.2 \%$ & $2.7 \%$ & $2.2 \%$ & $2.2 \%$ & & $0.2 \%$ & $3.0 \%$ & $3.6 \%$ & $4.4 \%$ \\
\hline & 8 & $3.9 \%$ & $13.6 \%$ & $12.9 \%$ & $0.3 \%$ & & $4.0 \%$ & $14.1 \%$ & $12.2 \%$ & $0.2 \%$ \\
\hline & 9 & $2.1 \%$ & $30.7 \%$ & $11.6 \%$ & $11.1 \%$ & & $2.1 \%$ & $31.2 \%$ & $19.3 \%$ & $17.0 \%$ \\
\hline & 10 & $1.4 \%$ & $11.4 \%$ & $1.5 \%$ & $0.9 \%$ & & $1.0 \%$ & $11.1 \%$ & $1.2 \%$ & $0.7 \%$ \\
\hline & 11 & $5.6 \%$ & $2.9 \%$ & $0.8 \%$ & $28.8 \%$ & & $4.0 \%$ & $2.7 \%$ & $0.2 \%$ & $24.9 \%$ \\
\hline & 12 & $1.5 \%$ & $10.6 \%$ & $4.2 \%$ & $4.9 \%$ & & $0.9 \%$ & $10.7 \%$ & $5.6 \%$ & $6.5 \%$ \\
\hline & 13 & $5.6 \%$ & $39.4 \%$ & $25.2 \%$ & $28.6 \%$ & & $4.3 \%$ & $38.8 \%$ & $29.0 \%$ & $32.1 \%$ \\
\hline & 14 & $9.1 \%$ & $67.6 \%$ & $6.4 \%$ & $7.3 \%$ & & $9.7 \%$ & $64.5 \%$ & $11.9 \%$ & $13.5 \%$ \\
\hline & 15 & $2.2 \%$ & $2.8 \%$ & $0.1 \%$ & $15.5 \%$ & & $7.3 \%$ & $2.7 \%$ & $0.1 \%$ & $17.8 \%$ \\
\hline & 16 & $1.6 \%$ & $21.6 \%$ & $13.0 \%$ & $15.8 \%$ & & $1.4 \%$ & $21.3 \%$ & $9.6 \%$ & $14.8 \%$ \\
\hline & 17 & $6.3 \%$ & $67.4 \%$ & $14.2 \%$ & $10.6 \%$ & & $9.8 \%$ & $67.2 \%$ & $20.2 \%$ & $10.1 \%$ \\
\hline & 18 & $3.2 \%$ & $41.5 \%$ & $9.7 \%$ & $8.4 \%$ & & $3.2 \%$ & $41.4 \%$ & $10.5 \%$ & $8.2 \%$ \\
\hline & 19 & $4.7 \%$ & $56.9 \%$ & $23.3 \%$ & $24.2 \%$ & & $4.7 \%$ & $54.4 \%$ & $23.7 \%$ & $24.8 \%$ \\
\hline & 20 & $4.6 \%$ & $50.3 \%$ & $17.7 \%$ & $14.1 \%$ & & $4.2 \%$ & $48.5 \%$ & $23.7 \%$ & $23.3 \%$ \\
\hline & 1 & & & & & \multirow{20}{*}{ Rep 4} & $0.9 \%$ & $11.1 \%$ & $9.2 \%$ & $10.4 \%$ \\
\hline & 2 & & & & & & $5.8 \%$ & $37.0 \%$ & $17.3 \%$ & $16.4 \%$ \\
\hline & 3 & & & & & & $0.4 \%$ & $4.5 \%$ & $0.1 \%$ & $1.1 \%$ \\
\hline & 4 & & & & & & $1.6 \%$ & $13.9 \%$ & $21.5 \%$ & $28.3 \%$ \\
\hline & 5 & & & & & & $4.3 \%$ & $2.9 \%$ & $12.5 \%$ & $24.6 \%$ \\
\hline & 6 & & & & & & $8.3 \%$ & $52.4 \%$ & $15.1 \%$ & $10.3 \%$ \\
\hline & 7 & & & & & & $0.2 \%$ & $2.7 \%$ & $2.0 \%$ & $2.8 \%$ \\
\hline & 8 & & & & & & $5.4 \%$ & $13.5 \%$ & $12.1 \%$ & $0.3 \%$ \\
\hline & 9 & & & & & & $2.1 \%$ & $31.3 \%$ & $15.0 \%$ & $14.5 \%$ \\
\hline & 10 & & & & & & $0.8 \%$ & $11.4 \%$ & $1.5 \%$ & $1.0 \%$ \\
\hline & 11 & & & & & & $3.7 \%$ & $2.7 \%$ & $0.1 \%$ & $21.1 \%$ \\
\hline & 12 & & & & & & $1.1 \%$ & $11.2 \%$ & $7.0 \%$ & $6.9 \%$ \\
\hline & 13 & & & & & & $11.7 \%$ & $42.3 \%$ & $25.7 \%$ & $26.3 \%$ \\
\hline & 14 & & & & & & $8.7 \%$ & $69.0 \%$ & $9.9 \%$ & $13.3 \%$ \\
\hline & 15 & & & & & & $10.9 \%$ & $2.9 \%$ & $0.1 \%$ & $15.0 \%$ \\
\hline & 16 & & & & & & $1.4 \%$ & $20.5 \%$ & $9.7 \%$ & $13.9 \%$ \\
\hline & 17 & & & & & & $15.0 \%$ & $69.8 \%$ & $23.0 \%$ & $13.8 \%$ \\
\hline & 18 & & & & & & $3.0 \%$ & $41.5 \%$ & $9.7 \%$ & $7.9 \%$ \\
\hline & 19 & & & & & & $5.0 \%$ & $58.8 \%$ & $25.8 \%$ & $27.0 \%$ \\
\hline & 20 & & & & & & $4.7 \%$ & $51.2 \%$ & $26.3 \%$ & $24.2 \%$ \\
\hline
\end{tabular}


Table 43: Normalized EMG data for tapping foot with and without the helmet (population 1 - gray, population 2 - white)

\begin{tabular}{|c|c|c|c|c|c|c|c|c|c|c|}
\hline \multicolumn{11}{|c|}{ Tapping foot } \\
\hline & & \multicolumn{4}{|c|}{ Without helmet } & & \multicolumn{4}{|c|}{ With helmet } \\
\hline & Subject \# & SEM right & SEM left & TRAP left & TRAP right & & SEM right & SEM left & TRAP left & TRAP right \\
\hline \multirow{20}{*}{ Rep 1} & 1 & $0.8 \%$ & $10.7 \%$ & $7.2 \%$ & $6.4 \%$ & \multirow{20}{*}{ Rep 2} & $0.8 \%$ & $10.6 \%$ & $8.7 \%$ & $12.7 \%$ \\
\hline & 2 & $1.9 \%$ & $36.1 \%$ & $8.5 \%$ & $8.1 \%$ & & $2.0 \%$ & $36.0 \%$ & $9.9 \%$ & $10.4 \%$ \\
\hline & 3 & $0.3 \%$ & $4.5 \%$ & $0.3 \%$ & $0.9 \%$ & & $0.3 \%$ & $4.7 \%$ & $0.7 \%$ & $0.7 \%$ \\
\hline & 4 & $1.2 \%$ & $13.8 \%$ & $15.5 \%$ & $12.7 \%$ & & $0.9 \%$ & $14.1 \%$ & $18.7 \%$ & $45.3 \%$ \\
\hline & 5 & $3.4 \%$ & $2.8 \%$ & $8.8 \%$ & $19.1 \%$ & & $5.9 \%$ & $3.0 \%$ & $20.0 \%$ & $29.5 \%$ \\
\hline & 6 & $4.4 \%$ & $50.5 \%$ & $8.2 \%$ & $6.3 \%$ & & $4.7 \%$ & $51.0 \%$ & $9.9 \%$ & $6.7 \%$ \\
\hline & 7 & $0.3 \%$ & $38.4 \%$ & $4.0 \%$ & $9.1 \%$ & & $0.3 \%$ & $2.7 \%$ & $1.3 \%$ & $1.3 \%$ \\
\hline & 8 & $3.3 \%$ & $13.6 \%$ & $11.1 \%$ & $0.5 \%$ & & $3.4 \%$ & $13.7 \%$ & $10.9 \%$ & $0.2 \%$ \\
\hline & 9 & $6.8 \%$ & $30.5 \%$ & $5.1 \%$ & $4.7 \%$ & & $2.0 \%$ & $30.0 \%$ & $6.2 \%$ & $5.2 \%$ \\
\hline & 10 & $0.8 \%$ & $10.9 \%$ & $0.8 \%$ & $0.4 \%$ & & $0.8 \%$ & $10.9 \%$ & $1.1 \%$ & $0.6 \%$ \\
\hline & 11 & $8.0 \%$ & $2.7 \%$ & $0.2 \%$ & $11.1 \%$ & & $3.2 \%$ & $2.7 \%$ & $0.2 \%$ & $22.7 \%$ \\
\hline & 12 & $1.1 \%$ & $10.5 \%$ & $3.3 \%$ & $3.2 \%$ & & $0.7 \%$ & $10.5 \%$ & $3.8 \%$ & $3.6 \%$ \\
\hline & 13 & $3.2 \%$ & $38.9 \%$ & $25.4 \%$ & $29.7 \%$ & & $3.2 \%$ & $38.6 \%$ & $30.1 \%$ & $32.6 \%$ \\
\hline & 14 & $5.9 \%$ & $65.8 \%$ & $7.2 \%$ & $6.3 \%$ & & $9.1 \%$ & $69.6 \%$ & $10.2 \%$ & $8.7 \%$ \\
\hline & 15 & $2.0 \%$ & $2.8 \%$ & $0.4 \%$ & $14.3 \%$ & & $2.1 \%$ & $3.4 \%$ & $5.4 \%$ & $12.3 \%$ \\
\hline & 16 & $1.4 \%$ & $20.5 \%$ & $9.4 \%$ & $10.1 \%$ & & $1.5 \%$ & $20.5 \%$ & $9.0 \%$ & $10.5 \%$ \\
\hline & 17 & $8.0 \%$ & $69.8 \%$ & $14.7 \%$ & $7.1 \%$ & & $14.9 \%$ & $68.5 \%$ & $19.1 \%$ & $16.5 \%$ \\
\hline & 18 & $5.5 \%$ & $42.1 \%$ & $10.8 \%$ & $9.2 \%$ & & $3.1 \%$ & $42.0 \%$ & $10.8 \%$ & $8.6 \%$ \\
\hline & 19 & $5.1 \%$ & $56.9 \%$ & $16.9 \%$ & $16.2 \%$ & & $4.1 \%$ & $58.1 \%$ & $18.2 \%$ & $18.1 \%$ \\
\hline & 20 & $3.9 \%$ & $50.1 \%$ & $12.6 \%$ & $10.4 \%$ & & $4.0 \%$ & $50.5 \%$ & $15.3 \%$ & $12.8 \%$ \\
\hline \multirow{40}{*}{ Rep 5} & 1 & $0.9 \%$ & $10.9 \%$ & $6.5 \%$ & $5.7 \%$ & \multirow{20}{*}{ Rep 3} & $0.8 \%$ & $11.1 \%$ & $8.8 \%$ & $11.2 \%$ \\
\hline & 2 & $2.1 \%$ & $35.7 \%$ & $8.5 \%$ & $7.9 \%$ & & $2.5 \%$ & $35.8 \%$ & $11.5 \%$ & $10.2 \%$ \\
\hline & 3 & $0.9 \%$ & $4.6 \%$ & $0.1 \%$ & $0.6 \%$ & & $0.3 \%$ & $4.4 \%$ & $0.1 \%$ & $0.7 \%$ \\
\hline & 4 & $0.7 \%$ & $13.8 \%$ & $11.0 \%$ & $9.6 \%$ & & $1.5 \%$ & $13.8 \%$ & $22.7 \%$ & $31.5 \%$ \\
\hline & 5 & $3.8 \%$ & $2.8 \%$ & $6.3 \%$ & $15.0 \%$ & & $5.1 \%$ & $3.0 \%$ & $12.0 \%$ & $20.8 \%$ \\
\hline & 6 & $4.4 \%$ & $51.1 \%$ & $8.3 \%$ & $5.8 \%$ & & $7.1 \%$ & $51.6 \%$ & $9.2 \%$ & $6.7 \%$ \\
\hline & 7 & $0.1 \%$ & $2.7 \%$ & $1.0 \%$ & $1.3 \%$ & & $0.2 \%$ & $24.1 \%$ & $74.8 \%$ & $1.5 \%$ \\
\hline & 8 & $3.5 \%$ & $13.6 \%$ & $13.9 \%$ & $0.2 \%$ & & $3.7 \%$ & $13.6 \%$ & $8.5 \%$ & $0.1 \%$ \\
\hline & 9 & $1.9 \%$ & $30.0 \%$ & $4.9 \%$ & $4.6 \%$ & & $2.0 \%$ & $30.4 \%$ & $6.5 \%$ & $6.2 \%$ \\
\hline & 10 & $0.8 \%$ & $10.9 \%$ & $0.8 \%$ & $0.4 \%$ & & $0.8 \%$ & $10.9 \%$ & $1.0 \%$ & $0.5 \%$ \\
\hline & 11 & $3.9 \%$ & $2.6 \%$ & $0.2 \%$ & $12.3 \%$ & & $4.1 \%$ & $2.7 \%$ & $0.2 \%$ & $23.6 \%$ \\
\hline & 12 & $1.2 \%$ & $10.8 \%$ & $4.2 \%$ & $4.9 \%$ & & $0.7 \%$ & $10.4 \%$ & $4.6 \%$ & $4.6 \%$ \\
\hline & 13 & $3.1 \%$ & $38.9 \%$ & $24.3 \%$ & $23.8 \%$ & & $3.1 \%$ & $38.0 \%$ & $19.0 \%$ & $18.1 \%$ \\
\hline & 14 & $7.4 \%$ & $66.7 \%$ & $5.9 \%$ & $5.8 \%$ & & $7.5 \%$ & $68.3 \%$ & $10.9 \%$ & $10.1 \%$ \\
\hline & 15 & $2.0 \%$ & $2.8 \%$ & $0.1 \%$ & $10.8 \%$ & & $1.9 \%$ & $2.7 \%$ & $0.1 \%$ & $12.0 \%$ \\
\hline & 16 & $1.4 \%$ & $20.5 \%$ & $6.6 \%$ & $9.0 \%$ & & $1.4 \%$ & $20.8 \%$ & $8.3 \%$ & $10.9 \%$ \\
\hline & 17 & $4.5 \%$ & $68.6 \%$ & $12.9 \%$ & $6.9 \%$ & & $14.6 \%$ & $68.3 \%$ & $16.7 \%$ & $8.0 \%$ \\
\hline & 18 & $3.2 \%$ & $41.2 \%$ & $9.4 \%$ & $8.1 \%$ & & $3.0 \%$ & $42.1 \%$ & $10.0 \%$ & $7.9 \%$ \\
\hline & 19 & $3.5 \%$ & $58.5 \%$ & $15.0 \%$ & $14.5 \%$ & & $3.8 \%$ & $55.6 \%$ & $15.8 \%$ & $18.3 \%$ \\
\hline & 20 & $4.4 \%$ & $50.1 \%$ & $12.2 \%$ & $9.8 \%$ & & $3.9 \%$ & $49.2 \%$ & $12.7 \%$ & $11.3 \%$ \\
\hline & 1 & & & & & \multirow{20}{*}{ Rep 4} & $0.8 \%$ & $11.0 \%$ & $8.1 \%$ & $8.6 \%$ \\
\hline & 2 & & & & & & $2.3 \%$ & $36.1 \%$ & $10.8 \%$ & $10.2 \%$ \\
\hline & 3 & & & & & & $2.4 \%$ & $5.1 \%$ & $0.1 \%$ & $0.8 \%$ \\
\hline & 4 & & & & & & $0.8 \%$ & $13.6 \%$ & $15.4 \%$ & $18.0 \%$ \\
\hline & 5 & & & & & & $2.7 \%$ & $2.8 \%$ & $7.3 \%$ & $11.1 \%$ \\
\hline & 6 & & & & & & $4.3 \%$ & $51.0 \%$ & $8.7 \%$ & $5.8 \%$ \\
\hline & 7 & & & & & & $0.2 \%$ & $2.7 \%$ & $1.6 \%$ & $1.4 \%$ \\
\hline & 8 & & & & & & $5.0 \%$ & $13.6 \%$ & $7.2 \%$ & $0.1 \%$ \\
\hline & 9 & & & & & & $1.9 \%$ & $30.4 \%$ & $5.8 \%$ & $5.5 \%$ \\
\hline & 10 & & & & & & $0.7 \%$ & $11.0 \%$ & $1.2 \%$ & $0.8 \%$ \\
\hline & 11 & & & & & & $2.9 \%$ & $3.8 \%$ & $0.5 \%$ & $10.9 \%$ \\
\hline & 12 & & & & & & $0.7 \%$ & $10.9 \%$ & $3.2 \%$ & $4.4 \%$ \\
\hline & 13 & & & & & & $3.4 \%$ & $37.8 \%$ & $18.3 \%$ & $17.3 \%$ \\
\hline & 14 & & & & & & $8.1 \%$ & $68.7 \%$ & $12.0 \%$ & $12.1 \%$ \\
\hline & 15 & & & & & & $1.8 \%$ & $2.7 \%$ & $0.1 \%$ & $10.7 \%$ \\
\hline & 16 & & & & & & $1.5 \%$ & $21.2 \%$ & $8.8 \%$ & $10.7 \%$ \\
\hline & 17 & & & & & & $7.7 \%$ & $66.9 \%$ & $13.9 \%$ & $11.3 \%$ \\
\hline & 18 & & & & & & $3.0 \%$ & $41.6 \%$ & $9.5 \%$ & $7.2 \%$ \\
\hline & 19 & & & & & & $4.0 \%$ & $57.1 \%$ & $15.4 \%$ & $17.8 \%$ \\
\hline & 20 & & & & & & $4.1 \%$ & $49.8 \%$ & $12.3 \%$ & $9.4 \%$ \\
\hline
\end{tabular}


Table 44: Normalized EMG data for walking in place with and without the helmet (population 1 - gray, population 2 - white)

\begin{tabular}{|c|c|c|c|c|c|c|c|c|c|c|}
\hline \multicolumn{11}{|c|}{ Walking in place } \\
\hline & \multirow[b]{2}{*}{ Subject \# } & \multicolumn{4}{|c|}{ Without helmet } & & \multicolumn{4}{|c|}{ With helmet } \\
\hline & & SEM right & SEM left & TRAP left & TRAP right & & SEM right & SEM left & TRAP left & TRAP right \\
\hline \multirow{20}{*}{ Rep 1} & 1 & $0.9 \%$ & $10.6 \%$ & $8.4 \%$ & $9.4 \%$ & \multirow{20}{*}{ Rep 2} & $1.0 \%$ & $10.9 \%$ & $11.5 \%$ & $15.0 \%$ \\
\hline & 2 & $2.5 \%$ & $35.6 \%$ & $9.4 \%$ & $11.2 \%$ & & $3.3 \%$ & $36.3 \%$ & $9.9 \%$ & $9.6 \%$ \\
\hline & 3 & $1.0 \%$ & $4.5 \%$ & $0.3 \%$ & $0.7 \%$ & & $0.7 \%$ & $4.5 \%$ & $0.1 \%$ & $0.6 \%$ \\
\hline & 4 & $2.1 \%$ & $14.8 \%$ & $32.0 \%$ & $25.2 \%$ & & $1.1 \%$ & $14.2 \%$ & $18.8 \%$ & $19.1 \%$ \\
\hline & 5 & $3.0 \%$ & $2.8 \%$ & $9.0 \%$ & $19.1 \%$ & & $3.6 \%$ & $2.8 \%$ & $11.4 \%$ & $18.6 \%$ \\
\hline & 6 & $4.5 \%$ & $52.4 \%$ & $10.7 \%$ & $8.2 \%$ & & $5.8 \%$ & $51.7 \%$ & $11.1 \%$ & $8.1 \%$ \\
\hline & 7 & $0.2 \%$ & $2.8 \%$ & $1.2 \%$ & $45.8 \%$ & & $0.2 \%$ & $2.8 \%$ & $2.3 \%$ & $1.9 \%$ \\
\hline & 8 & $3.4 \%$ & $13.6 \%$ & $13.0 \%$ & $0.3 \%$ & & $4.0 \%$ & $13.7 \%$ & $12.8 \%$ & $0.3 \%$ \\
\hline & 9 & $6.7 \%$ & $31.0 \%$ & $6.0 \%$ & $5.4 \%$ & & $2.0 \%$ & $29.8 \%$ & $6.6 \%$ & $6.3 \%$ \\
\hline & 10 & $7.3 \%$ & $19.5 \%$ & $9.5 \%$ & $4.9 \%$ & & $24.0 \%$ & $29.4 \%$ & $26.1 \%$ & $22.4 \%$ \\
\hline & 11 & $10.1 \%$ & $2.7 \%$ & $0.2 \%$ & $15.1 \%$ & & $5.3 \%$ & $2.7 \%$ & $0.2 \%$ & $21.4 \%$ \\
\hline & 12 & $1.3 \%$ & $10.7 \%$ & $3.6 \%$ & $3.3 \%$ & & $0.8 \%$ & $10.6 \%$ & $3.7 \%$ & $3.7 \%$ \\
\hline & 13 & $3.6 \%$ & $40.2 \%$ & $28.1 \%$ & $29.1 \%$ & & $3.3 \%$ & $39.7 \%$ & $26.9 \%$ & $29.9 \%$ \\
\hline & 14 & $12.7 \%$ & $67.5 \%$ & $7.6 \%$ & $6.8 \%$ & & $17.0 \%$ & $70.9 \%$ & $10.0 \%$ & $11.8 \%$ \\
\hline & 15 & $7.6 \%$ & $3.2 \%$ & $0.5 \%$ & $15.9 \%$ & & $2.0 \%$ & $2.8 \%$ & $0.1 \%$ & $12.1 \%$ \\
\hline & 16 & $1.4 \%$ & $20.7 \%$ & $11.6 \%$ & $12.0 \%$ & & $1.8 \%$ & $20.6 \%$ & $10.2 \%$ & $12.8 \%$ \\
\hline & 17 & $16.9 \%$ & $70.5 \%$ & $17.4 \%$ & $8.2 \%$ & & $13.1 \%$ & $69.3 \%$ & $21.5 \%$ & $17.9 \%$ \\
\hline & 18 & $5.1 \%$ & $42.1 \%$ & $11.6 \%$ & $9.6 \%$ & & $3.1 \%$ & $41.4 \%$ & $11.3 \%$ & $9.3 \%$ \\
\hline & 19 & $5.3 \%$ & $58.3 \%$ & $18.2 \%$ & $15.7 \%$ & & $8.8 \%$ & $58.4 \%$ & $27.9 \%$ & $27.8 \%$ \\
\hline & 20 & $4.0 \%$ & $50.6 \%$ & $12.5 \%$ & $9.8 \%$ & & $4.1 \%$ & $51.0 \%$ & $15.0 \%$ & $12.3 \%$ \\
\hline \multirow{40}{*}{ Rep 5} & 1 & $0.9 \%$ & $10.8 \%$ & $8.1 \%$ & $8.4 \%$ & \multirow{20}{*}{ Rep 3} & $1.1 \%$ & $11.2 \%$ & $10.1 \%$ & $12.3 \%$ \\
\hline & 2 & $2.3 \%$ & $36.3 \%$ & $11.6 \%$ & $11.0 \%$ & & $2.4 \%$ & $35.7 \%$ & $11.5 \%$ & $12.1 \%$ \\
\hline & 3 & $0.5 \%$ & $4.6 \%$ & $0.1 \%$ & $0.8 \%$ & & $1.1 \%$ & $4.7 \%$ & $0.1 \%$ & $0.7 \%$ \\
\hline & 4 & $1.4 \%$ & $14.0 \%$ & $17.3 \%$ & $17.7 \%$ & & $1.3 \%$ & $13.9 \%$ & $21.1 \%$ & $22.0 \%$ \\
\hline & 5 & $7.1 \%$ & $2.9 \%$ & $9.0 \%$ & $19.9 \%$ & & $5.9 \%$ & $2.9 \%$ & $9.5 \%$ & $20.4 \%$ \\
\hline & 6 & $4.5 \%$ & $52.3 \%$ & $9.6 \%$ & $6.3 \%$ & & $6.3 \%$ & $51.9 \%$ & $10.8 \%$ & $7.6 \%$ \\
\hline & 7 & $0.1 \%$ & $2.7 \%$ & $0.9 \%$ & $1.0 \%$ & & $0.2 \%$ & $2.6 \%$ & $1.5 \%$ & $1.6 \%$ \\
\hline & 8 & $3.7 \%$ & $14.0 \%$ & $11.9 \%$ & $0.2 \%$ & & $3.6 \%$ & $13.4 \%$ & $9.8 \%$ & $0.2 \%$ \\
\hline & 9 & $2.0 \%$ & $29.9 \%$ & $6.0 \%$ & $5.6 \%$ & & $2.0 \%$ & $29.6 \%$ & $5.6 \%$ & $5.8 \%$ \\
\hline & 10 & $1.0 \%$ & $11.1 \%$ & $0.8 \%$ & $0.5 \%$ & & $1.7 \%$ & $12.8 \%$ & $2.3 \%$ & $0.9 \%$ \\
\hline & 11 & $10.5 \%$ & $3.0 \%$ & $0.3 \%$ & $13.4 \%$ & & $2.9 \%$ & $2.7 \%$ & $0.2 \%$ & $27.4 \%$ \\
\hline & 12 & $1.4 \%$ & $11.4 \%$ & $2.3 \%$ & $3.2 \%$ & & $0.8 \%$ & $10.5 \%$ & $4.0 \%$ & $4.3 \%$ \\
\hline & 13 & $3.1 \%$ & $40.9 \%$ & $21.3 \%$ & $22.2 \%$ & & $3.5 \%$ & $43.3 \%$ & $22.3 \%$ & $20.4 \%$ \\
\hline & 14 & $8.5 \%$ & $67.3 \%$ & $5.4 \%$ & $5.9 \%$ & & $12.0 \%$ & $66.9 \%$ & $10.3 \%$ & $9.8 \%$ \\
\hline & 15 & $2.1 \%$ & $2.8 \%$ & $0.1 \%$ & $15.7 \%$ & & $2.0 \%$ & $2.7 \%$ & $0.1 \%$ & $11.4 \%$ \\
\hline & 16 & $1.4 \%$ & $20.7 \%$ & $7.5 \%$ & $10.7 \%$ & & $1.7 \%$ & $20.5 \%$ & $7.8 \%$ & $12.5 \%$ \\
\hline & 17 & $4.9 \%$ & $67.8 \%$ & $10.8 \%$ & $7.4 \%$ & & $12.2 \%$ & $64.7 \%$ & $19.3 \%$ & $11.4 \%$ \\
\hline & 18 & $3.4 \%$ & $42.7 \%$ & $11.3 \%$ & $9.9 \%$ & & $2.9 \%$ & $40.9 \%$ & $9.7 \%$ & $7.7 \%$ \\
\hline & 19 & $3.7 \%$ & $59.0 \%$ & $16.2 \%$ & $15.9 \%$ & & $3.8 \%$ & $55.7 \%$ & $14.8 \%$ & $18.3 \%$ \\
\hline & 20 & $4.3 \%$ & $51.1 \%$ & $13.0 \%$ & $12.7 \%$ & & $3.8 \%$ & $47.4 \%$ & $12.4 \%$ & $11.1 \%$ \\
\hline & 1 & & & & & \multirow{20}{*}{ Rep 4} & $0.9 \%$ & $11.0 \%$ & $10.1 \%$ & $11.4 \%$ \\
\hline & 2 & & & & & & $2.5 \%$ & $36.3 \%$ & $10.8 \%$ & $10.8 \%$ \\
\hline & 3 & & & & & & $0.9 \%$ & $4.6 \%$ & $0.2 \%$ & $0.8 \%$ \\
\hline & 4 & & & & & & $0.8 \%$ & $14.0 \%$ & $18.0 \%$ & $18.3 \%$ \\
\hline & 5 & & & & & & $8.8 \%$ & $3.0 \%$ & $10.1 \%$ & $21.4 \%$ \\
\hline & 6 & & & & & & $9.1 \%$ & $53.0 \%$ & $10.8 \%$ & $11.0 \%$ \\
\hline & 7 & & & & & & $0.3 \%$ & $2.8 \%$ & $1.2 \%$ & $1.1 \%$ \\
\hline & 8 & & & & & & $4.8 \%$ & $13.3 \%$ & $9.2 \%$ & $0.2 \%$ \\
\hline & 9 & & & & & & $1.9 \%$ & $30.1 \%$ & $5.8 \%$ & $6.4 \%$ \\
\hline & 10 & & & & & & $0.8 \%$ & $12.7 \%$ & $1.3 \%$ & $0.9 \%$ \\
\hline & 11 & & & & & & $3.6 \%$ & $3.5 \%$ & $1.0 \%$ & $32.7 \%$ \\
\hline & 12 & & & & & & $0.8 \%$ & $10.8 \%$ & $4.1 \%$ & $4.3 \%$ \\
\hline & 13 & & & & & & $3.6 \%$ & $43.3 \%$ & $21.2 \%$ & $21.5 \%$ \\
\hline & 14 & & & & & & $10.3 \%$ & $68.7 \%$ & $11.4 \%$ & $10.0 \%$ \\
\hline & 15 & & & & & & $1.9 \%$ & $2.7 \%$ & $0.1 \%$ & $12.5 \%$ \\
\hline & 16 & & & & & & $1.6 \%$ & $20.5 \%$ & $8.8 \%$ & $11.7 \%$ \\
\hline & 17 & & & & & & $11.1 \%$ & $67.8 \%$ & $15.2 \%$ & $9.4 \%$ \\
\hline & 18 & & & & & & $3.0 \%$ & $41.5 \%$ & $10.0 \%$ & $7.8 \%$ \\
\hline & 19 & & & & & & $4.5 \%$ & $57.9 \%$ & $15.6 \%$ & $18.8 \%$ \\
\hline & 20 & & & & & & $4.5 \%$ & $50.4 \%$ & $12.8 \%$ & $10.6 \%$ \\
\hline
\end{tabular}


Table 45: Normalized EMG data for clapping hands with and without the helmet (population 1 - gray, population 2-white)

\begin{tabular}{|c|c|c|c|c|c|c|c|c|c|c|}
\hline \multicolumn{11}{|c|}{ Clapping hands } \\
\hline & & \multicolumn{4}{|c|}{ Without helmet } & & \multicolumn{4}{|c|}{ With helmet } \\
\hline & Subject \# & SEM right & SEM left & TRAP left & TRAP right & & SEM right & SEM left & TRAP left & TRAP right \\
\hline \multirow{20}{*}{ Rep 1} & 1 & $1.12 \%$ & $10.8 \%$ & $8.8 \%$ & $11.7 \%$ & \multirow{20}{*}{ Rep 2} & $0.9 \%$ & $11.0 \%$ & $12.5 \%$ & $16.2 \%$ \\
\hline & 2 & $9.85 \%$ & $38.4 \%$ & $32.0 \%$ & $34.8 \%$ & & $3.8 \%$ & $36.1 \%$ & $16.5 \%$ & $15.8 \%$ \\
\hline & 3 & $1.26 \%$ & $4.6 \%$ & $0.3 \%$ & $1.0 \%$ & & $0.4 \%$ & $4.4 \%$ & $0.3 \%$ & $0.8 \%$ \\
\hline & 4 & $1.26 \%$ & $14.1 \%$ & $18.9 \%$ & $16.8 \%$ & & $1.2 \%$ & $13.8 \%$ & $18.0 \%$ & $59.0 \%$ \\
\hline & 5 & $3.65 \%$ & $38.5 \%$ & $24.5 \%$ & $22.6 \%$ & & $3.2 \%$ & $2.8 \%$ & $9.4 \%$ & $18.0 \%$ \\
\hline & 6 & $4.66 \%$ & $51.9 \%$ & $11.2 \%$ & $8.5 \%$ & & $6.0 \%$ & $50.3 \%$ & $9.0 \%$ & $7.0 \%$ \\
\hline & 7 & $0.21 \%$ & $2.7 \%$ & $1.1 \%$ & $1.5 \%$ & & $0.3 \%$ & $2.8 \%$ & $3.1 \%$ & $1.4 \%$ \\
\hline & 8 & $3.57 \%$ & $13.6 \%$ & $13.8 \%$ & $0.3 \%$ & & $5.4 \%$ & $13.7 \%$ & $10.9 \%$ & $0.2 \%$ \\
\hline & 9 & $8.77 \%$ & $32.1 \%$ & $6.3 \%$ & $5.9 \%$ & & $2.2 \%$ & $30.1 \%$ & $7.1 \%$ & $6.7 \%$ \\
\hline & 10 & $1.00 \%$ & $10.9 \%$ & $1.0 \%$ & $0.6 \%$ & & $0.8 \%$ & $10.9 \%$ & $1.0 \%$ & $0.6 \%$ \\
\hline & 11 & $4.44 \%$ & $2.6 \%$ & $0.2 \%$ & $11.5 \%$ & & $5.3 \%$ & $2.7 \%$ & $0.1 \%$ & $11.1 \%$ \\
\hline & 12 & $2.17 \%$ & $10.8 \%$ & $3.4 \%$ & $3.7 \%$ & & $1.9 \%$ & $10.7 \%$ & $5.1 \%$ & $5.4 \%$ \\
\hline & 13 & $3.56 \%$ & $37.5 \%$ & $31.2 \%$ & $31.7 \%$ & & $3.5 \%$ & $38.9 \%$ & $35.9 \%$ & $38.3 \%$ \\
\hline & 14 & $10.80 \%$ & $66.4 \%$ & $7.0 \%$ & $7.3 \%$ & & $9.3 \%$ & $68.1 \%$ & $7.6 \%$ & $9.3 \%$ \\
\hline & 15 & $5.37 \%$ & $2.8 \%$ & $0.6 \%$ & $19.3 \%$ & & $2.2 \%$ & $2.8 \%$ & $0.1 \%$ & $12.6 \%$ \\
\hline & 16 & $2.03 \%$ & $20.4 \%$ & $11.7 \%$ & $13.6 \%$ & & $1.5 \%$ & $20.8 \%$ & $9.0 \%$ & $11.2 \%$ \\
\hline & 17 & $16.19 \%$ & $70.5 \%$ & $24.4 \%$ & $10.6 \%$ & & $11.3 \%$ & $66.4 \%$ & $16.8 \%$ & $11.2 \%$ \\
\hline & 18 & $3.90 \%$ & $41.9 \%$ & $10.9 \%$ & $10.1 \%$ & & $3.3 \%$ & $41.7 \%$ & $9.7 \%$ & $7.5 \%$ \\
\hline & 19 & $5.19 \%$ & $59.0 \%$ & $17.7 \%$ & $16.5 \%$ & & $3.9 \%$ & $58.6 \%$ & $18.3 \%$ & $17.6 \%$ \\
\hline & 20 & $4.25 \%$ & $49.4 \%$ & $11.7 \%$ & $9.6 \%$ & & $25.5 \%$ & $59.0 \%$ & $39.1 \%$ & $35.4 \%$ \\
\hline \multirow{40}{*}{ Rep 5} & 1 & $0.87 \%$ & $10.7 \%$ & $9.0 \%$ & $10.8 \%$ & \multirow{20}{*}{ Rep 3} & $0.9 \%$ & $11.1 \%$ & $13.0 \%$ & $17.5 \%$ \\
\hline & 2 & $22.10 \%$ & $48.2 \%$ & $24.2 \%$ & $27.0 \%$ & & $3.8 \%$ & $36.4 \%$ & $14.1 \%$ & $14.4 \%$ \\
\hline & 3 & $0.40 \%$ & $4.4 \%$ & $0.1 \%$ & $0.7 \%$ & & $0.4 \%$ & $4.5 \%$ & $0.1 \%$ & $0.9 \%$ \\
\hline & 4 & $0.78 \%$ & $13.8 \%$ & $12.9 \%$ & $14.8 \%$ & & $0.9 \%$ & $13.8 \%$ & $20.5 \%$ & $21.1 \%$ \\
\hline & 5 & $9.41 \%$ & $2.8 \%$ & $8.4 \%$ & $16.1 \%$ & & $3.9 \%$ & $2.8 \%$ & $9.1 \%$ & $16.2 \%$ \\
\hline & 6 & $4.52 \%$ & $50.9 \%$ & $9.0 \%$ & $5.8 \%$ & & $4.5 \%$ & $51.7 \%$ & $9.5 \%$ & $6.9 \%$ \\
\hline & 7 & $0.16 \%$ & $2.7 \%$ & $1.0 \%$ & $1.1 \%$ & & $0.2 \%$ & $2.7 \%$ & $1.4 \%$ & $1.6 \%$ \\
\hline & 8 & $3.76 \%$ & $13.9 \%$ & $13.2 \%$ & $0.2 \%$ & & $3.9 \%$ & $13.4 \%$ & $9.2 \%$ & $0.2 \%$ \\
\hline & 9 & $2.14 \%$ & $30.2 \%$ & $5.1 \%$ & $5.1 \%$ & & $2.0 \%$ & $30.2 \%$ & $5.7 \%$ & $6.0 \%$ \\
\hline & 10 & $17.63 \%$ & $29.3 \%$ & $5.1 \%$ & $3.0 \%$ & & $0.9 \%$ & $11.1 \%$ & $1.0 \%$ & $0.7 \%$ \\
\hline & 11 & $8.58 \%$ & $2.8 \%$ & $0.3 \%$ & $9.5 \%$ & & $4.6 \%$ & $2.7 \%$ & $0.1 \%$ & $22.0 \%$ \\
\hline & 12 & $1.57 \%$ & $10.9 \%$ & $2.9 \%$ & $4.4 \%$ & & $0.8 \%$ & $10.8 \%$ & $4.9 \%$ & $6.5 \%$ \\
\hline & 13 & $3.34 \%$ & $38.6 \%$ & $21.8 \%$ & $25.1 \%$ & & $3.6 \%$ & $37.7 \%$ & $37.5 \%$ & $45.3 \%$ \\
\hline & 14 & $14.60 \%$ & $66.6 \%$ & $7.0 \%$ & $7.6 \%$ & & $8.4 \%$ & $67.7 \%$ & $9.7 \%$ & $10.6 \%$ \\
\hline & 15 & $2.29 \%$ & $2.7 \%$ & $0.1 \%$ & $12.6 \%$ & & $2.3 \%$ & $2.8 \%$ & $0.1 \%$ & $13.3 \%$ \\
\hline & 16 & $1.33 \%$ & $20.3 \%$ & $6.6 \%$ & $9.4 \%$ & & $1.4 \%$ & $20.5 \%$ & $7.1 \%$ & $10.9 \%$ \\
\hline & 17 & $4.82 \%$ & $67.4 \%$ & $12.3 \%$ & $6.7 \%$ & & $12.3 \%$ & $67.1 \%$ & $14.8 \%$ & $9.1 \%$ \\
\hline & 18 & $3.32 \%$ & $42.0 \%$ & $9.9 \%$ & $8.6 \%$ & & $19.3 \%$ & $45.8 \%$ & $11.7 \%$ & $8.4 \%$ \\
\hline & 19 & $3.86 \%$ & $58.5 \%$ & $15.9 \%$ & $16.1 \%$ & & $3.8 \%$ & $59.1 \%$ & $17.9 \%$ & $17.4 \%$ \\
\hline & 20 & $4.28 \%$ & $50.1 \%$ & $14.5 \%$ & $9.2 \%$ & & $4.0 \%$ & $50.0 \%$ & $14.3 \%$ & $11.7 \%$ \\
\hline & 1 & & & & & \multirow{20}{*}{ Rep 4} & $0.8 \%$ & $10.9 \%$ & $11.1 \%$ & $13.4 \%$ \\
\hline & 2 & & & & & & $2.9 \%$ & $36.6 \%$ & $14.6 \%$ & $13.2 \%$ \\
\hline & 3 & & & & & & $0.4 \%$ & $4.4 \%$ & $0.1 \%$ & $0.8 \%$ \\
\hline & 4 & & & & & & $0.8 \%$ & $14.0 \%$ & $17.8 \%$ & $20.3 \%$ \\
\hline & 5 & & & & & & $2.6 \%$ & $2.8 \%$ & $9.2 \%$ & $18.3 \%$ \\
\hline & 6 & & & & & & $4.6 \%$ & $51.3 \%$ & $10.3 \%$ & $6.8 \%$ \\
\hline & 7 & & & & & & $0.2 \%$ & $2.7 \%$ & $1.6 \%$ & $1.4 \%$ \\
\hline & 8 & & & & & & $4.5 \%$ & $13.4 \%$ & $9.6 \%$ & $0.2 \%$ \\
\hline & 9 & & & & & & $2.7 \%$ & $29.8 \%$ & $5.6 \%$ & $6.1 \%$ \\
\hline & 10 & & & & & & $0.9 \%$ & $10.8 \%$ & $1.2 \%$ & $0.6 \%$ \\
\hline & 11 & & & & & & $3.5 \%$ & $3.1 \%$ & $0.3 \%$ & $12.9 \%$ \\
\hline & 12 & & & & & & $1.3 \%$ & $10.8 \%$ & $6.2 \%$ & $8.4 \%$ \\
\hline & 13 & & & & & & $3.6 \%$ & $38.8 \%$ & $36.0 \%$ & $34.2 \%$ \\
\hline & 14 & & & & & & $13.3 \%$ & $67.6 \%$ & $11.8 \%$ & $11.0 \%$ \\
\hline & 15 & & & & & & $2.2 \%$ & $2.8 \%$ & $0.1 \%$ & $13.4 \%$ \\
\hline & 16 & & & & & & $2.0 \%$ & $20.5 \%$ & $9.6 \%$ & $9.3 \%$ \\
\hline & 17 & & & & & & $10.3 \%$ & $67.3 \%$ & $13.9 \%$ & $7.8 \%$ \\
\hline & 18 & & & & & & $3.1 \%$ & $41.6 \%$ & $9.2 \%$ & $8.0 \%$ \\
\hline & 19 & & & & & & $3.8 \%$ & $58.5 \%$ & $16.6 \%$ & $17.6 \%$ \\
\hline & 20 & & & & & & $4.1 \%$ & $49.9 \%$ & $12.9 \%$ & $10.8 \%$ \\
\hline
\end{tabular}


Table 46: Normalized EMG data for turning head with and without the helmet (population 1 -gray, population 2 - white)

\begin{tabular}{|c|c|c|c|c|c|c|c|c|c|c|}
\hline \multicolumn{11}{|c|}{ Turning head } \\
\hline & \multirow[b]{2}{*}{ Subject \# } & \multicolumn{4}{|c|}{ Without helmet } & & \multicolumn{4}{|c|}{ With helmet } \\
\hline & & SEM right & SEM left & TRAP left & TRAP right & & SEM right & SEM left & TRAP left & TRAP right \\
\hline \multirow{20}{*}{ Rep 1} & 1 & $4.8 \%$ & $11.8 \%$ & $15.6 \%$ & $10.4 \%$ & \multirow{20}{*}{ Rep 2} & $8.1 \%$ & $13.1 \%$ & $18.4 \%$ & $16.8 \%$ \\
\hline & 2 & $5.2 \%$ & $36.7 \%$ & $13.7 \%$ & $13.3 \%$ & & $20.0 \%$ & $42.8 \%$ & $28.2 \%$ & $27.9 \%$ \\
\hline & 3 & $10.9 \%$ & $56.5 \%$ & $50.4 \%$ & $2.0 \%$ & & $7.7 \%$ & $10.3 \%$ & $3.2 \%$ & $2.1 \%$ \\
\hline & 4 & $1.9 \%$ & $14.2 \%$ & $20.1 \%$ & $22.1 \%$ & & $11.4 \%$ & $19.0 \%$ & $22.3 \%$ & $50.2 \%$ \\
\hline & 5 & $13.8 \%$ & $3.0 \%$ & $9.0 \%$ & $13.6 \%$ & & $34.5 \%$ & $4.4 \%$ & $12.1 \%$ & $19.6 \%$ \\
\hline & 6 & $27.8 \%$ & $57.0 \%$ & $23.2 \%$ & $16.5 \%$ & & $26.1 \%$ & $55.1 \%$ & $16.2 \%$ & $13.9 \%$ \\
\hline & 7 & $4.1 \%$ & $5.5 \%$ & $5.1 \%$ & $5.7 \%$ & & $1.5 \%$ & $4.8 \%$ & $17.6 \%$ & $6.1 \%$ \\
\hline & 8 & $20.6 \%$ & $15.4 \%$ & $13.9 \%$ & $0.3 \%$ & & $29.1 \%$ & $16.2 \%$ & $18.9 \%$ & $0.2 \%$ \\
\hline & 9 & $7.2 \%$ & $31.0 \%$ & $10.0 \%$ & $11.1 \%$ & & $10.4 \%$ & $32.6 \%$ & $10.2 \%$ & $10.6 \%$ \\
\hline & 10 & $25.9 \%$ & $38.5 \%$ & $3.7 \%$ & $3.3 \%$ & & $25.2 \%$ & $28.5 \%$ & $2.8 \%$ & $3.5 \%$ \\
\hline & 11 & $19.2 \%$ & $3.1 \%$ & $0.6 \%$ & $39.6 \%$ & & $17.2 \%$ & $2.9 \%$ & $0.1 \%$ & $28.3 \%$ \\
\hline & 12 & $2.7 \%$ & $11.2 \%$ & $6.0 \%$ & $4.6 \%$ & & $9.9 \%$ & $14.4 \%$ & $5.2 \%$ & $5.8 \%$ \\
\hline & 13 & $4.4 \%$ & $38.3 \%$ & $29.2 \%$ & $29.5 \%$ & & $11.2 \%$ & $38.6 \%$ & $28.9 \%$ & $33.8 \%$ \\
\hline & 14 & $39.0 \%$ & $76.3 \%$ & $10.8 \%$ & $11.4 \%$ & & $35.0 \%$ & $74.8 \%$ & $18.4 \%$ & $16.4 \%$ \\
\hline & 15 & $6.2 \%$ & $2.9 \%$ & $0.6 \%$ & $20.3 \%$ & & $7.2 \%$ & $2.8 \%$ & $0.1 \%$ & $13.0 \%$ \\
\hline & 16 & $3.5 \%$ & $22.1 \%$ & $23.8 \%$ & $24.2 \%$ & & $9.0 \%$ & $23.1 \%$ & $12.9 \%$ & $12.5 \%$ \\
\hline & 17 & $8.1 \%$ & $67.7 \%$ & $15.9 \%$ & $11.8 \%$ & & $38.6 \%$ & $69.4 \%$ & $24.1 \%$ & $17.6 \%$ \\
\hline & 18 & $45.3 \%$ & $62.3 \%$ & $14.2 \%$ & $15.1 \%$ & & $23.9 \%$ & $47.1 \%$ & $9.8 \%$ & $7.9 \%$ \\
\hline & 19 & $23.3 \%$ & $62.4 \%$ & $39.6 \%$ & $38.9 \%$ & & $11.4 \%$ & $56.6 \%$ & $22.6 \%$ & $20.9 \%$ \\
\hline & 20 & $6.0 \%$ & $52.1 \%$ & $35.1 \%$ & $27.3 \%$ & & $24.3 \%$ & $56.2 \%$ & $37.2 \%$ & $33.7 \%$ \\
\hline \multirow{40}{*}{ Rep 5} & 1 & $9.6 \%$ & $15.0 \%$ & $14.3 \%$ & $10.0 \%$ & \multirow{20}{*}{ Rep 3} & $9.7 \%$ & $14.9 \%$ & $18.9 \%$ & $18.8 \%$ \\
\hline & 2 & $2.8 \%$ & $37.0 \%$ & $12.6 \%$ & $13.4 \%$ & & $25.5 \%$ & $47.4 \%$ & $30.6 \%$ & $30.3 \%$ \\
\hline & 3 & $8.4 \%$ & $9.1 \%$ & $0.1 \%$ & $1.5 \%$ & & $5.8 \%$ & $7.0 \%$ & $0.1 \%$ & $1.3 \%$ \\
\hline & 4 & $5.8 \%$ & $16.2 \%$ & $22.9 \%$ & $15.7 \%$ & & $9.1 \%$ & $18.3 \%$ & $37.0 \%$ & $24.7 \%$ \\
\hline & 5 & $12.2 \%$ & $3.0 \%$ & $10.1 \%$ & $13.6 \%$ & & $37.7 \%$ & $4.8 \%$ & $13.6 \%$ & $22.4 \%$ \\
\hline & 6 & $18.8 \%$ & $54.2 \%$ & $15.0 \%$ & $10.6 \%$ & & $24.8 \%$ & $55.0 \%$ & $14.9 \%$ & $13.7 \%$ \\
\hline & 7 & $0.9 \%$ & $3.1 \%$ & $2.9 \%$ & $3.4 \%$ & & $1.7 \%$ & $3.5 \%$ & $3.8 \%$ & $3.8 \%$ \\
\hline & 8 & $12.9 \%$ & $14.2 \%$ & $12.0 \%$ & $0.2 \%$ & & $32.7 \%$ & $16.8 \%$ & $14.2 \%$ & $0.2 \%$ \\
\hline & 9 & $3.7 \%$ & $30.1 \%$ & $7.2 \%$ & $7.8 \%$ & & $19.3 \%$ & $35.8 \%$ & $8.7 \%$ & $9.2 \%$ \\
\hline & 10 & $1.7 \%$ & $10.9 \%$ & $1.2 \%$ & $0.7 \%$ & & $23.8 \%$ & $26.4 \%$ & $3.1 \%$ & $3.1 \%$ \\
\hline & 11 & $12.3 \%$ & $2.9 \%$ & $0.5 \%$ & $28.7 \%$ & & $17.2 \%$ & $2.8 \%$ & $0.1 \%$ & $25.3 \%$ \\
\hline & 12 & $5.0 \%$ & $12.5 \%$ & $6.3 \%$ & $5.0 \%$ & & $8.9 \%$ & $14.6 \%$ & $6.3 \%$ & $6.3 \%$ \\
\hline & 13 & $3.5 \%$ & $39.1 \%$ & $23.4 \%$ & $26.4 \%$ & & $29.4 \%$ & $47.4 \%$ & $29.5 \%$ & $33.5 \%$ \\
\hline & 14 & $52.9 \%$ & $80.3 \%$ & $12.8 \%$ & $14.6 \%$ & & $20.0 \%$ & $70.4 \%$ & $12.0 \%$ & $12.9 \%$ \\
\hline & 15 & $3.3 \%$ & $2.7 \%$ & $0.1 \%$ & $45.7 \%$ & & $14.4 \%$ & $2.8 \%$ & $0.1 \%$ & $15.8 \%$ \\
\hline & 16 & $6.5 \%$ & $23.5 \%$ & $19.0 \%$ & $32.8 \%$ & & $7.0 \%$ & $22.7 \%$ & $10.2 \%$ & $13.0 \%$ \\
\hline & 17 & $6.3 \%$ & $67.6 \%$ & $13.8 \%$ & $25.3 \%$ & & $40.0 \%$ & $71.8 \%$ & $27.5 \%$ & $19.6 \%$ \\
\hline & 18 & $15.7 \%$ & $45.9 \%$ & $10.4 \%$ & $8.9 \%$ & & $11.2 \%$ & $43.5 \%$ & $18.1 \%$ & $11.3 \%$ \\
\hline & 19 & $14.8 \%$ & $60.7 \%$ & $36.0 \%$ & $31.5 \%$ & & $10.1 \%$ & $58.4 \%$ & $19.6 \%$ & $22.3 \%$ \\
\hline & 20 & $12.6 \%$ & $54.5 \%$ & $44.4 \%$ & $38.3 \%$ & & $29.8 \%$ & $60.0 \%$ & $23.0 \%$ & $39.1 \%$ \\
\hline & 1 & & & & & \multirow{20}{*}{ Rep 4} & $7.2 \%$ & $13.2 \%$ & $16.0 \%$ & $14.3 \%$ \\
\hline & 2 & & & & & & $21.2 \%$ & $44.1 \%$ & $27.1 \%$ & $29.1 \%$ \\
\hline & 3 & & & & & & $5.9 \%$ & $7.2 \%$ & $0.1 \%$ & $0.9 \%$ \\
\hline & 4 & & & & & & $8.5 \%$ & $17.0 \%$ & $23.0 \%$ & $21.6 \%$ \\
\hline & 5 & & & & & & $23.5 \%$ & $3.8 \%$ & $17.4 \%$ & $21.1 \%$ \\
\hline & 6 & & & & & & $22.1 \%$ & $54.1 \%$ & $13.7 \%$ & $12.4 \%$ \\
\hline & 7 & & & & & & $1.8 \%$ & $3.5 \%$ & $3.8 \%$ & $4.4 \%$ \\
\hline & 8 & & & & & & $30.8 \%$ & $16.3 \%$ & $12.4 \%$ & $0.2 \%$ \\
\hline & 9 & & & & & & $16.7 \%$ & $35.1 \%$ & $8.0 \%$ & $8.4 \%$ \\
\hline & 10 & & & & & & $21.0 \%$ & $24.4 \%$ & $3.0 \%$ & $3.2 \%$ \\
\hline & 11 & & & & & & $37.3 \%$ & $3.9 \%$ & $0.6 \%$ & $27.1 \%$ \\
\hline & 12 & & & & & & $12.8 \%$ & $16.8 \%$ & $6.1 \%$ & $7.0 \%$ \\
\hline & 13 & & & & & & $16.7 \%$ & $41.3 \%$ & $27.8 \%$ & $24.9 \%$ \\
\hline & 14 & & & & & & $38.6 \%$ & $74.0 \%$ & $11.4 \%$ & $16.8 \%$ \\
\hline & 15 & & & & & & $8.3 \%$ & $2.8 \%$ & $0.1 \%$ & $21.1 \%$ \\
\hline & 16 & & & & & & $14.0 \%$ & $28.3 \%$ & $13.3 \%$ & $11.9 \%$ \\
\hline & 17 & & & & & & $5.6 \%$ & $67.8 \%$ & $12.5 \%$ & $7.9 \%$ \\
\hline & 18 & & & & & & $24.1 \%$ & $49.0 \%$ & $10.3 \%$ & $8.3 \%$ \\
\hline & 19 & & & & & & $17.8 \%$ & $60.3 \%$ & $24.6 \%$ & $25.1 \%$ \\
\hline & 20 & & & & & & $8.6 \%$ & $51.5 \%$ & $27.9 \%$ & $30.1 \%$ \\
\hline
\end{tabular}


Table 47: Normalized EMG data for shaking head with and without the helmet (population 1-gray, population 2 - white)

\begin{tabular}{|c|c|c|c|c|c|c|c|c|c|c|}
\hline \multicolumn{11}{|c|}{ Shaking head } \\
\hline & \multirow[b]{2}{*}{ Subject \# } & \multicolumn{4}{|c|}{ Without helmet } & & \multicolumn{4}{|c|}{ With helmet } \\
\hline & & SEM right & SEM left & TRAP left & TRAP right & & SEM right & SEM left & TRAP left & TRAP right \\
\hline \multirow{20}{*}{ Rep 1} & 1 & $1.5 \%$ & $10.7 \%$ & $7.2 \%$ & $6.4 \%$ & \multirow{20}{*}{ Rep 2} & $3.5 \%$ & $12.6 \%$ & $9.6 \%$ & $12.7 \%$ \\
\hline & 2 & $5.3 \%$ & $36.4 \%$ & $22.0 \%$ & $17.3 \%$ & & $8.2 \%$ & $36.7 \%$ & $15.7 \%$ & $13.9 \%$ \\
\hline & 3 & $0.4 \%$ & $63.9 \%$ & $60.4 \%$ & $2.0 \%$ & & $4.6 \%$ & $6.3 \%$ & $0.1 \%$ & $3.1 \%$ \\
\hline & 4 & $1.0 \%$ & $13.9 \%$ & $16.4 \%$ & $11.7 \%$ & & $1.3 \%$ & $14.0 \%$ & $23.8 \%$ & $34.6 \%$ \\
\hline & 5 & $10.8 \%$ & $2.9 \%$ & $8.9 \%$ & $17.6 \%$ & & $7.5 \%$ & $3.0 \%$ & $11.4 \%$ & $19.8 \%$ \\
\hline & 6 & $8.5 \%$ & $52.2 \%$ & $26.5 \%$ & $22.3 \%$ & & $9.9 \%$ & $52.0 \%$ & $34.2 \%$ & $20.3 \%$ \\
\hline & 7 & $47.5 \%$ & $32.1 \%$ & $4.8 \%$ & $6.4 \%$ & & $0.6 \%$ & $2.9 \%$ & $1.5 \%$ & $1.9 \%$ \\
\hline & 8 & $4.8 \%$ & $13.8 \%$ & $13.9 \%$ & $0.3 \%$ & & $5.8 \%$ & $13.5 \%$ & $22.8 \%$ & $0.2 \%$ \\
\hline & 9 & $3.3 \%$ & $30.3 \%$ & $11.3 \%$ & $18.5 \%$ & & $2.9 \%$ & $30.6 \%$ & $12.5 \%$ & $14.0 \%$ \\
\hline & 10 & $8.8 \%$ & $15.5 \%$ & $2.3 \%$ & $1.5 \%$ & & $3.7 \%$ & $12.8 \%$ & $3.2 \%$ & $2.9 \%$ \\
\hline & 11 & $16.1 \%$ & $2.8 \%$ & $0.4 \%$ & $37.7 \%$ & & $5.4 \%$ & $2.7 \%$ & $0.1 \%$ & $27.2 \%$ \\
\hline & 12 & $1.4 \%$ & $10.5 \%$ & $5.2 \%$ & $4.6 \%$ & & $2.8 \%$ & $10.9 \%$ & $5.4 \%$ & $8.2 \%$ \\
\hline & 13 & $5.4 \%$ & $38.8 \%$ & $27.1 \%$ & $39.5 \%$ & & 7.9\% & $39.1 \%$ & $29.4 \%$ & $41.3 \%$ \\
\hline & 14 & $15.3 \%$ & $66.9 \%$ & $7.7 \%$ & $18.8 \%$ & & $22.4 \%$ & $69.7 \%$ & $12.6 \%$ & $12.7 \%$ \\
\hline & 15 & $25.5 \%$ & $3.1 \%$ & $0.6 \%$ & $17.6 \%$ & & $32.7 \%$ & $3.6 \%$ & $0.1 \%$ & $26.8 \%$ \\
\hline & 16 & $4.5 \%$ & $22.4 \%$ & $32.6 \%$ & $31.7 \%$ & & $2.0 \%$ & $20.5 \%$ & $15.0 \%$ & $21.0 \%$ \\
\hline & 17 & $10.5 \%$ & $73.8 \%$ & $45.1 \%$ & $11.2 \%$ & & $12.4 \%$ & $67.6 \%$ & $19.1 \%$ & $10.2 \%$ \\
\hline & 18 & $9.3 \%$ & $42.9 \%$ & $15.1 \%$ & $12.7 \%$ & & $3.4 \%$ & $41.3 \%$ & $10.8 \%$ & $7.6 \%$ \\
\hline & 19 & $5.7 \%$ & $59.1 \%$ & $41.2 \%$ & $42.5 \%$ & & $4.1 \%$ & $58.1 \%$ & $17.4 \%$ & $19.6 \%$ \\
\hline & 20 & $29.2 \%$ & $59.3 \%$ & $27.6 \%$ & $12.3 \%$ & & $5.3 \%$ & $50.2 \%$ & $20.0 \%$ & $15.3 \%$ \\
\hline \multirow{40}{*}{ Rep 5} & 1 & $1.1 \%$ & $10.7 \%$ & $6.3 \%$ & $5.6 \%$ & \multirow{20}{*}{ Rep 3} & $1.4 \%$ & $11.0 \%$ & $12.6 \%$ & $14.4 \%$ \\
\hline & 2 & $7.6 \%$ & $36.7 \%$ & $17.3 \%$ & $14.4 \%$ & & $5.8 \%$ & $36.2 \%$ & $24.4 \%$ & $20.9 \%$ \\
\hline & 3 & $2.2 \%$ & $4.9 \%$ & $0.1 \%$ & $2.0 \%$ & & $6.3 \%$ & $7.5 \%$ & $0.1 \%$ & $4.7 \%$ \\
\hline & 4 & $2.4 \%$ & $14.2 \%$ & $16.8 \%$ & $11.1 \%$ & & $1.6 \%$ & $14.1 \%$ & $27.9 \%$ & $17.6 \%$ \\
\hline & 5 & $11.4 \%$ & $3.0 \%$ & $27.3 \%$ & $16.8 \%$ & & $13.7 \%$ & $3.1 \%$ & $16.3 \%$ & $32.1 \%$ \\
\hline & 6 & $9.5 \%$ & $52.1 \%$ & $22.0 \%$ & $15.0 \%$ & & $6.9 \%$ & $51.9 \%$ & $24.3 \%$ & $16.3 \%$ \\
\hline & 7 & $0.4 \%$ & $2.8 \%$ & $2.9 \%$ & $3.1 \%$ & & $0.3 \%$ & $2.7 \%$ & $2.4 \%$ & $2.6 \%$ \\
\hline & 8 & $4.1 \%$ & $13.6 \%$ & $15.0 \%$ & $0.2 \%$ & & $10.0 \%$ & $14.0 \%$ & $30.8 \%$ & $0.3 \%$ \\
\hline & 9 & $3.1 \%$ & $30.2 \%$ & $8.3 \%$ & $12.2 \%$ & & $4.6 \%$ & $31.1 \%$ & $14.4 \%$ & $14.6 \%$ \\
\hline & 10 & $15.3 \%$ & $21.6 \%$ & $2.5 \%$ & $2.4 \%$ & & $7.5 \%$ & $15.3 \%$ & $5.6 \%$ & $3.6 \%$ \\
\hline & 11 & $13.8 \%$ & $2.8 \%$ & $0.4 \%$ & $33.8 \%$ & & $9.0 \%$ & $2.8 \%$ & $0.1 \%$ & $38.4 \%$ \\
\hline & 12 & $3.7 \%$ & $11.3 \%$ & $4.4 \%$ & $5.8 \%$ & & $2.8 \%$ & $11.0 \%$ & $4.8 \%$ & $7.2 \%$ \\
\hline & 13 & $5.0 \%$ & $37.5 \%$ & $19.3 \%$ & $22.5 \%$ & & $9.7 \%$ & $37.8 \%$ & $23.1 \%$ & $31.9 \%$ \\
\hline & 14 & $12.5 \%$ & $68.3 \%$ & $8.4 \%$ & $10.4 \%$ & & $19.5 \%$ & $72.0 \%$ & $18.6 \%$ & $14.4 \%$ \\
\hline & 15 & $2.2 \%$ & $2.7 \%$ & $0.1 \%$ & $46.7 \%$ & & $29.7 \%$ & $8.4 \%$ & $34.4 \%$ & $23.7 \%$ \\
\hline & 16 & $4.6 \%$ & $22.2 \%$ & $31.2 \%$ & $47.0 \%$ & & $3.0 \%$ & $20.8 \%$ & $16.6 \%$ & $28.6 \%$ \\
\hline & 17 & $8.3 \%$ & $68.2 \%$ & $21.0 \%$ & $35.6 \%$ & & $16.4 \%$ & $72.6 \%$ & $39.4 \%$ & $14.2 \%$ \\
\hline & 18 & $7.6 \%$ & $41.9 \%$ & $11.4 \%$ & $9.3 \%$ & & $3.0 \%$ & $41.5 \%$ & $9.7 \%$ & $7.9 \%$ \\
\hline & 19 & $4.4 \%$ & $58.6 \%$ & $22.6 \%$ & $23.4 \%$ & & $4.0 \%$ & $57.4 \%$ & $22.2 \%$ & $29.9 \%$ \\
\hline & 20 & $37.6 \%$ & $67.8 \%$ & $86.0 \%$ & $21.1 \%$ & & $4.2 \%$ & $50.6 \%$ & $25.0 \%$ & $12.8 \%$ \\
\hline & 1 & & & & & \multirow{20}{*}{ Rep 4} & $1.2 \%$ & $11.0 \%$ & $11.6 \%$ & $12.5 \%$ \\
\hline & 2 & & & & & & $10.4 \%$ & $37.7 \%$ & $11.9 \%$ & $12.8 \%$ \\
\hline & 3 & & & & & & $5.4 \%$ & $6.9 \%$ & $0.1 \%$ & $4.6 \%$ \\
\hline & 4 & & & & & & $2.0 \%$ & $14.3 \%$ & $20.9 \%$ & $17.3 \%$ \\
\hline & 5 & & & & & & $13.7 \%$ & $3.1 \%$ & $21.3 \%$ & $20.8 \%$ \\
\hline & 6 & & & & & & $7.9 \%$ & $52.8 \%$ & $25.1 \%$ & $18.0 \%$ \\
\hline & 7 & & & & & & $0.2 \%$ & $2.8 \%$ & $3.3 \%$ & $3.3 \%$ \\
\hline & 8 & & & & & & $8.6 \%$ & $14.0 \%$ & $29.3 \%$ & $0.3 \%$ \\
\hline & 9 & & & & & & $6.8 \%$ & $31.0 \%$ & $17.7 \%$ & $13.6 \%$ \\
\hline & 10 & & & & & & $8.2 \%$ & $15.9 \%$ & $5.8 \%$ & $3.6 \%$ \\
\hline & 11 & & & & & & $10.2 \%$ & $3.2 \%$ & $0.7 \%$ & $34.2 \%$ \\
\hline & 12 & & & & & & $7.0 \%$ & $12.8 \%$ & $5.4 \%$ & $8.7 \%$ \\
\hline & 13 & & & & & & $16.8 \%$ & $41.7 \%$ & $29.6 \%$ & $44.2 \%$ \\
\hline & 14 & & & & & & $24.4 \%$ & $72.1 \%$ & $17.5 \%$ & $19.1 \%$ \\
\hline & 15 & & & & & & $15.0 \%$ & $38.5 \%$ & $0.7 \%$ & $46.9 \%$ \\
\hline & 16 & & & & & & $3.4 \%$ & $21.1 \%$ & $13.1 \%$ & $42.6 \%$ \\
\hline & 17 & & & & & & $10.3 \%$ & $69.9 \%$ & $37.1 \%$ & $25.3 \%$ \\
\hline & 18 & & & & & & $3.6 \%$ & $41.2 \%$ & $11.0 \%$ & $7.9 \%$ \\
\hline & 19 & & & & & & $4.2 \%$ & $58.3 \%$ & $17.9 \%$ & $22.7 \%$ \\
\hline & 20 & & & & & & $4.3 \%$ & $49.5 \%$ & $19.4 \%$ & $10.9 \%$ \\
\hline
\end{tabular}




\section{APPENDIX C}

Table 48: Nodding head data for speed (population 1 - gray, population 2 - white)

\begin{tabular}{|c|r|r|r|r|r|}
\hline \multicolumn{7}{|c|}{ Nodding head (speed) } \\
\hline Subject \# & Rep 1 & Rep 2 & Rep 3 & Rep 4 & Rep 5 \\
\hline 1 & 0.0 & 35.8 & 39.5 & 39.8 & 75.5 \\
2 & 79.6 & 48.6 & 104.6 & 88.8 & 196.9 \\
3 & 16.5 & 93.3 & 64.0 & 78.3 & 122.3 \\
4 & 38.0 & 72.8 & 49.2 & 52.0 & 60.3 \\
5 & 70.0 & 42.3 & 55.9 & 60.9 & 76.3 \\
6 & 47.5 & 59.9 & 53.8 & 27.2 & 74.7 \\
7 & 185.9 & 69.3 & 38.8 & 33.0 & 26.3 \\
8 & 116.4 & 46.5 & 47.5 & 60.3 & 74.4 \\
9 & 88.4 & 54.8 & 58.4 & 58.7 & 113.4 \\
10 & 73.0 & 58.4 & 65.4 & 81.7 & 149.3 \\
11 & 169.4 & 105.4 & 77.7 & 91.0 & 217.7 \\
12 & 64.6 & 81.6 & 72.9 & 90.9 & 142.7 \\
13 & 88.8 & 65.6 & 75.5 & 69.9 & 91.5 \\
14 & 60.9 & 39.8 & 35.0 & 46.2 & 84.5 \\
15 & 126.2 & 106.1 & 89.7 & 89.8 & 137.5 \\
16 & 98.0 & 54.7 & 53.1 & 51.1 & 141.9 \\
17 & 78.1 & 69.6 & 60.1 & 73.9 & 108.0 \\
18 & 72.9 & 31.8 & 27.4 & 24.1 & 36.3 \\
19 & 80.1 & 61.2 & 45.8 & 59.7 & 85.6 \\
20 & 84.8 & 84.9 & 44.2 & 53.3 & 88.8 \\
\hline
\end{tabular}

Table 49: Tapping foot data for speed (population 1 - gray, population 2 - white)

\begin{tabular}{|c|rrrrr|}
\hline \multicolumn{7}{|c|}{ Tapping foot (speed) } \\
\hline Subject \# & Rep 1 & Rep 2 & Rep 3 & Rep 4 & Rep 5 \\
\hline 1 & 26.8 & 15.9 & 12.2 & 14.1 & 30.6 \\
2 & 15.4 & 9.8 & 22.4 & 16.2 & 28.5 \\
3 & 30.4 & 17.4 & 23.0 & 29.9 & 25.7 \\
4 & 20.5 & 18.2 & 20.4 & 17.2 & 23.1 \\
5 & 121.9 & 21.9 & 21.7 & 14.2 & 19.3 \\
6 & 20.7 & 11.0 & 12.0 & 14.6 & 18.3 \\
7 & 33.3 & 9.6 & 15.1 & 9.2 & 20.2 \\
8 & 22.8 & 8.4 & 8.1 & 10.2 & 25.3 \\
9 & 13.5 & 13.6 & 15.8 & 16.8 & 24.7 \\
10 & 17.3 & 12.8 & 17.0 & 11.6 & 21.8 \\
11 & 42.8 & 28.1 & 16.5 & 20.1 & 72.4 \\
12 & 23.2 & 18.0 & 19.2 & 28.9 & 42.0 \\
13 & 23.6 & 16.0 & 10.1 & 14.0 & 23.9
\end{tabular}




\begin{tabular}{|r|r|r|r|r|r|}
14 & 31.9 & 18.0 & 17.5 & 24.5 & 32.6 \\
15 & 24.3 & 25.0 & 24.6 & 22.2 & 40.8 \\
16 & 13.3 & 11.8 & 11.6 & 12.9 & 29.0 \\
17 & 17.3 & 9.8 & 12.2 & 9.5 & 16.8 \\
18 & 20.4 & 9.6 & 10.4 & 10.3 & 20.4 \\
19 & 20.9 & 18.0 & 21.9 & 19.9 & 29.5 \\
20 & 19.2 & 11.7 & 7.2 & 9.5 & 16.1 \\
\hline
\end{tabular}

Table 50: Walking in place data for speed (population 1 - gray, population 2 - white)

\begin{tabular}{|c|r|rrrr|}
\hline \multicolumn{7}{|c|}{ Walking in place (speed) } \\
\hline Subject \# & Rep 1 & Rep 2 & Rep 3 & Rep 4 & \multicolumn{1}{c|}{ Rep 5 } \\
\hline 1 & 149.1 & 52.8 & 60.1 & 58.2 & 137.4 \\
2 & 165.5 & 107.4 & 44.8 & 97.5 & 142.5 \\
3 & 199.4 & 105.1 & 112.5 & 93.6 & 208.1 \\
4 & 219.0 & 83.6 & 61.9 & 59.1 & 165.0 \\
5 & 94.5 & 30.5 & 42.6 & 51.2 & 82.4 \\
6 & 139.9 & 53.8 & 55.6 & 52.2 & 104.4 \\
7 & 113.1 & 65.4 & 52.1 & 52.1 & 96.6 \\
8 & 95.6 & 38.2 & 31.1 & 35.7 & 92.6 \\
9 & 129.7 & 82.2 & 76.2 & 72.7 & 141.5 \\
10 & 123.9 & 51.2 & 48.4 & 51.9 & 128.9 \\
11 & 164.4 & 69.6 & 64.9 & 54.3 & 193.4 \\
12 & 118.0 & 52.8 & 49.8 & 57.2 & 103.5 \\
13 & 106.3 & 51.1 & 50.6 & 39.1 & 87.0 \\
14 & 83.6 & 37.0 & 34.5 & 35.6 & 71.9 \\
15 & 126.2 & 130.5 & 91.2 & 87.9 & 133.3 \\
16 & 105.7 & 32.3 & 34.2 & 29.4 & 96.7 \\
17 & 111.7 & 62.4 & 57.1 & 38.4 & 59.1 \\
18 & 155.8 & 63.6 & 40.5 & 46.2 & 114.2 \\
19 & 57.6 & 30.8 & 41.0 & 34.5 & 66.9 \\
20 & 103.4 & 38.3 & 36.6 & 39.9 & 103.3 \\
\hline
\end{tabular}

Table 51: Clapping hands data for speed (population 1 - gray, population 2 - white)

\begin{tabular}{|c|rrrrr|}
\hline \multicolumn{7}{|c|}{ Clapping hands (speed) } \\
\hline Subject \# & \multicolumn{1}{|c|}{$\operatorname{Rep~1}$} & Rep 2 & Rep 3 & Rep 4 & \multicolumn{1}{c|}{ Rep 5 } \\
\hline 1 & 32.9 & 14.4 & 12.1 & 13.7 & 22.4 \\
2 & 200.6 & 14.8 & 18.5 & 16.3 & 160.7 \\
3 & 34.4 & 16.6 & 20.6 & 17.9 & 41.5 \\
4 & 23.3 & 14.6 & 14.0 & 14.8 & 18.7 \\
5 & 26.0 & 10.5 & 13.3 & 25.1 & 29.3 \\
6 & 38.4 & 11.4 & 11.6 & 11.4 & 30.6
\end{tabular}




\begin{tabular}{|c|r|rrrr|}
7 & 19.6 & 15.6 & 18.0 & 17.7 & 19.6 \\
8 & 16.3 & 10.2 & 11.4 & 7.9 & 29.3 \\
9 & 23.6 & 17.0 & 17.7 & 17.6 & 22.6 \\
10 & 25.9 & 13.4 & 12.2 & 13.2 & 147.5 \\
11 & 51.5 & 18.1 & 17.6 & 18.2 & 44.1 \\
12 & 21.6 & 16.9 & 21.7 & 19.7 & 24.8 \\
13 & 26.5 & 15.4 & 17.3 & 13.7 & 25.2 \\
14 & 20.6 & 9.8 & 15.4 & 15.4 & 29.8 \\
15 & 39.1 & 23.5 & 22.3 & 22.6 & 30.0 \\
16 & 20.6 & 8.5 & 9.6 & 8.3 & 24.4 \\
17 & 33.1 & 12.0 & 11.1 & 10.6 & 15.8 \\
18 & 13.2 & 9.1 & 7.3 & 7.1 & 13.4 \\
19 & 15.1 & 9.7 & 12.1 & 11.0 & 22.2 \\
20 & 25.4 & 10.5 & 11.5 & 11.3 & 23.8 \\
\hline
\end{tabular}

Table 52: Turning head data for speed (population 1 - gray, population 2 - white)

\begin{tabular}{|c|r|rrrr|}
\hline \multicolumn{7}{|c|}{ Turning head (speed) } \\
\hline Subject \# & Rep 1 & Rep 2 & Rep 3 & Rep 4 & Rep 5 \\
\hline 1 & 165.0 & 28.5 & 41.0 & 38.2 & 197.4 \\
2 & 28.7 & 41.3 & 64.2 & 52.0 & 34.6 \\
3 & 159.7 & 105.7 & 69.1 & 42.9 & 203.9 \\
4 & 106.5 & 32.1 & 50.8 & 29.7 & 71.9 \\
5 & 59.4 & 46.6 & 43.9 & 42.6 & 69.1 \\
6 & 130.9 & 32.5 & 24.1 & 28.1 & 83.8 \\
7 & 81.7 & 29.2 & 38.5 & 33.2 & 111.3 \\
8 & 141.7 & 140.6 & 101.6 & 57.5 & 137.3 \\
9 & 142.5 & 60.4 & 43.3 & 46.8 & 123.3 \\
10 & 107.6 & 269.0 & 34.5 & 37.1 & 32.6 \\
11 & 379.9 & 110.8 & 968.7 & 63.7 & 260.0 \\
12 & 93.1 & 54.0 & 58.9 & 89.8 & 140.1 \\
13 & 123.9 & 64.3 & 52.1 & 50.3 & 137.7 \\
14 & 102.5 & 48.9 & 27.9 & 59.1 & 180.1 \\
15 & 197.1 & 44.1 & 59.3 & 64.5 & 225.2 \\
16 & 229.5 & 43.7 & 45.7 & 34.3 & 230.5 \\
17 & 138.9 & 38.3 & 33.1 & 35.9 & 188.0 \\
18 & 84.7 & 31.1 & 26.4 & 28.6 & 95.5 \\
19 & 123.2 & 48.5 & 36.8 & 43.2 & 148.6 \\
20 & 190.9 & 55.0 & 46.9 & 24.3 & 208.1 \\
\hline
\end{tabular}

Table 53: Shaking head data for speed (population 1 - gray, population 2 - white)

Shaking head (speed) 


\begin{tabular}{|c|r|rrrr|} 
Subject \# & Rep 1 & \multicolumn{1}{c}{ Rep 2 } & \multicolumn{1}{c}{ Rep 3 } & Rep 4 & \multicolumn{1}{c|}{ Rep 5 } \\
\hline 1 & 150.6 & 85.6 & 66.9 & 71.9 & 98.1 \\
2 & 208.4 & 120.6 & 59.5 & 124.7 & 257.7 \\
3 & 253.0 & 119.8 & 148.4 & 138.7 & 296.9 \\
4 & 125.8 & 78.7 & 92.5 & 119.8 & 95.4 \\
5 & 129.4 & 83.4 & 48.5 & 107.8 & 147.1 \\
6 & 104.2 & 33.5 & 24.6 & 27.2 & 146.1 \\
7 & 184.6 & 86.2 & 105.0 & 96.0 & 138.3 \\
8 & 143.6 & 88.5 & 50.5 & 48.4 & 159.5 \\
9 & 208.8 & 74.3 & 43.2 & 58.5 & 213.2 \\
10 & 243.5 & 105.5 & 82.2 & 126.6 & 338.9 \\
11 & 332.8 & 151.0 & 149.6 & 127.3 & 397.5 \\
12 & 171.7 & 134.2 & 102.7 & 151.3 & 276.8 \\
13 & 245.0 & 158.7 & 126.9 & 125.8 & 201.8 \\
14 & 136.7 & 68.0 & 59.3 & 75.2 & 200.0 \\
15 & 314.6 & 170.7 & 195.8 & 215.1 & 311.3 \\
16 & 257.2 & 75.8 & 65.0 & 70.3 & 284.8 \\
17 & 272.0 & 84.1 & 112.2 & 94.8 & 236.4 \\
18 & 152.7 & 44.2 & 44.7 & 56.7 & 134.7 \\
19 & 164.8 & 36.9 & 35.8 & 39.5 & 131.2 \\
20 & 150.7 & 105.1 & 77.2 & 59.8 & 216.1 \\
\hline
\end{tabular}




\section{APPENDIX D}

Table 54: Nodding head data for acceleration (population 1 -gray, population 2 - white)

\begin{tabular}{|c|r|rrrr|}
\hline \multicolumn{7}{|c|}{ Nodding head (acceleration) } \\
\hline Subject \# & Rep 1 & Rep 2 & Rep 3 & Rep 4 & \multicolumn{1}{c|}{ Rep 5 } \\
\hline 1 & 379.3 & 222.2 & 240.3 & 271.7 & 459.5 \\
2 & 424.4 & 252.0 & 517.8 & 453.1 & 861.1 \\
3 & 99.9 & 654.8 & 484.3 & 576.6 & 926.5 \\
4 & 146.8 & 193.1 & 156.8 & 152.1 & 137.6 \\
5 & 368.3 & 307.2 & 407.6 & 456.2 & 491.0 \\
6 & 304.9 & 509.1 & 459.8 & 403.9 & 493.8 \\
7 & 549.7 & 201.5 & 171.1 & 194.1 & 123.0 \\
8 & 635.4 & 330.2 & 306.9 & 370.7 & 504.9 \\
9 & 432.3 & 250.5 & 417.2 & 427.8 & 768.0 \\
10 & 477.0 & 447.6 & 448.8 & 620.3 & 743.1 \\
11 & 1186.4 & 659.3 & 548.5 & 686.8 & 1468.3 \\
12 & 420.2 & 543.3 & 470.9 & 585.8 & 939.9 \\
13 & 461.3 & 415.8 & 579.3 & 407.4 & 468.2 \\
14 & 399.7 & 146.4 & 188.8 & 326.2 & 588.1 \\
15 & 763.7 & 641.8 & 537.0 & 713.2 & 1006.0 \\
16 & 534.8 & 280.8 & 314.8 & 262.3 & 788.9 \\
17 & 444.7 & 438.5 & 287.9 & 431.4 & 628.6 \\
18 & 537.0 & 232.7 & 189.3 & 182.4 & 271.7 \\
19 & 328.5 & 463.4 & 248.3 & 441.8 & 538.1 \\
20 & 288.8 & 359.8 & 227.4 & 281.2 & 356.5 \\
\hline
\end{tabular}

Table 55: Tapping foot data for acceleration (population 1 - gray, population 2 - white)

\begin{tabular}{|c|rrrrr|}
\hline \multicolumn{7}{|c|}{ Tapping foot (acceleration) } \\
\hline Subject \# & Rep 1 & Rep 2 & Rep 3 & Rep 4 & \multicolumn{1}{c|}{ Rep 5 } \\
\hline 1 & 98.4 & 63.4 & 54.0 & 60.5 & 116.2 \\
2 & 73.5 & 32.9 & 78.3 & 56.0 & 121.7 \\
3 & 87.4 & 72.0 & 77.0 & 112.8 & 92.1 \\
4 & 90.5 & 121.8 & 150.4 & 86.9 & 97.7 \\
5 & 67.9 & 96.5 & 70.8 & 54.5 & 58.3 \\
6 & 68.6 & 48.7 & 44.7 & 52.4 & 56.0 \\
7 & 78.5 & 28.4 & 42.2 & 28.5 & 65.7 \\
8 & 80.2 & 41.8 & 32.8 & 51.0 & 114.0 \\
9 & 52.8 & 75.0 & 63.7 & 93.6 & 103.1 \\
10 & 63.4 & 52.4 & 53.4 & 52.1 & 85.1 \\
11 & 192.0 & 104.6 & 65.7 & 63.3 & 321.8 \\
12 & 85.3 & 90.0 & 77.0 & 101.4 & 206.9 \\
13 & 93.0 & 71.5 & 50.5 & 83.6 & 118.4 \\
\hline
\end{tabular}




\begin{tabular}{|r|r|rrrr|}
14 & 118.9 & 116.1 & 91.1 & 126.8 & 102.8 \\
15 & 109.7 & 191.2 & 128.3 & 178.7 & 167.7 \\
16 & 61.3 & 50.9 & 52.5 & 55.3 & 101.3 \\
17 & 59.4 & 53.0 & 45.7 & 39.4 & 77.9 \\
18 & 85.6 & 37.3 & 44.9 & 52.3 & 77.8 \\
19 & 109.8 & 90.3 & 132.0 & 82.1 & 123.5 \\
20 & 77.0 & 43.1 & 33.1 & 43.5 & 57.9 \\
\hline
\end{tabular}

Table 56: Walking in place data for acceleration (population 1 - gray, population 2 - white)

\begin{tabular}{|c|r|r|r|r|r|}
\hline \multicolumn{7}{|c|}{ Walking in place (acceleration) } \\
\hline Subject \# & Rep 1 & Rep 2 & Rep 3 & Rep 4 & \multicolumn{1}{c|}{ Rep 5 } \\
\hline 1 & 528.9 & 175.7 & 204.0 & 180.7 & 495.5 \\
2 & 774.1 & 437.8 & 169.2 & 448.1 & 692.1 \\
3 & 1010.1 & 531.3 & 588.2 & 436.6 & 1020.1 \\
4 & 725.6 & 334.9 & 294.4 & 293.9 & 649.5 \\
5 & 305.2 & 104.2 & 143.7 & 197.7 & 289.3 \\
6 & 597.3 & 204.0 & 217.8 & 180.5 & 448.0 \\
7 & 425.6 & 187.9 & 166.9 & 184.5 & 385.5 \\
8 & 482.2 & 158.8 & 130.9 & 148.2 & 417.1 \\
9 & 625.8 & 363.2 & 315.8 & 301.9 & 706.6 \\
10 & 554.7 & 191.5 & 212.3 & 214.3 & 551.0 \\
11 & 951.2 & 307.8 & 275.3 & 225.7 & 1039.8 \\
12 & 424.4 & 190.8 & 183.0 & 219.2 & 465.4 \\
13 & 505.2 & 232.7 & 208.5 & 159.3 & 408.1 \\
14 & 303.6 & 146.4 & 140.4 & 178.7 & 281.4 \\
15 & 559.7 & 571.4 & 493.5 & 445.8 & 599.7 \\
16 & 524.6 & 124.3 & 154.2 & 147.4 & 453.2 \\
17 & 384.9 & 208.9 & 182.8 & 125.8 & 272.3 \\
18 & 699.1 & 242.2 & 155.3 & 182.5 & 514.3 \\
19 & 242.6 & 119.4 & 157.0 & 137.3 & 229.3 \\
20 & 399.1 & 180.1 & 161.0 & 162.2 & 457.3 \\
\hline
\end{tabular}

Table 57: Clapping hands data for acceleration (population 1 - gray, population 2 - white)

\begin{tabular}{|c|rrrrr|}
\hline \multicolumn{7}{|c|}{ Clapping hands (acceleration) } \\
\hline Subject \# & \multicolumn{1}{|c|}{ Rep 1 } & Rep 2 & Rep 3 & Rep 4 & \multicolumn{1}{c|}{ Rep 5 } \\
\hline 1 & 119.9 & 64.2 & 60.8 & 68.6 & 96.3 \\
2 & 28.8 & 76.2 & 70.6 & 65.3 & 446.5 \\
3 & 180.5 & 76.3 & 81.6 & 66.3 & 138.4 \\
4 & 118.2 & 90.5 & 95.4 & 77.3 & 85.0 \\
5 & 129.5 & 48.9 & 68.7 & 113.5 & 141.3 \\
6 & 178.4 & 48.6 & 58.3 & 56.3 & 123.4
\end{tabular}




\begin{tabular}{|c|r|rrrr|}
7 & 105.6 & 55.3 & 63.0 & 63.5 & 76.2 \\
8 & 87.0 & 49.5 & 54.0 & 45.6 & 133.8 \\
9 & 125.0 & 92.9 & 95.8 & 262.3 & 92.5 \\
10 & 122.9 & 59.4 & 70.4 & 74.7 & 389.9 \\
11 & 326.1 & 63.6 & 55.3 & 68.3 & 236.7 \\
12 & 103.7 & 84.7 & 100.4 & 106.2 & 104.5 \\
13 & 116.0 & 78.2 & 89.6 & 76.3 & 100.4 \\
14 & 94.9 & 57.5 & 98.3 & 76.3 & 145.5 \\
15 & 152.8 & 138.7 & 280.2 & 123.6 & 139.1 \\
16 & 99.5 & 47.3 & 42.9 & 42.1 & 95.2 \\
17 & 162.8 & 68.4 & 54.8 & 47.8 & 74.1 \\
18 & 61.0 & 43.0 & 35.7 & 31.8 & 64.9 \\
19 & 69.3 & 43.3 & 45.3 & 55.2 & 100.3 \\
20 & 126.8 & 62.6 & 54.6 & 64.4 & 112.7 \\
\hline
\end{tabular}

Table 58: Turning head data for acceleration (population 1 -gray, population 2 - white)

\begin{tabular}{|c|r|rrrr|}
\hline \multicolumn{7}{|c|}{ Turning head (acceleration) } \\
\hline Subject \# & Rep 1 & Rep 2 & Rep 3 & Rep 4 & \multicolumn{1}{c|}{ Rep 5 } \\
\hline 1 & 548.3 & 97.6 & 125.5 & 120.4 & 872.2 \\
2 & 132.4 & 127.2 & 177.9 & 165.5 & 130.3 \\
3 & 484.6 & 407.9 & 303.7 & 180.2 & 854.6 \\
4 & 224.9 & 136.3 & 321.1 & 129.2 & 161.5 \\
5 & 242.3 & 262.1 & 208.7 & 158.5 & 245.1 \\
6 & 559.1 & 176.0 & 136.5 & 133.5 & 427.6 \\
7 & 207.6 & 118.5 & 132.0 & 141.5 & 344.4 \\
8 & 500.3 & 658.6 & 509.7 & 278.3 & 657.5 \\
9 & 661.9 & 307.0 & 221.8 & 262.3 & 533.5 \\
10 & 285.9 & 144.2 & 101.4 & 114.0 & 131.0 \\
11 & 1745.0 & 297.7 & 563.2 & 247.3 & 1336.9 \\
12 & 346.9 & 123.1 & 261.2 & 379.9 & 540.7 \\
13 & 398.7 & 192.0 & 155.5 & 218.2 & 493.6 \\
14 & 260.7 & 189.7 & 141.2 & 259.9 & 602.0 \\
15 & 540.5 & 177.8 & 253.6 & 258.3 & 1043.4 \\
16 & 574.4 & 113.1 & 111.3 & 96.4 & 655.1 \\
17 & 429.3 & 116.4 & 108.1 & 126.1 & 660.9 \\
18 & 300.9 & 102.4 & 141.8 & 145.1 & 475.2 \\
19 & 371.1 & 147.7 & 161.3 & 168.4 & 411.9 \\
20 & 467.3 & 178.3 & 223.0 & 109.0 & 570.8 \\
\hline
\end{tabular}

Table 59: Shaking head data for acceleration (population 1 - gray, population 2 - white)

Shaking head (acceleration) 


\begin{tabular}{|c|c|c|c|c|c|}
\hline Subject \# & $\operatorname{Rep} 1$ & $\operatorname{Rep} 2$ & Rep 3 & Rep 4 & Rep 5 \\
\hline 1 & 1000.3 & 233.5 & 225.0 & 254.1 & 677.3 \\
\hline 2 & 1506.0 & 371.6 & 345.8 & 376.1 & 1854.4 \\
\hline 3 & 1666.5 & 943.8 & 986.4 & 1079.6 & 2203.3 \\
\hline 4 & 777.2 & 240.0 & 229.6 & 606.3 & 294.6 \\
\hline 5 & 830.8 & 179.9 & 398.7 & 186.0 & 1048.0 \\
\hline 6 & 783.9 & 165.6 & 167.0 & 169.0 & 1029.7 \\
\hline 7 & 866.7 & 146.8 & 212.0 & 171.5 & 578.6 \\
\hline 8 & 985.0 & 336.0 & 313.0 & 290.3 & 849.2 \\
\hline 9 & 1398.4 & 344.6 & 272.9 & 303.6 & 1456.0 \\
\hline 10 & 1392.3 & 326.2 & 406.0 & 487.7 & 2402.0 \\
\hline 11 & 2466.8 & 464.5 & 563.2 & 523.3 & 2817.8 \\
\hline 12 & 1085.5 & 416.5 & 431.8 & 488.4 & 1669.7 \\
\hline 13 & 1505.4 & 424.1 & 346.9 & 440.0 & 1208.8 \\
\hline 14 & 1050.1 & 194.8 & 213.8 & 231.2 & 1110.2 \\
\hline 15 & 1493.8 & 580.4 & 758.1 & 763.2 & 1672.8 \\
\hline 16 & 1430.0 & 204.4 & 254.9 & 191.9 & 1582.1 \\
\hline 17 & 1344.3 & 210.0 & 337.4 & 317.2 & 1185.3 \\
\hline 18 & 934.4 & 128.4 & 196.9 & 180.8 & 942.0 \\
\hline 19 & 890.4 & 85.3 & 123.0 & 120.1 & 666.9 \\
\hline 20 & 735.8 & 290.3 & 234.7 & 198.6 & 996.3 \\
\hline
\end{tabular}




\section{APPENDIX E}

Table 60: Normalized range of motion for nodding head (population 1 - gray, population 2 - white)

\begin{tabular}{|c|r|r|r|r|r|}
\hline \multicolumn{6}{|c|}{ Nodding head (range of motion) [units: mm] } \\
\hline Subject \# & Rep 1 & Rep 2 & Rep 3 & Rep 4 & Rep 5 \\
\hline 1 & 45.2 & 13.7 & 15.7 & 13.7 & 31.7 \\
2 & 101.7 & 31.2 & 66.0 & 58.0 & 133.1 \\
3 & 42.5 & 30.5 & 21.4 & 23.0 & 42.7 \\
4 & 27.9 & 65.4 & 44.2 & 45.1 & 86.3 \\
5 & 53.1 & 17.1 & 20.6 & 22.7 & 31.7 \\
6 & 24.9 & 19.0 & 15.7 & 14.0 & 33.3 \\
7 & 198.6 & 69.5 & 71.0 & 31.8 & 84.5 \\
8 & 64.2 & 13.2 & 15.9 & 18.7 & 40.2 \\
9 & 60.3 & 27.1 & 18.5 & 17.3 & 46.7 \\
10 & 27.9 & 17.0 & 19.4 & 24.4 & 85.3 \\
11 & 61.5 & 48.7 & 28.1 & 31.9 & 90.3 \\
12 & 33.0 & 34.4 & 25.3 & 30.4 & 60.9 \\
13 & 57.2 & 26.9 & 25.4 & 37.4 & 62.6 \\
14 & 38.1 & 20.2 & 16.2 & 19.3 & 48.4 \\
15 & 62.0 & 43.3 & 28.9 & 25.5 & 64.0 \\
16 & 51.6 & 34.8 & 34.0 & 37.0 & 73.6 \\
17 & 44.9 & 30.5 & 33.6 & 35.0 & 58.2 \\
18 & 37.3 & 14.0 & 9.5 & 7.7 & 19.8 \\
19 & 71.4 & 29.8 & 23.9 & 30.4 & 45.9 \\
20 & 77.9 & 55.9 & 22.4 & 30.3 & 60.8 \\
\hline
\end{tabular}

Table 61: Range of motion for turning head (y-axis) (population 1 -gray, population 2 - white)

\begin{tabular}{|c|rrrrr|}
\hline \multicolumn{6}{|c|}{ Turning head (y-axis) (range of motion) [units: $\mathrm{mm}$ ] } \\
\hline Subject \# & Rep 1 & \multicolumn{1}{|c|}{ Rep 2 } & Rep 3 & Rep 4 & \multicolumn{1}{c|}{ Rep 5 } \\
\hline 1 & 165.9 & 48.9 & 70.8 & 59.9 & 129.8 \\
2 & 25.1 & 54.9 & 101.1 & 57.3 & 39.2 \\
3 & 116.5 & 105.3 & 52.0 & 19.1 & 110.4 \\
4 & 166.7 & 60.2 & 60.8 & 38.7 & 113.4 \\
5 & 29.0 & 39.9 & 35.7 & 35.4 & 49.9 \\
6 & 106.8 & 28.1 & 16.1 & 26.6 & 46.2 \\
7 & 176.2 & 33.1 & 39.9 & 38.7 & 123.8 \\
8 & 105.1 & 123.0 & 85.7 & 39.6 & 98.6 \\
9 & 88.7 & 54.9 & 44.8 & 30.7 & 69.3 \\
10 & 120.0 & 36.8 & 34.2 & 44.2 & 23.2 \\
11 & 236.4 & 135.6 & 109.8 & 45.4 & 154.6
\end{tabular}




\begin{tabular}{|l|r|r|r|r|r|}
12 & 67.9 & 40.7 & 39.4 & 66.0 & 116.9 \\
13 & 129.4 & 83.1 & 65.8 & 49.0 & 120.4 \\
14 & 133.3 & 59.4 & 44.0 & 52.1 & 157.4 \\
15 & 181.2 & 19.9 & 47.4 & 54.2 & 160.9 \\
16 & 246.9 & 78.0 & 68.1 & 54.6 & 209.1 \\
17 & 131.2 & 28.3 & 38.6 & 25.9 & 145.1 \\
18 & 58.0 & 27.0 & 19.5 & 17.5 & 65.2 \\
19 & 102.0 & 64.7 & 55.9 & 33.1 & 130.1 \\
20 & 222.0 & 66.4 & 71.8 & 25.1 & 221.4 \\
\hline
\end{tabular}

Table 62: Range of motion for turning head (z-axis) (population 1 -gray, population 2 - white)

\begin{tabular}{|c|r|rrrr|}
\hline \multicolumn{6}{|c|}{ Turning head (z-axis) (range of motion) [units: mm] } \\
\hline Subject \# & Rep 1 & Rep 2 & Rep 3 & Rep 4 & \multicolumn{1}{c|}{ Rep 5 } \\
\hline 1 & 75.3 & 19.2 & 26.7 & 21.0 & 66.7 \\
2 & 22.6 & 46.0 & 57.8 & 42.0 & 18.3 \\
3 & 71.4 & 59.2 & 32.7 & 38.2 & 66.6 \\
4 & 75.2 & 29.5 & 31.6 & 29.0 & 64.2 \\
5 & 53.8 & 36.4 & 38.8 & 43.1 & 47.3 \\
6 & 56.0 & 14.8 & 8.6 & 11.2 & 32.1 \\
7 & 111.5 & 23.4 & 25.3 & 20.0 & 71.2 \\
8 & 57.9 & 19.2 & 32.7 & 27.6 & 37.4 \\
9 & 45.3 & 20.6 & 19.2 & 18.5 & 48.4 \\
10 & 79.9 & 35.5 & 38.2 & 40.7 & 13.3 \\
11 & 66.7 & 32.3 & 18.9 & 21.1 & 57.8 \\
12 & 47.3 & 31.2 & 33.8 & 40.1 & 56.1 \\
13 & 57.6 & 25.5 & 31.2 & 35.6 & 48.3 \\
14 & 71.4 & 17.3 & 30.9 & 26.9 & 88.3 \\
15 & 92.0 & 19.9 & 28.4 & 24.3 & 78.3 \\
16 & 131.0 & 21.4 & 24.0 & 25.9 & 125.6 \\
17 & 53.8 & 36.3 & 29.5 & 33.4 & 71.2 \\
18 & 58.3 & 13.2 & 13.6 & 12.2 & 29.1 \\
19 & 118.0 & 24.1 & 33.3 & 35.9 & 97.5 \\
20 & 81.7 & 25.1 & 25.1 & 12.8 & 103.9 \\
\hline
\end{tabular}

Table 63: Normalized range of motion for shaking head (population 1 - gray, population 2 - white)

\begin{tabular}{|c|rrrrr|}
\hline \multicolumn{6}{|c|}{ Shaking head (range of motion) [units: mm] } \\
\hline Subject \# & \multicolumn{1}{|c|}{ Rep 1 } & \multicolumn{1}{|c|}{ Rep 2 } & Rep 3 & Rep 4 & \multicolumn{1}{c|}{ Rep 5 } \\
\hline 1 & 62.7 & 99.1 & 68.0 & 76.8 & 41.7 \\
2 & 89.1 & 167.2 & 62.6 & 160.0 & 110.1 \\
3 & 105.9 & 44.9 & 50.8 & 58.2 & 96.7 \\
4 & 71.3 & 138.3 & 154.3 & 163.9 & 113.4 \\
\hline
\end{tabular}




\begin{tabular}{|c|r|r|r|r|r|}
5 & 61.5 & 130.6 & 42.2 & 139.1 & 72.8 \\
6 & 43.7 & 34.1 & 21.4 & 21.1 & 68.1 \\
7 & 124.9 & 155.5 & 161.0 & 150.8 & 105.4 \\
8 & 59.7 & 81.6 & 52.4 & 50.1 & 85.9 \\
9 & 74.2 & 59.9 & 35.3 & 51.0 & 68.8 \\
10 & 111.3 & 113.1 & 85.3 & 131.4 & 110.7 \\
11 & 108.0 & 169.4 & 112.3 & 99.4 & 159.0 \\
12 & 77.1 & 130.5 & 104.8 & 151.0 & 131.4 \\
13 & 95.8 & 187.9 & 164.5 & 130.9 & 95.7 \\
14 & 63.5 & 107.8 & 79.1 & 103.3 & 171.9 \\
15 & 161.4 & 17.4 & 183.0 & 215.0 & 150.3 \\
16 & 117.6 & 98.9 & 82.8 & 91.0 & 148.8 \\
17 & 144.0 & 110.3 & 123.2 & 106.2 & 135.3 \\
18 & 92.8 & 64.2 & 48.8 & 61.9 & 72.6 \\
19 & 105.8 & 53.0 & 64.3 & 43.9 & 93.1 \\
20 & 90.2 & 134.7 & 95.3 & 82.1 & 139.7 \\
\hline
\end{tabular}

